\title{
Synthesis and evaluation of galloyl conjugates
}

\section{of flavanones as BMP-2 up-regulators with}

promising bone anabolic and fracture healing

\section{properties}

Alka Raj Pandey,,$^{\dagger}$ ¥ o Divya Rai, ${ }^{\Psi}, ¥$ o Suriya Pratap Singh, ${ }^{\dagger}$ Ashish Kumar Tripathi, ${ }^{\Psi}$ Anirban Sardar, ${ }^{\Psi}, ¥$ Alisha Ansari, ${ }^{\dagger}, ¥$ Anjali Mishra, ${ }^{\S}, ¥$ Sudha Bhagwati, ${ }^{\natural}$ Rabi Sankar Bhatta, ${ }^{\S}$ Mohammad Imran Siddiqi, $₫$ Naibedya Chattopadhyay, ${ }^{\Psi} ¥$ Ritu Trivedi,,$* ¥ *$ Koneni V. Sashidhara $^{\dagger, \phi, * *}$

$\dagger$ Medicinal and Process Chemistry Division, CSIR-Central Drug Research Institute, BS-10/1, Sector 10, Jankipuram Extension, Sitapur Road, Lucknow 226031, India.

${ }^{\Psi}$ Division of Endocrinology and Centre for Research on ASTHI, CSIR-Central Drug Research Institute, BS-10/1, Sector 10, Jankipuram Extension, Sitapur Road, Lucknow 226031, India.

\$Pharmacokinetics and Metabolism Division, CSIR-Central Drug Research Institute, BS-10/1, Sector 10, Jankipuram Extension, Sitapur Road, Lucknow 226031, India.

${ }^{\top}$ Molecular and Structural Biology Division, CSIR-Central Drug Research Institute, BS-10/1, Sector 10, Jankipuram Extension, Sitapur Road, Lucknow 226031, India.

${ }^{\phi}$ Sophisticated Analytical Instrument Facility \& Research, CSIR-Central Drug Research Institute, BS10/1, Sector 10, Jankipuram Extension, Sitapur Road, Lucknow 226031, U.P., India.

${ }^{¥}$ Academy of Scientific and Innovative Research (AcSIR), Ghaziabad 201002, U.P., India.

o These authors contributed equally

* Corresponding authors 


\section{Table of Contents}

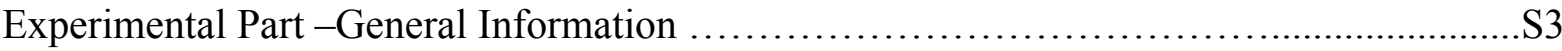

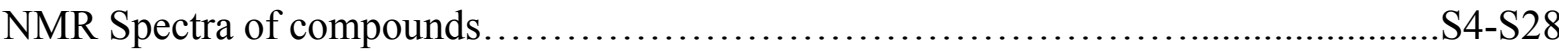

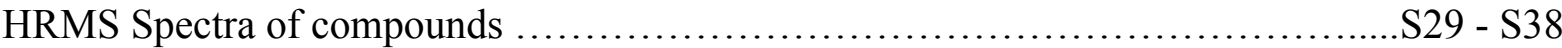

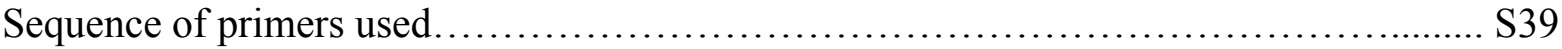

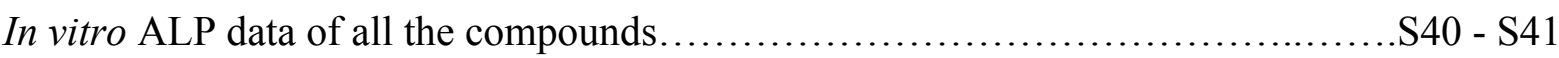

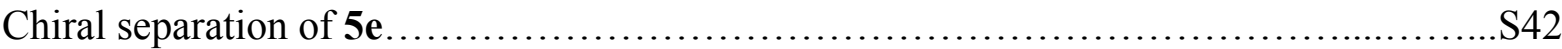

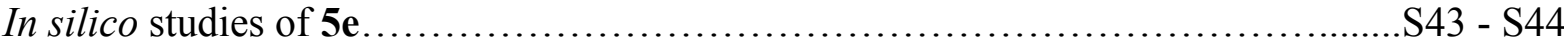

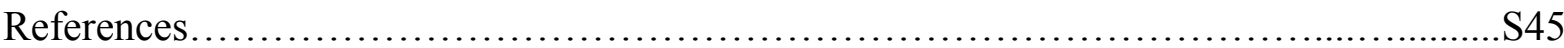




\section{General Information}

Reagents obtained from commercial sources were used without further purification.100-200 mesh silica gel was used column chromatography for purification of compounds. The pace of chemical reactions was monitored by TLC (silica gel plates with fluorescence F254). Melting points were uncorrected. The ${ }^{1} \mathrm{H}$ and ${ }^{13} \mathrm{C}$ NMR spectra were recorded at $400 \mathrm{MHz}$, and 100 $\mathrm{MHz}$, respectively, using $\mathrm{CDCl}_{3}$ and DMSO- $d_{6}$ as a solvent. All chemical shift values were described in ppm and their multiplicities expressed as: $\mathrm{m}=$ multiplet, $\mathrm{q}=$ quartet, $\mathrm{t}=$ triplet, $\mathrm{dd}=$ double doublet, $\mathrm{brd}=$ broad doublet, $\mathrm{d}=$ doublet, $\mathrm{brs}=$ broad singlet, and $\mathrm{s}=$ singlet . The ESI-MS spectra were recorded on an ion trap LCQ Advantage Max mass spectrometer (Thermo Electron Corporation) and HRMS spectra were recorded by Q-TOF (Agilent 6520). All the final compounds were found to be $>95 \%$ pure as determined by the HPLC method. 


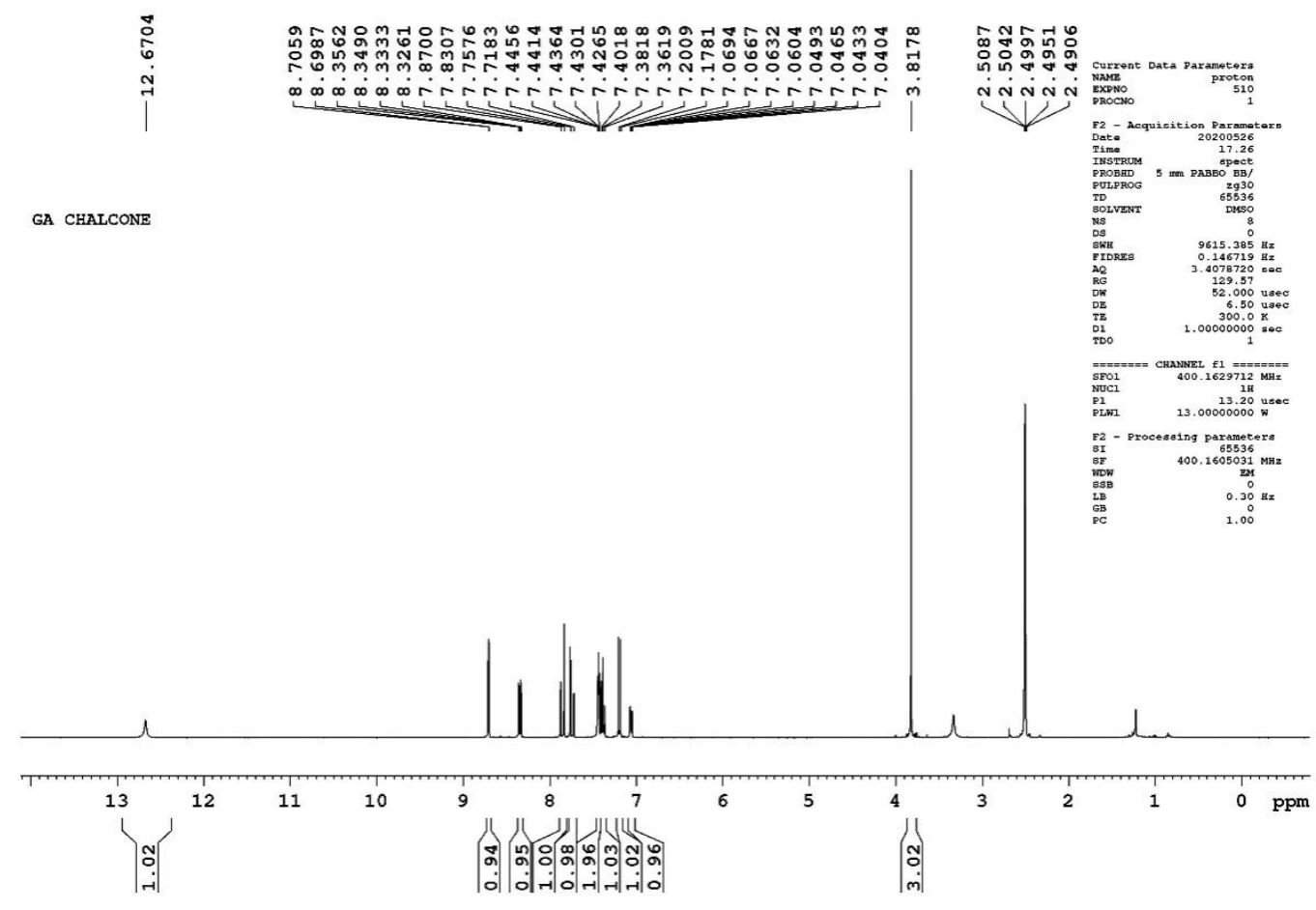

${ }^{1} \mathrm{H}$ Spectrum of Compound $2 \mathrm{e}$

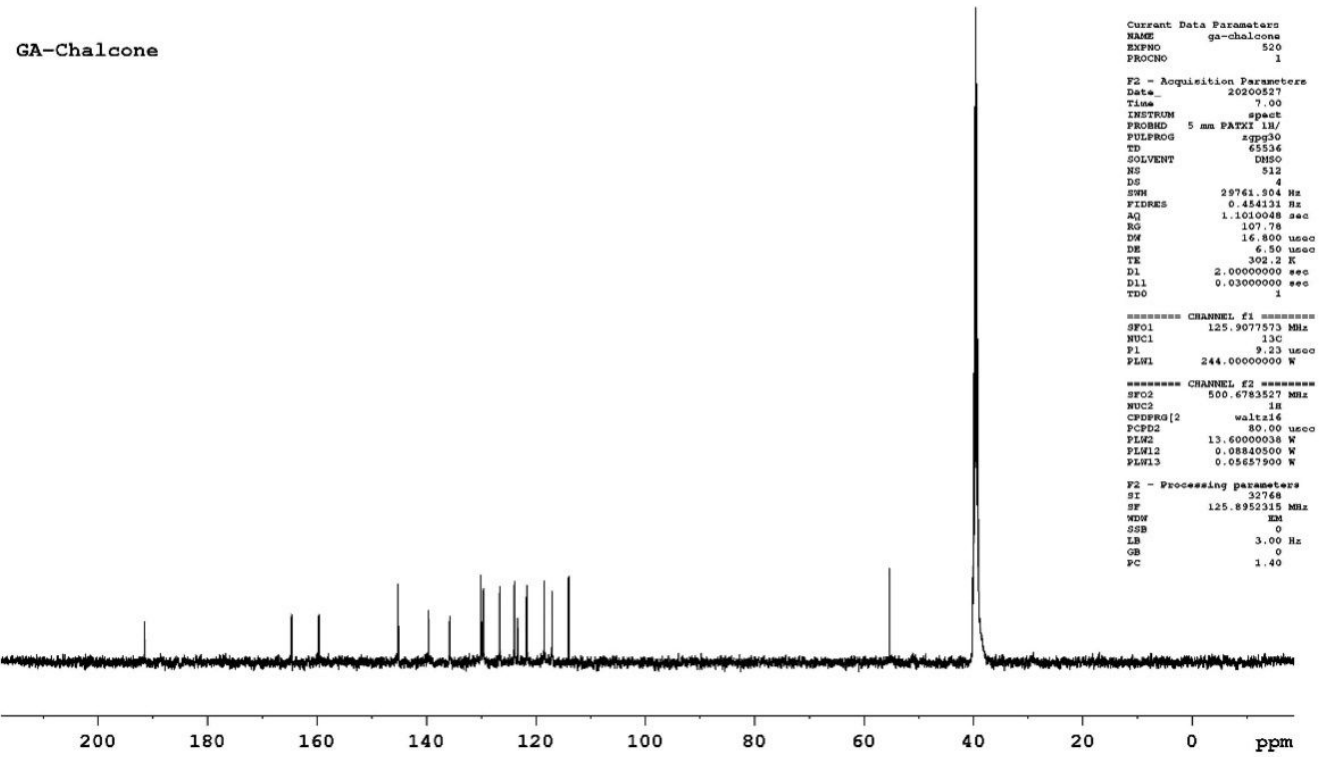

${ }^{13} \mathrm{C}$ Spectrum of Compound $2 \mathrm{e}$ 


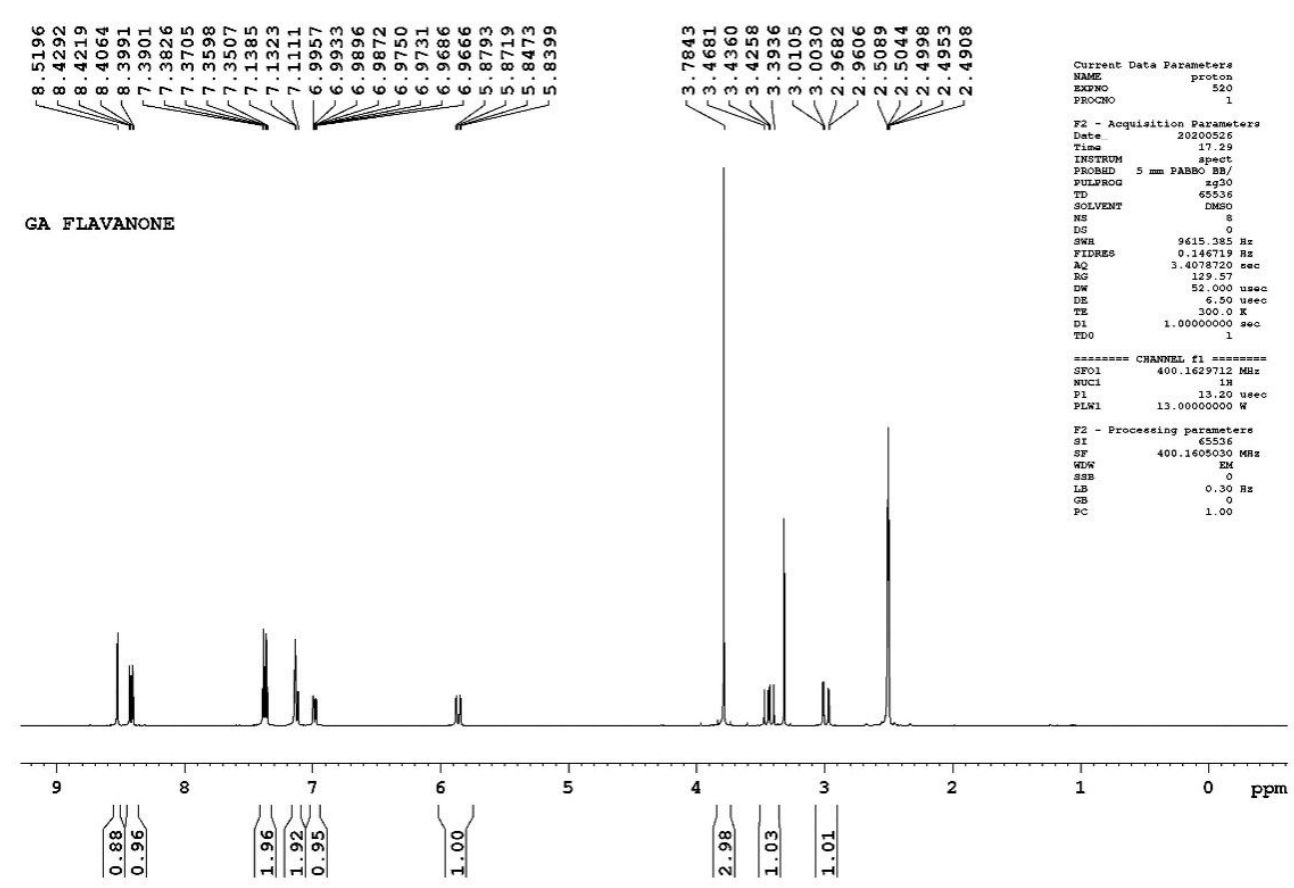

${ }^{1} \mathrm{H}$ Spectrum of Compound $3 \mathrm{e}$

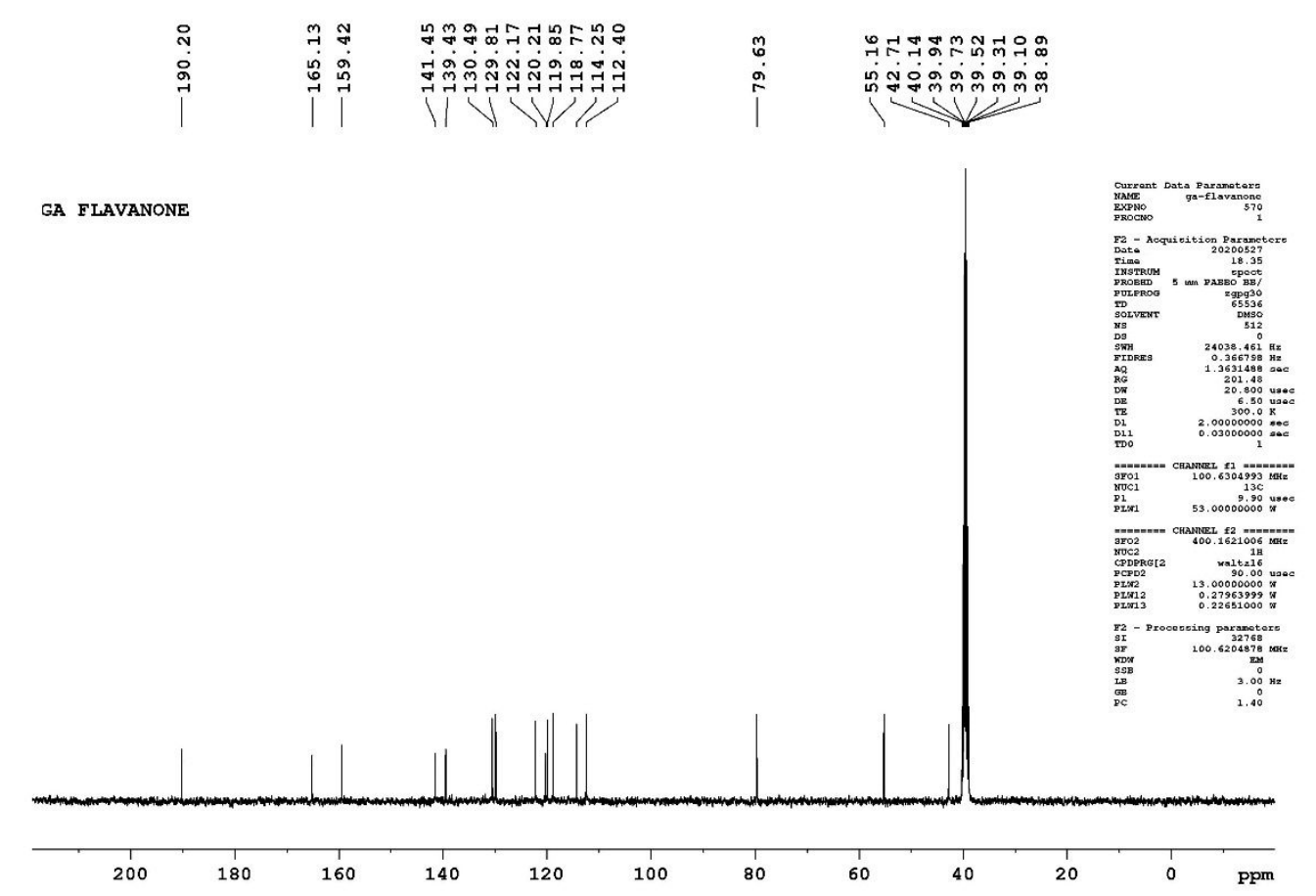

${ }^{13} \mathrm{C}$ Spectrum of Compound $3 \mathrm{e}$ 


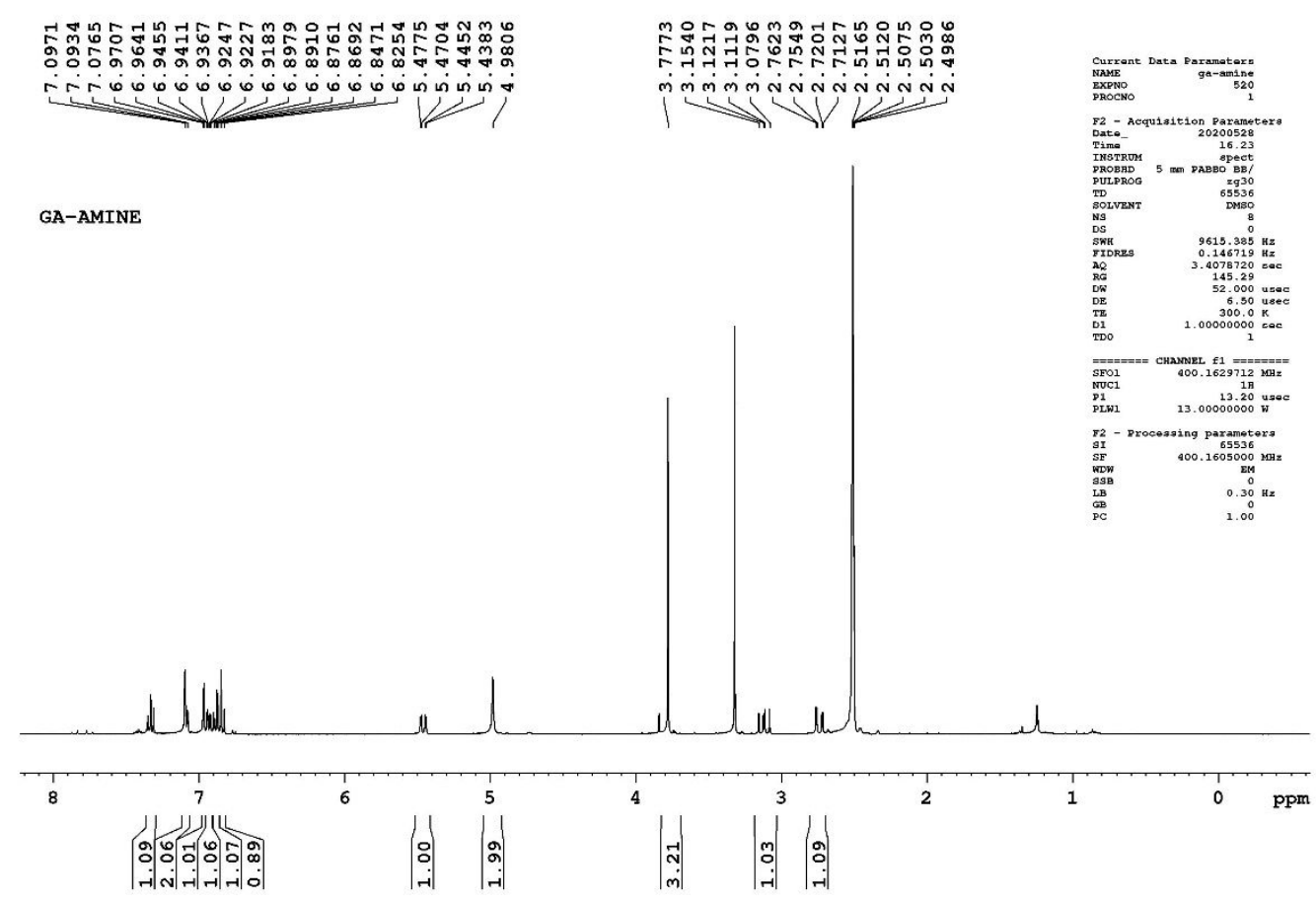

${ }^{1} \mathrm{H}$ Spectrum of Compound $4 \mathrm{e}$

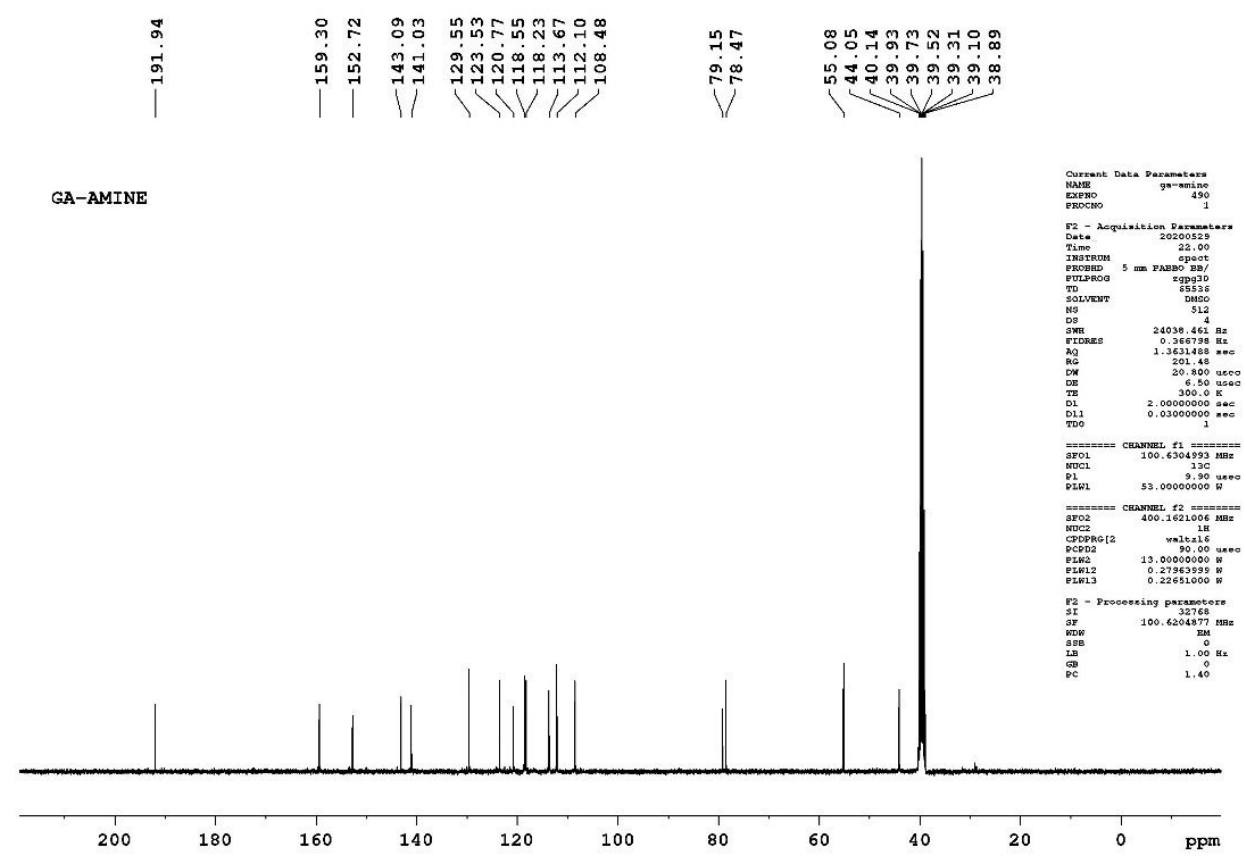

${ }^{13} \mathrm{C}$ Spectrum of Compound $4 \mathrm{e}$ 


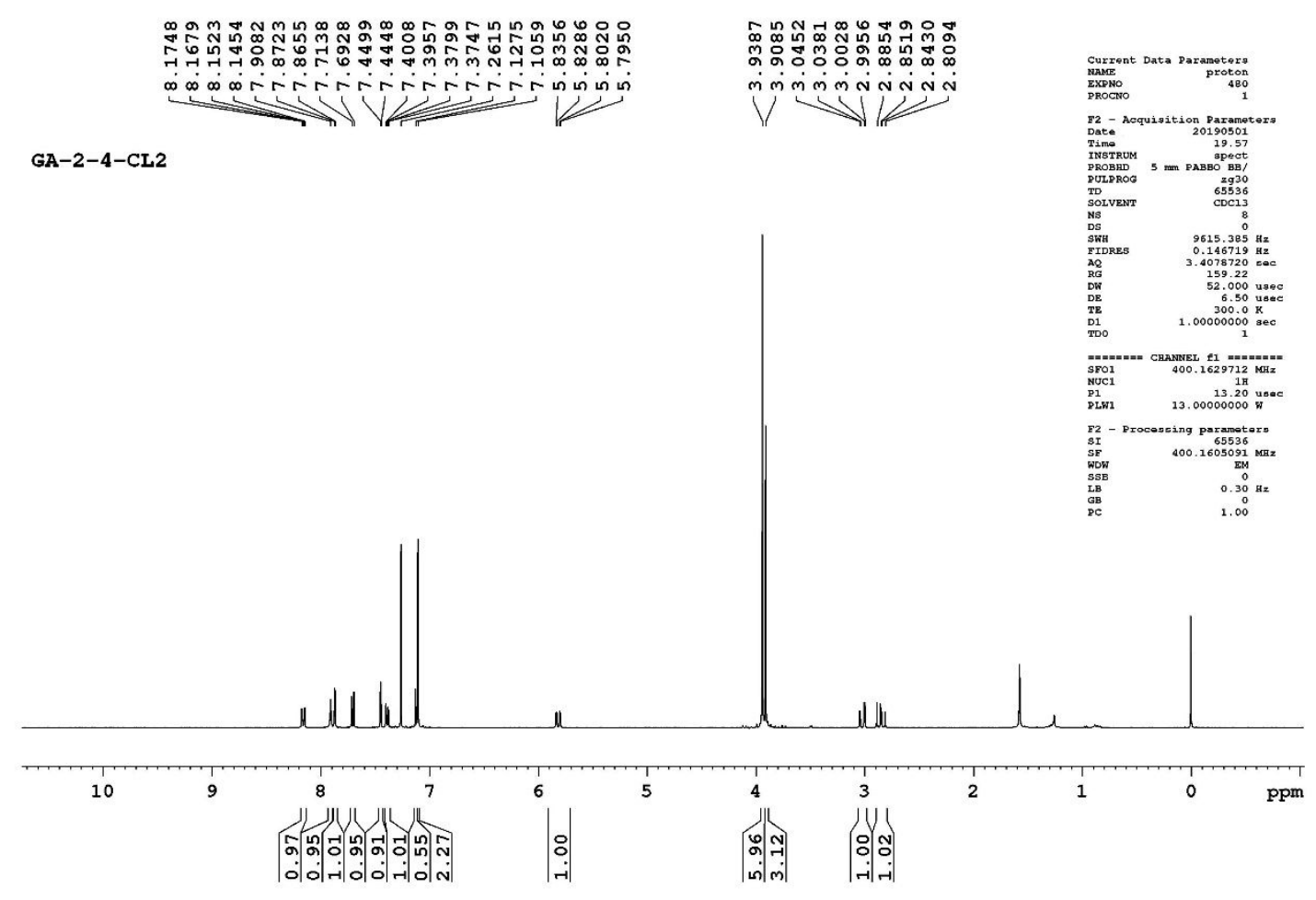

${ }^{1} \mathrm{H}$ Spectrum of Compound $5 \mathrm{a}$

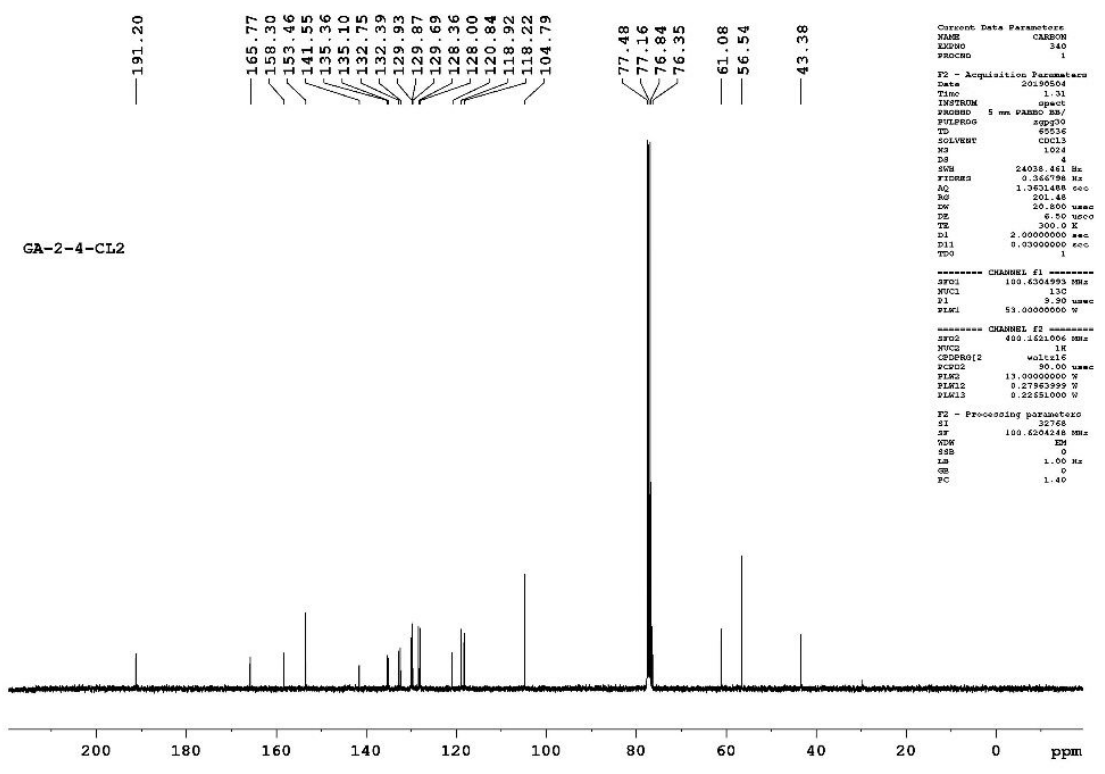

${ }^{13}$ C Spectrum of Compound 5a 


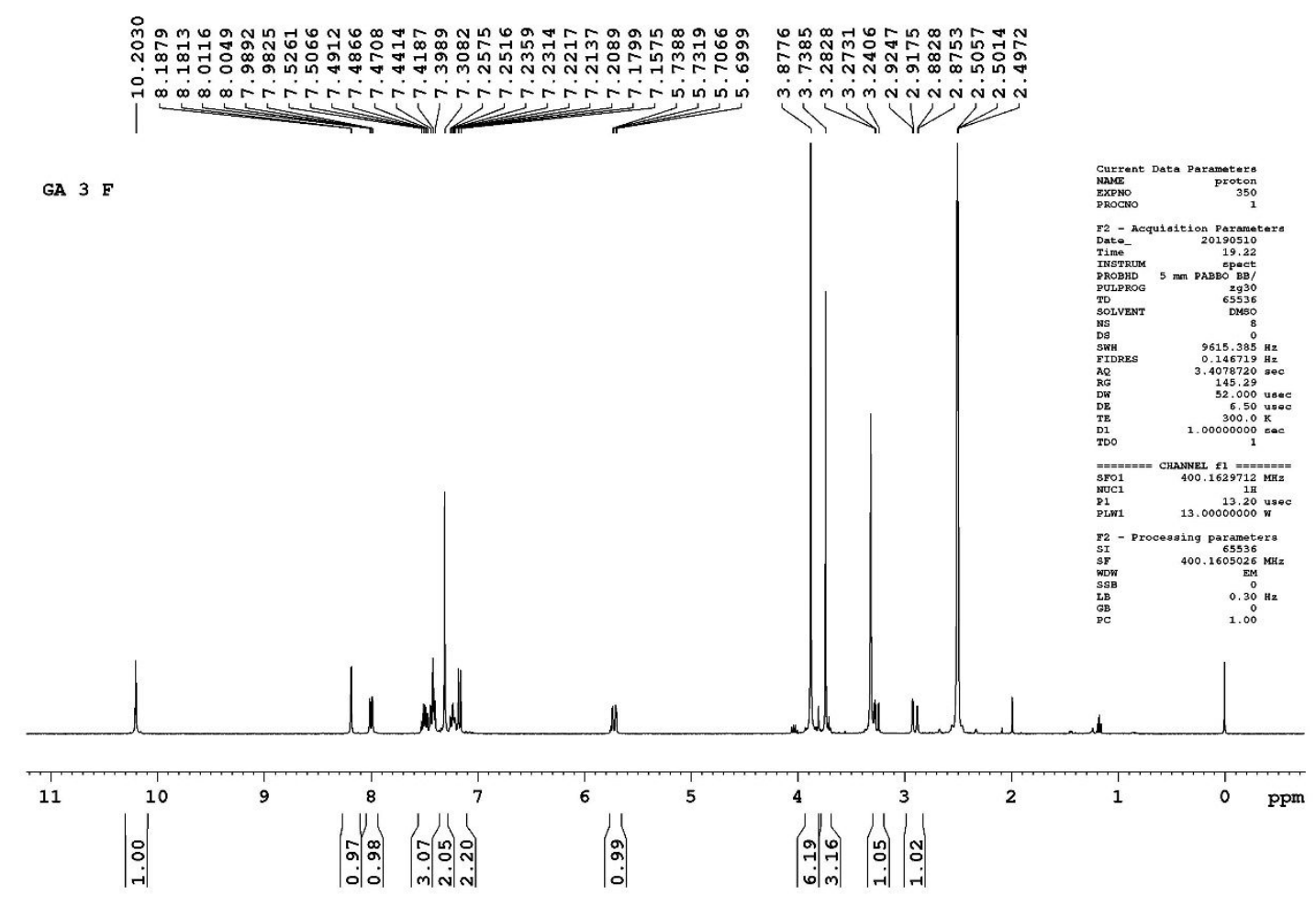

${ }^{1} \mathrm{H}$ Spectrum of Compound $5 \mathrm{~b}$

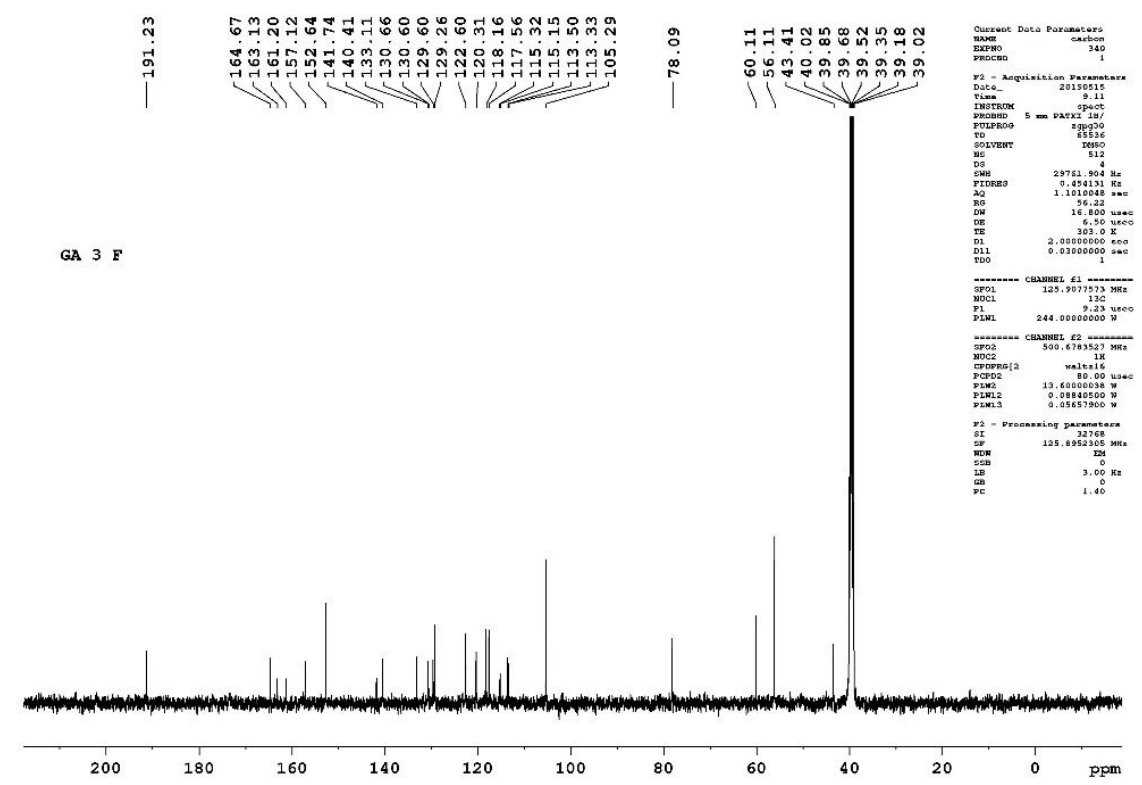

${ }^{13} \mathrm{C}$ Spectrum of Compound $5 \mathrm{~b}$ 


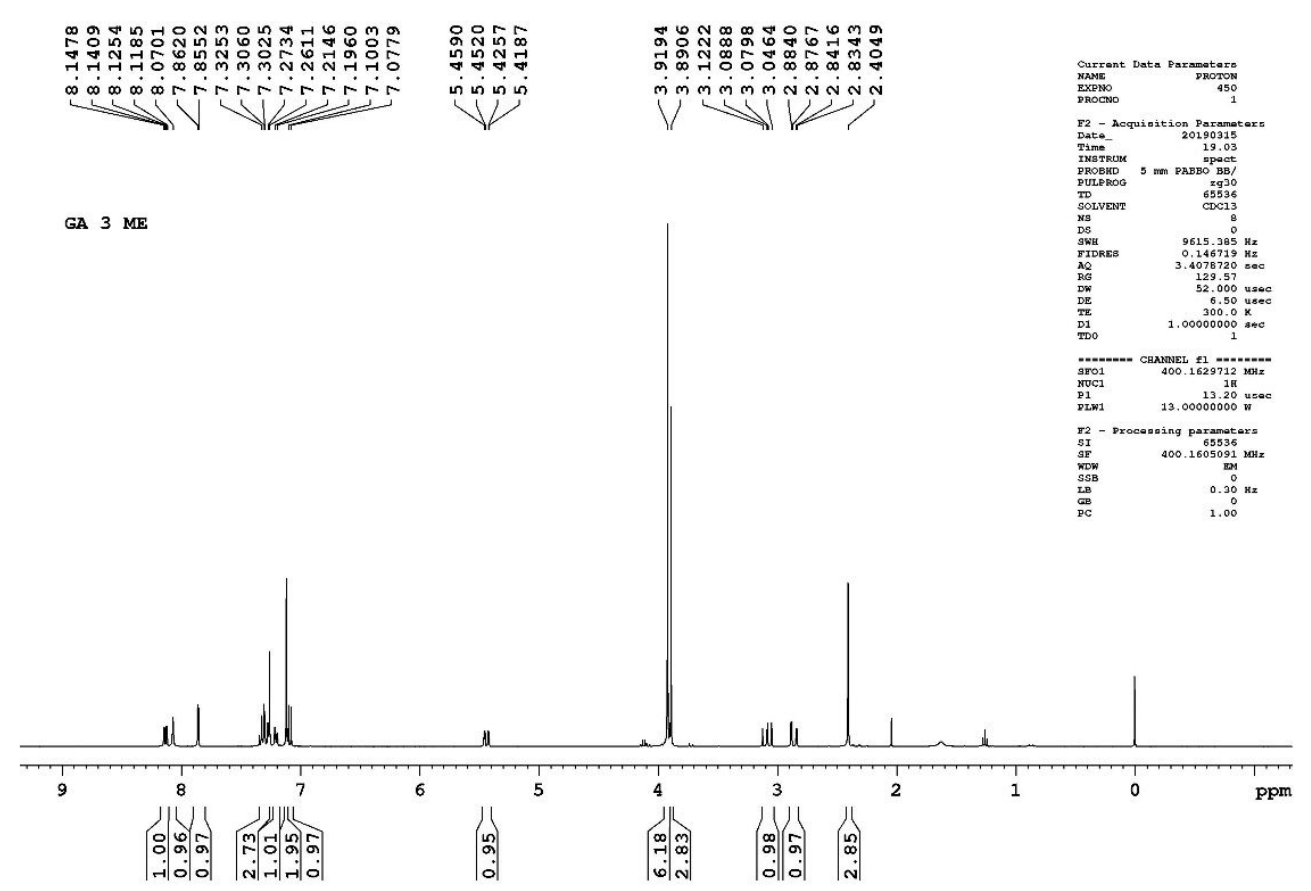

${ }^{1} \mathrm{H}$ Spectrum of Compound $5 \mathrm{c}$

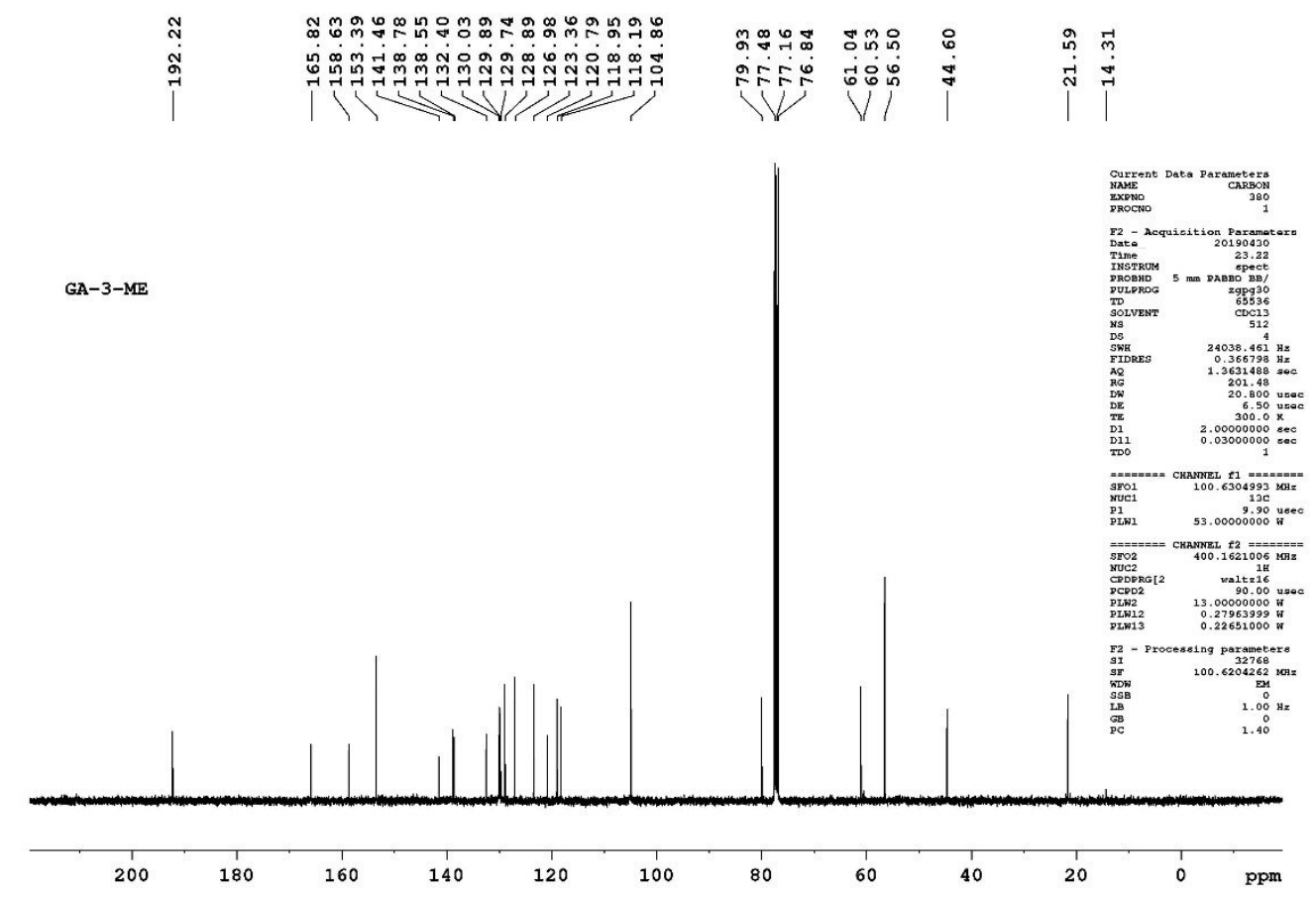

${ }^{13} \mathrm{C}$ Spectrum of Compound $5 \mathrm{c}$ 


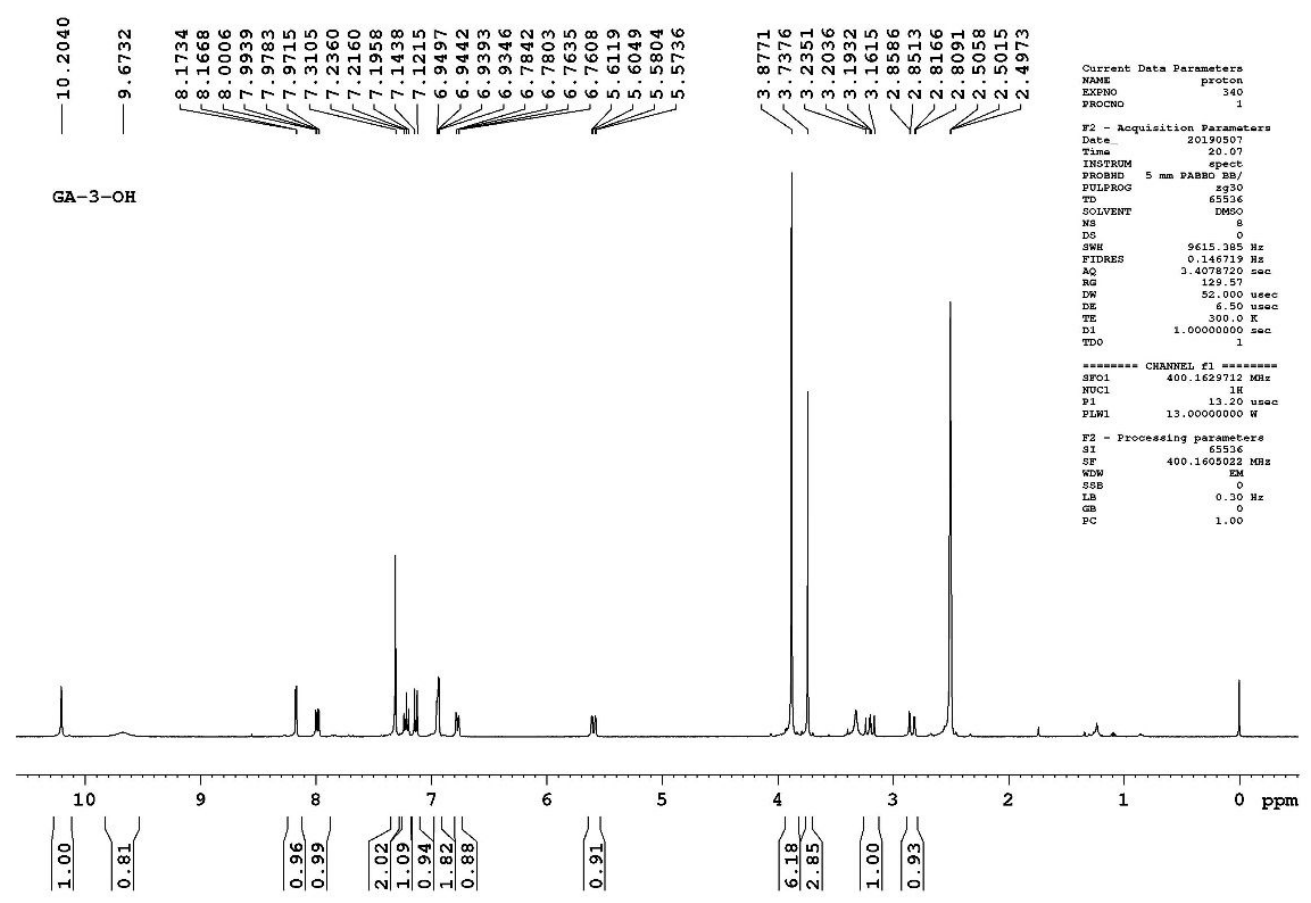

${ }^{1} \mathrm{H}$ Spectrum of Compound $5 \mathrm{~d}$

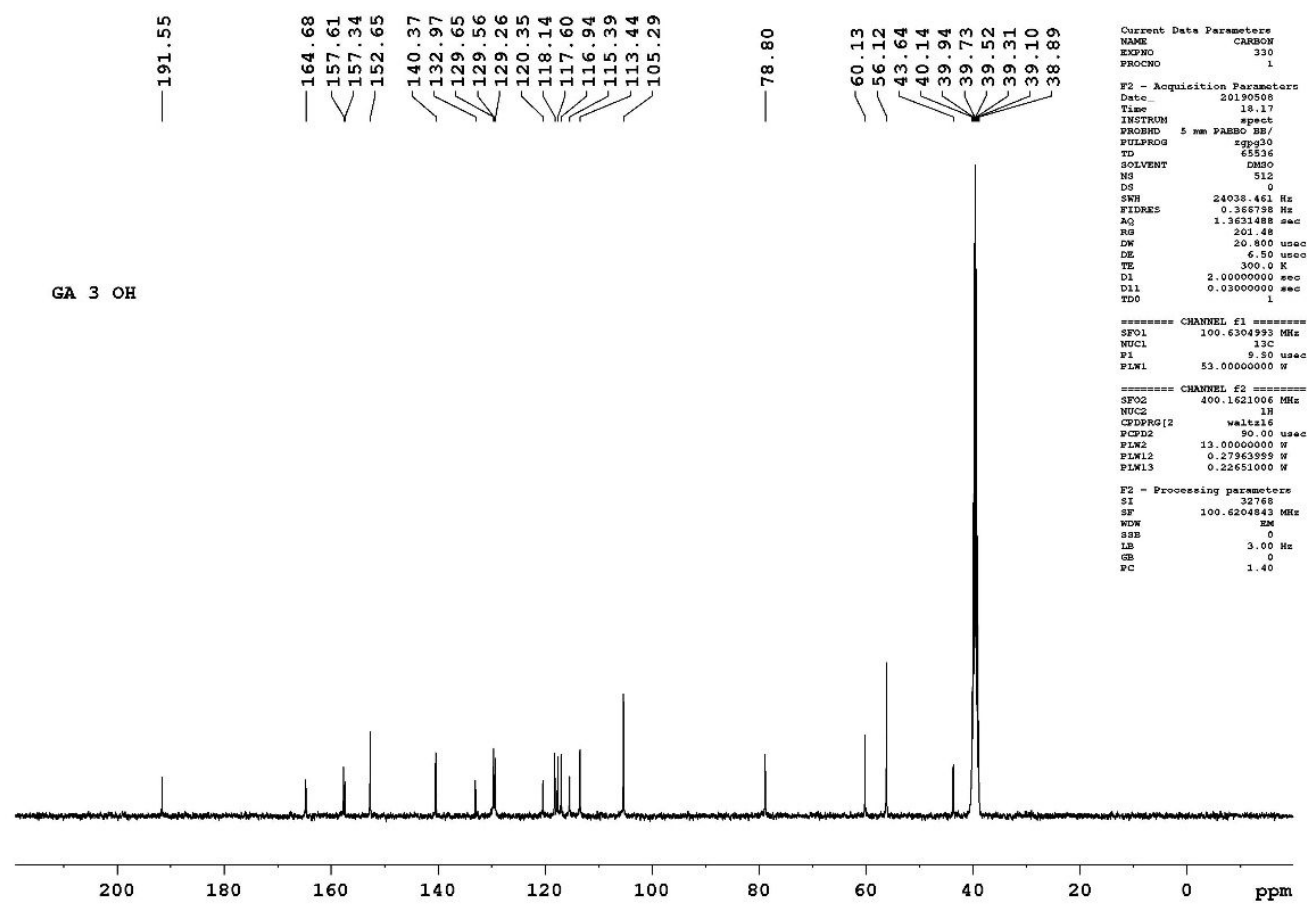

${ }^{13} \mathrm{C}$ Spectrum of Compound 5d 


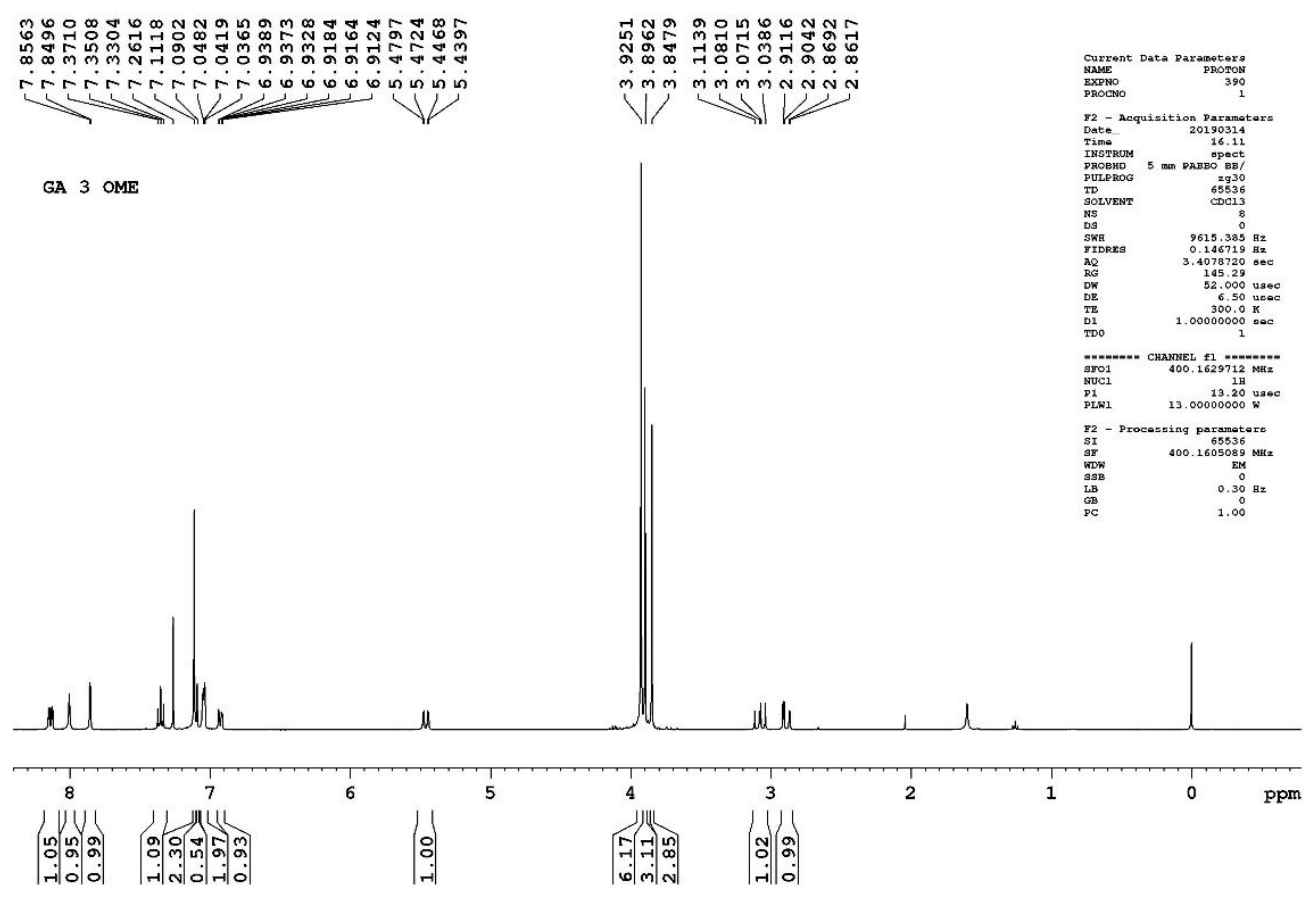

${ }^{1} \mathrm{H}$ Spectrum of Compound $5 \mathrm{e}$

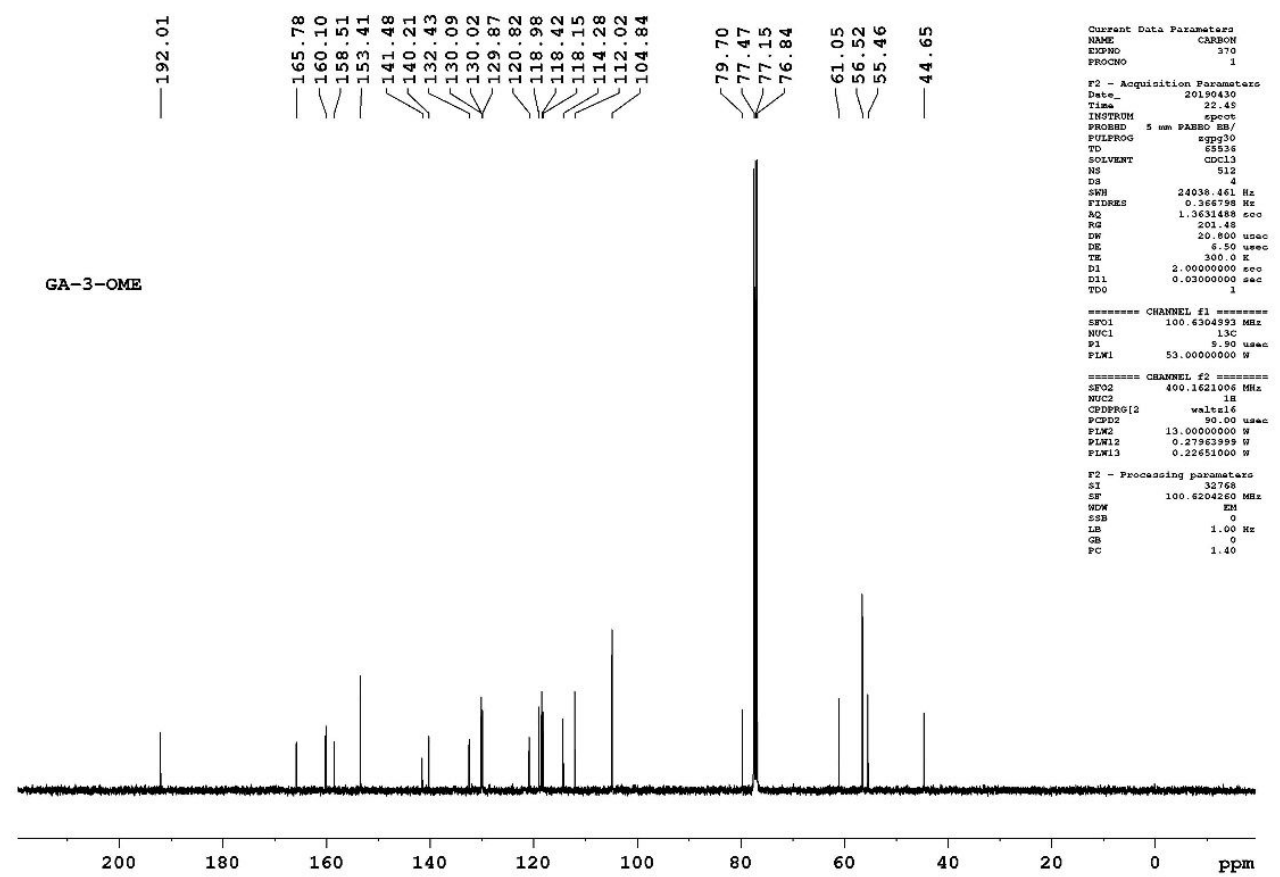

${ }^{13} \mathrm{C}$ Spectrum of Compound $5 \mathrm{e}$ 


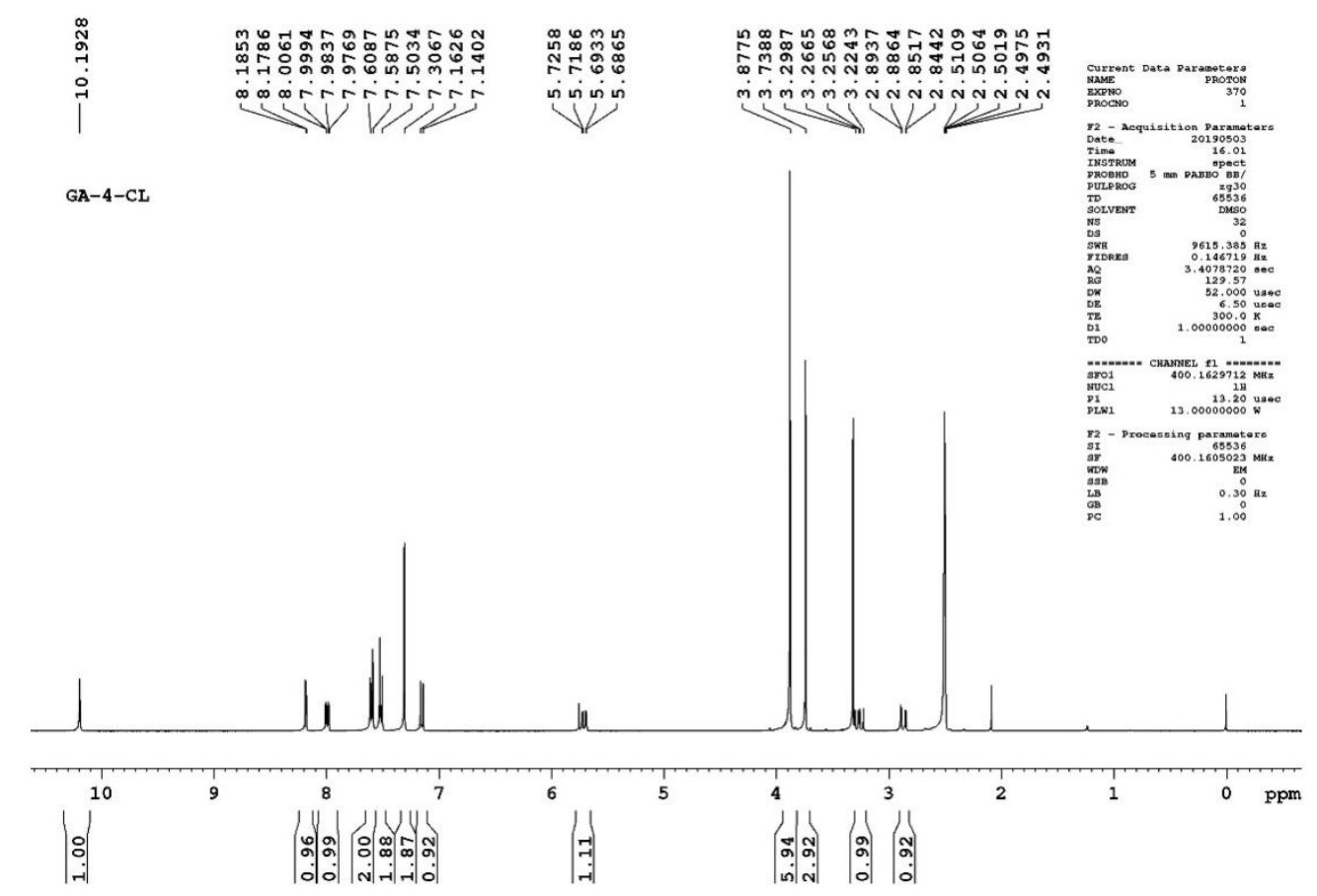

${ }^{1} \mathrm{H}$ Spectrum of Compound $5 f$

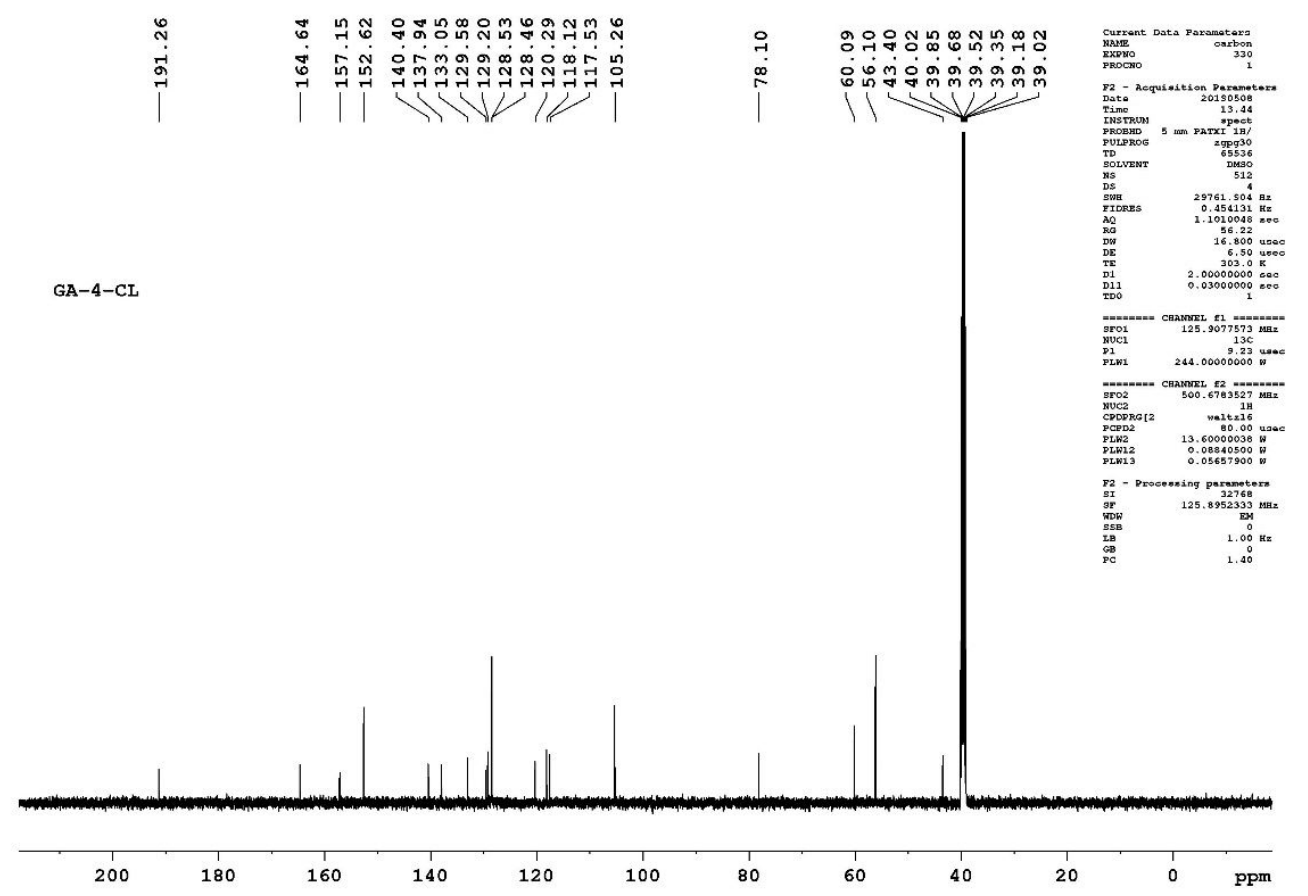

${ }^{13} \mathrm{C}$ Spectrum of Compound $5 \mathrm{f}$ 


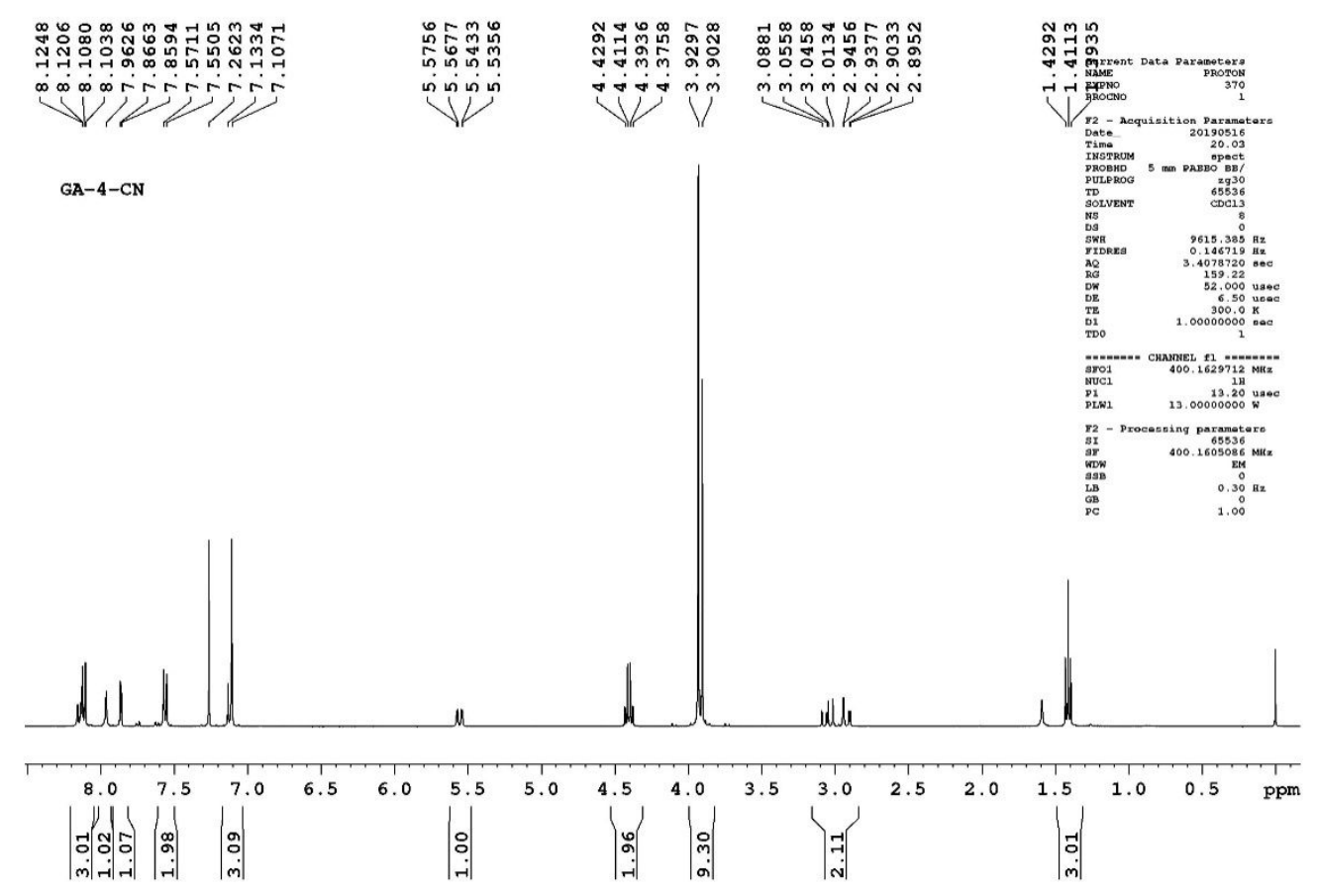

${ }^{1} \mathrm{H}$ Spectrum of Compound $5 \mathrm{~g}$

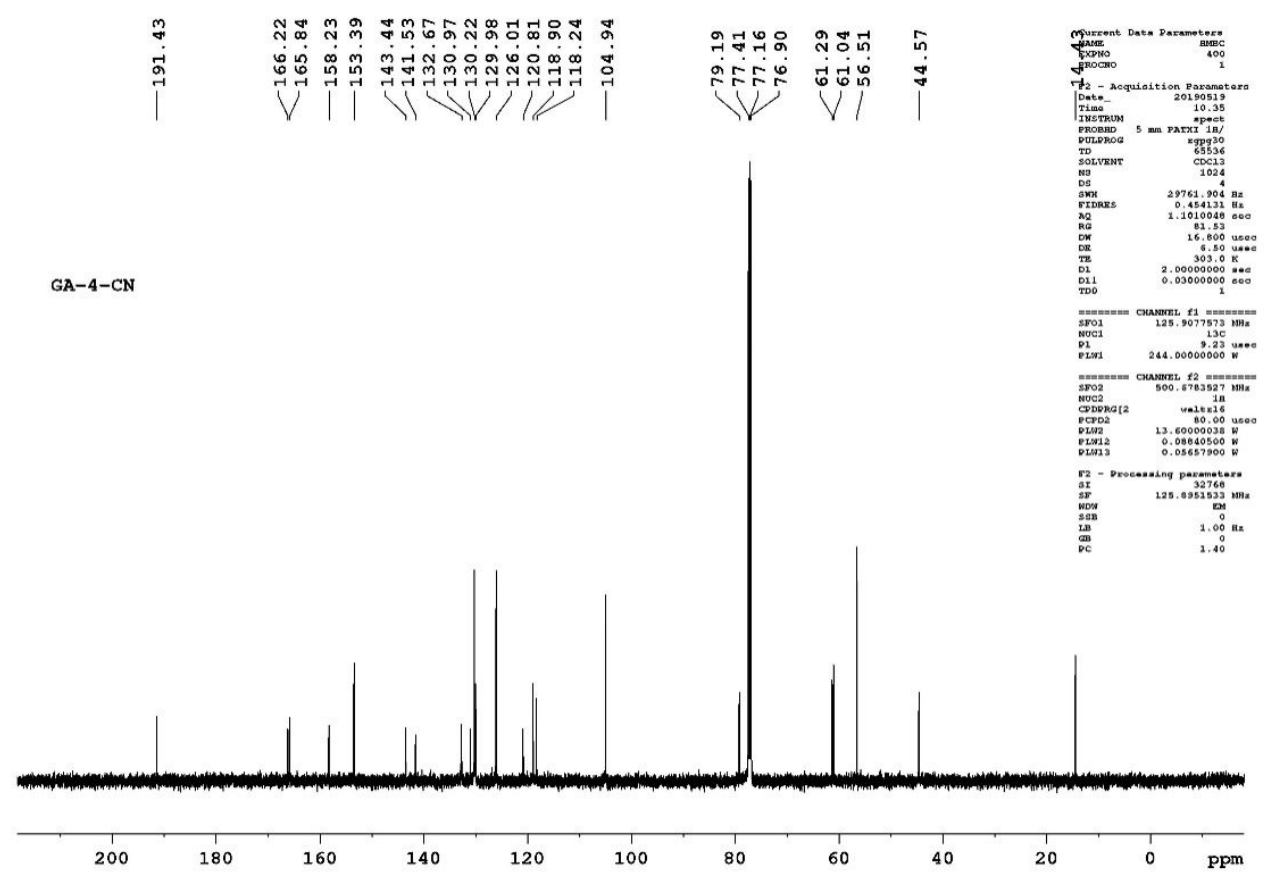

${ }^{13} \mathrm{C}$ Spectrum of Compound $5 \mathrm{~g}$ 


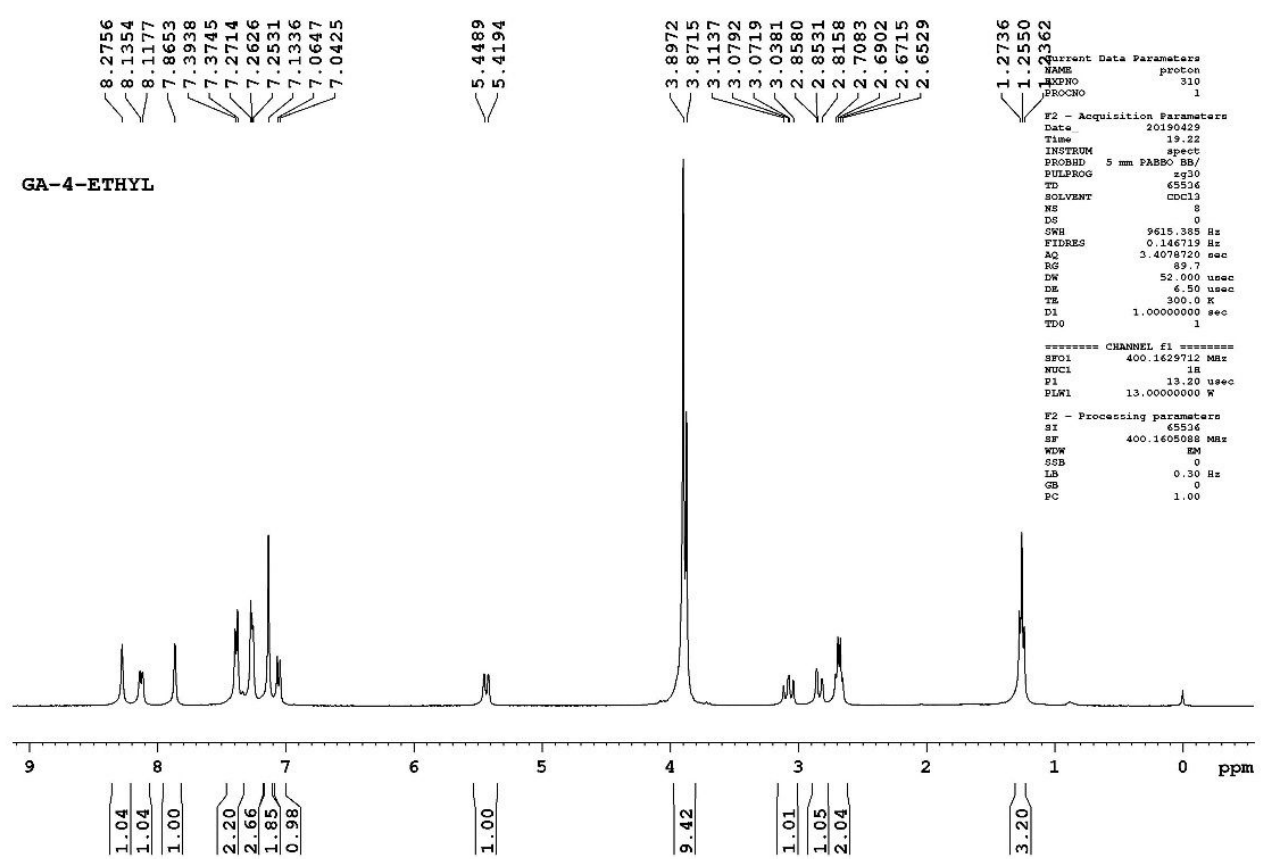

${ }^{1} \mathrm{H}$ Spectrum of Compound $5 \mathrm{~h}$

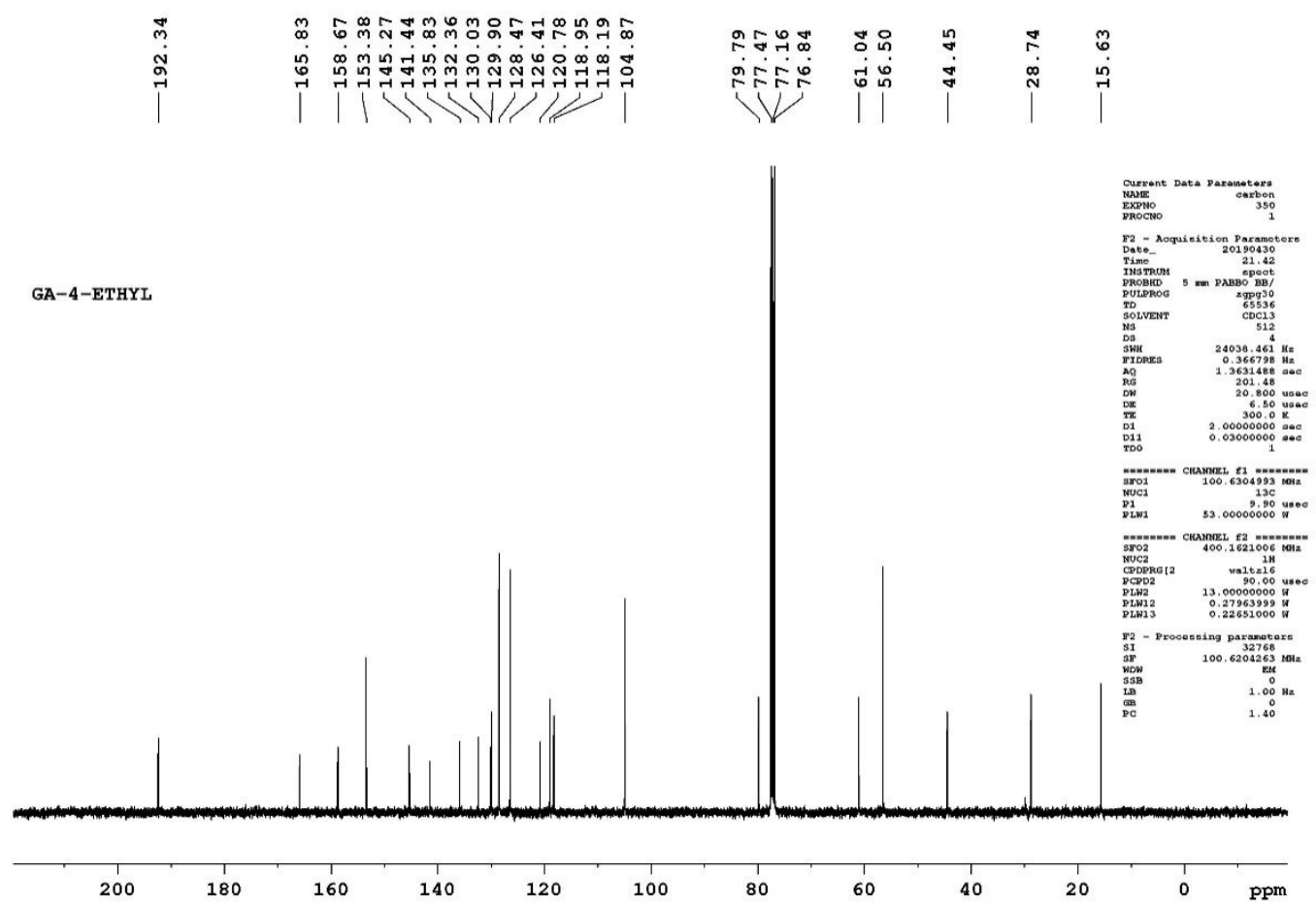

${ }^{13} \mathrm{C}$ Spectrum of Compound $5 \mathrm{~h}$ 


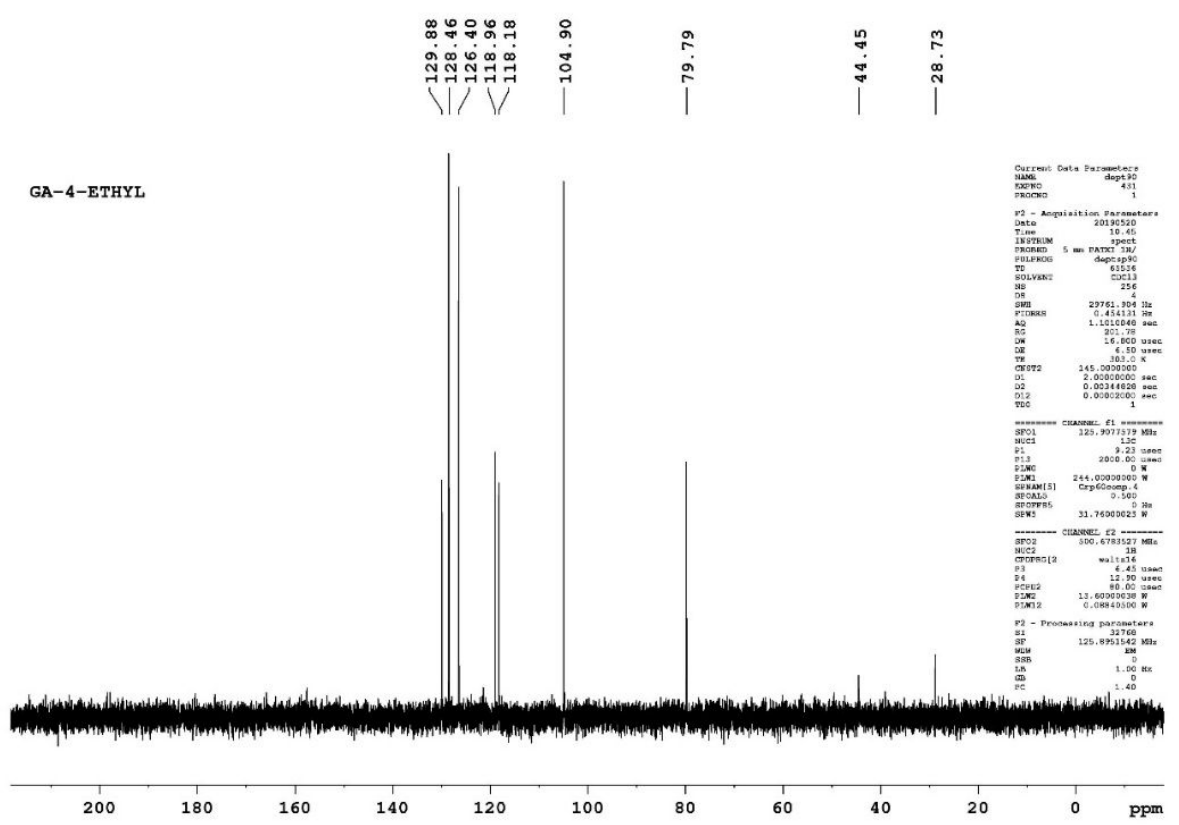

DEPT 90 of Compound $5 \mathrm{~h}$

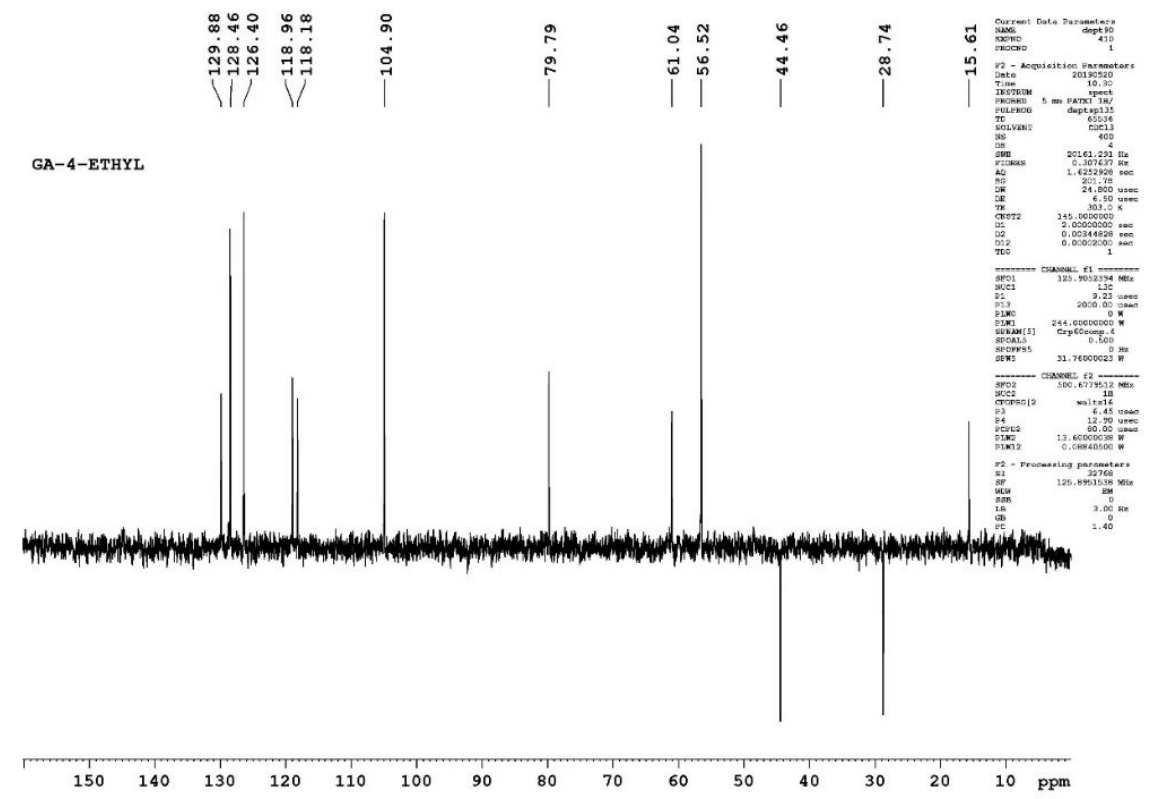

DEPT 135 of Compound $5 h$ 


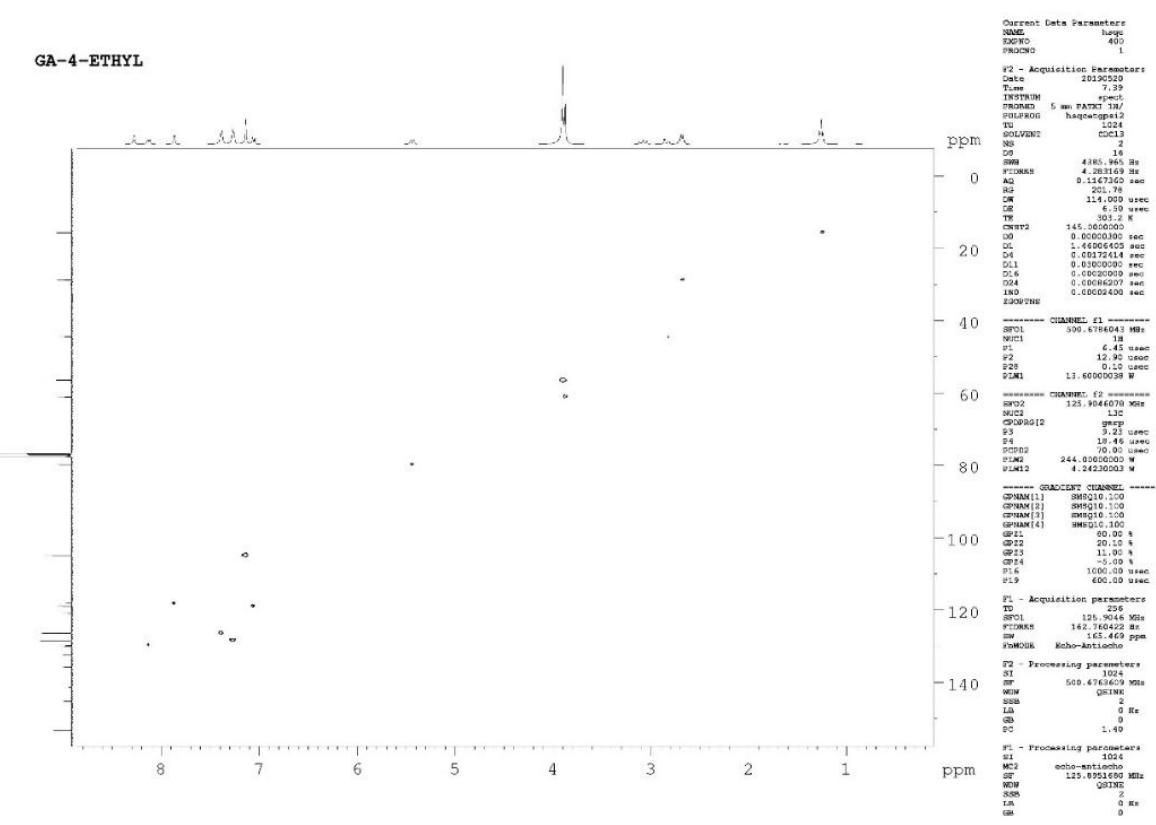

HSQC of Compound $5 \mathrm{~h}$

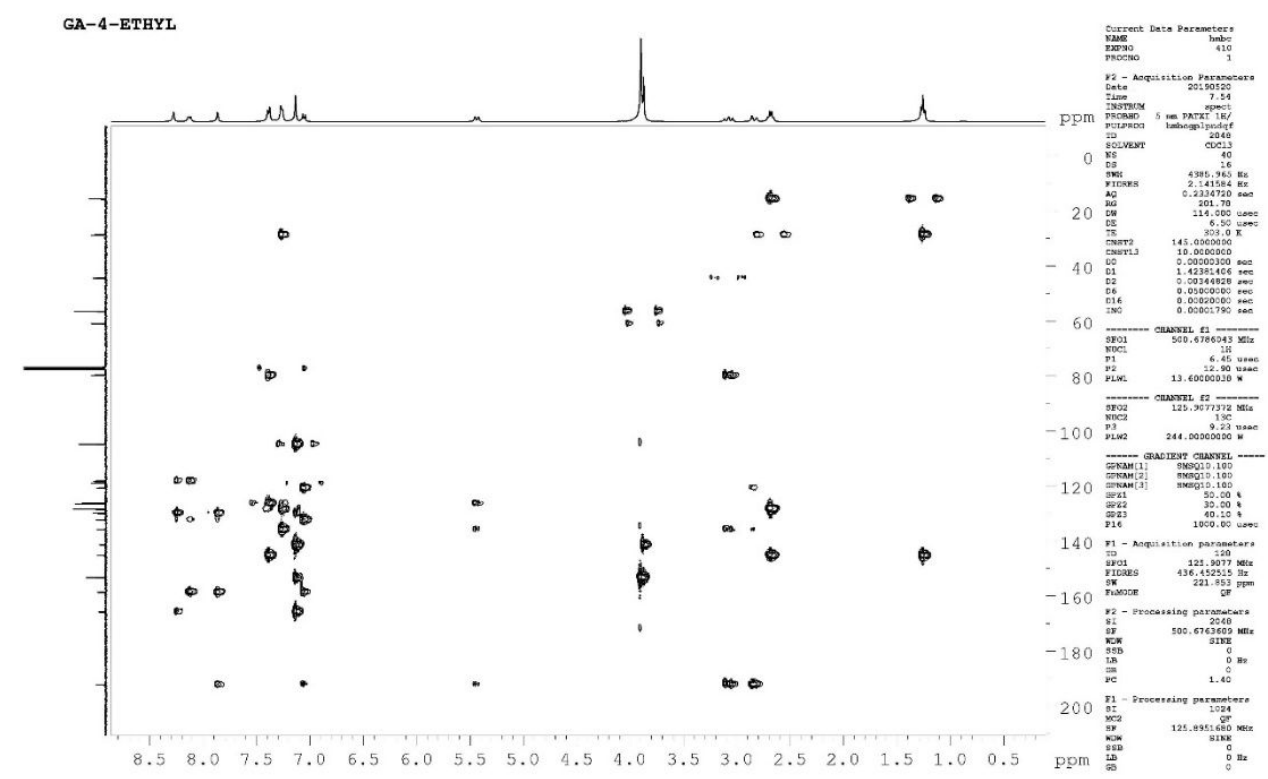

HMBC of Compound $5 \mathrm{~h}$ 


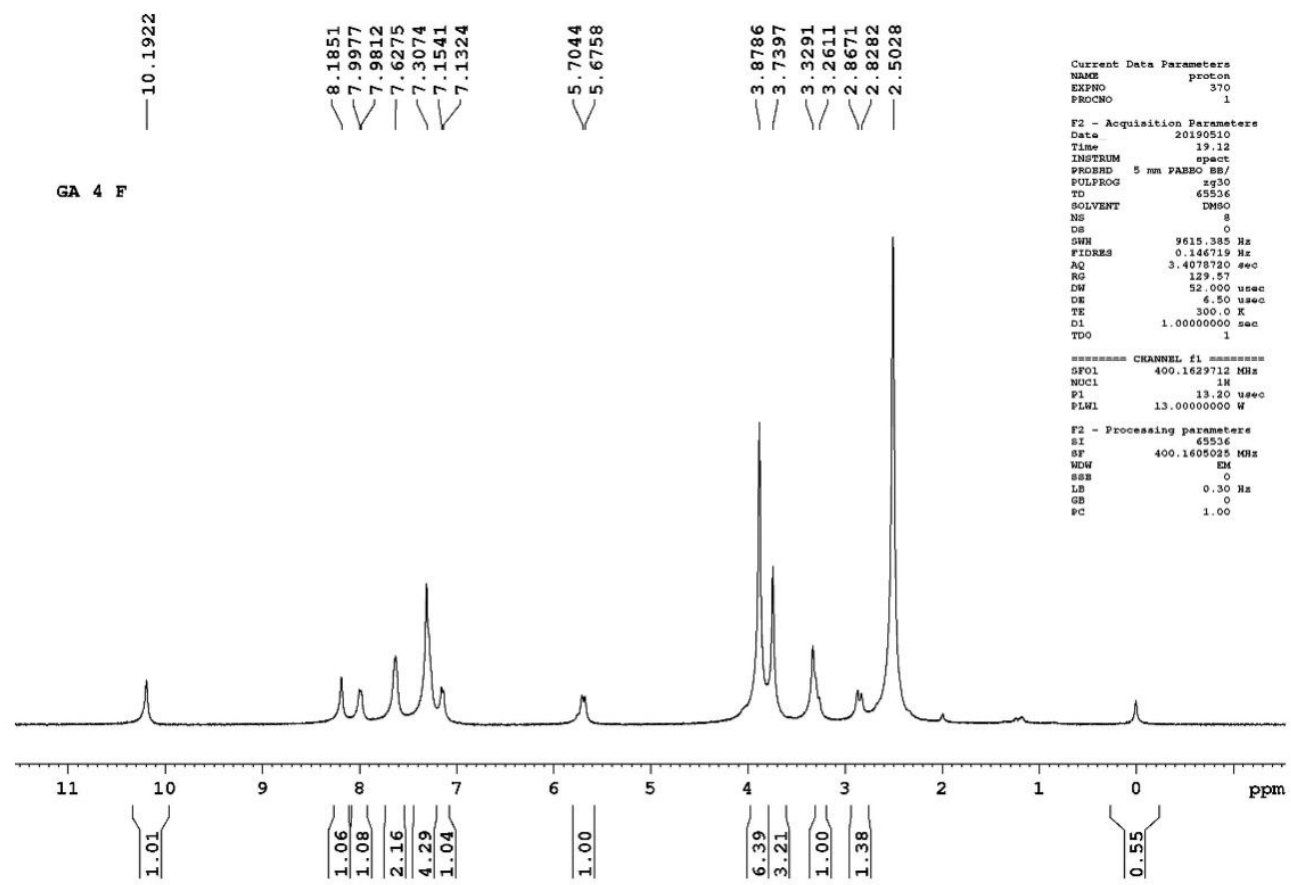

${ }^{1} \mathrm{H}$ Spectrum of Compound $5 \mathrm{i}$

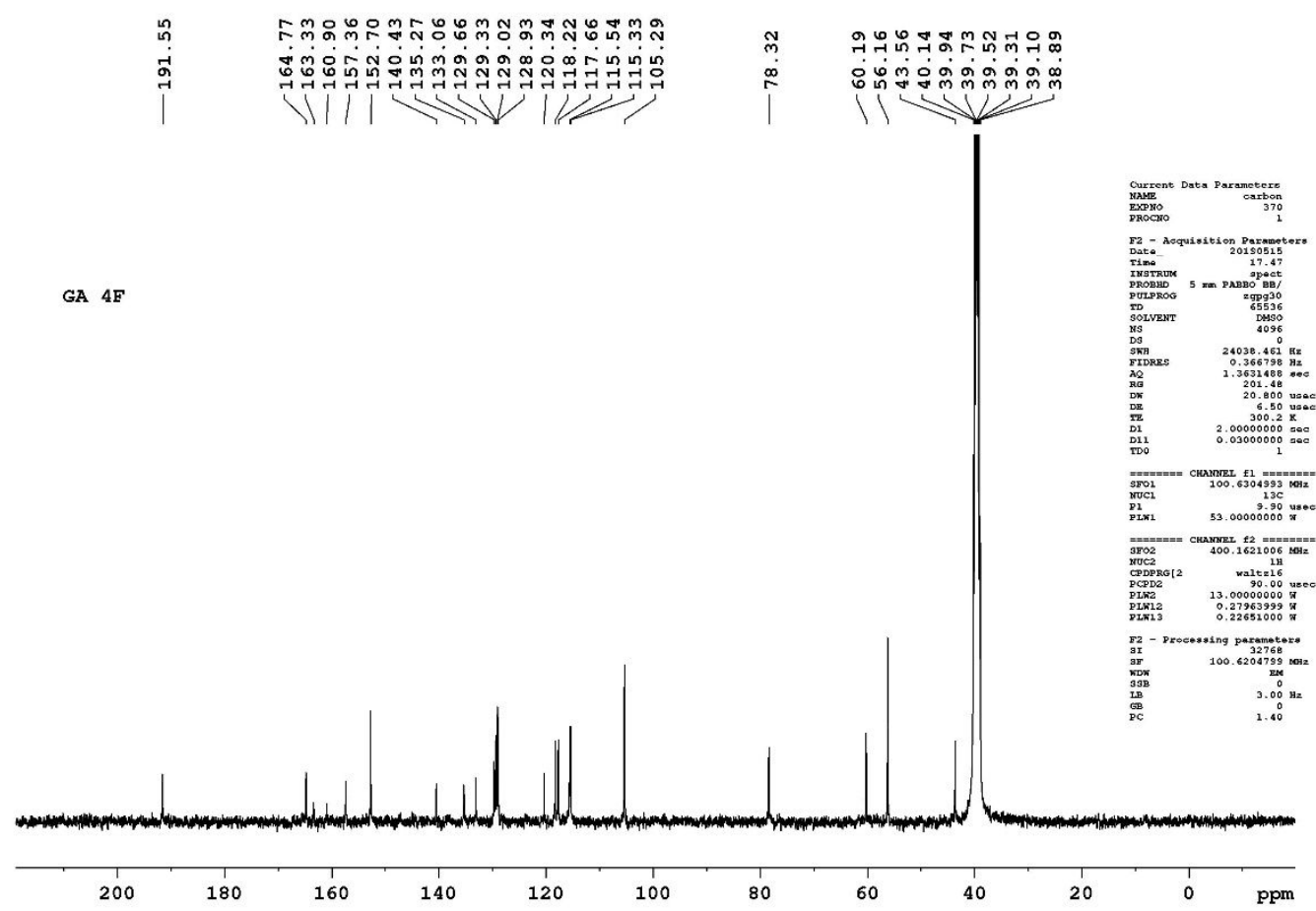

${ }^{13} \mathrm{C}$ Spectrum of Compound $5 \mathrm{i}$ 


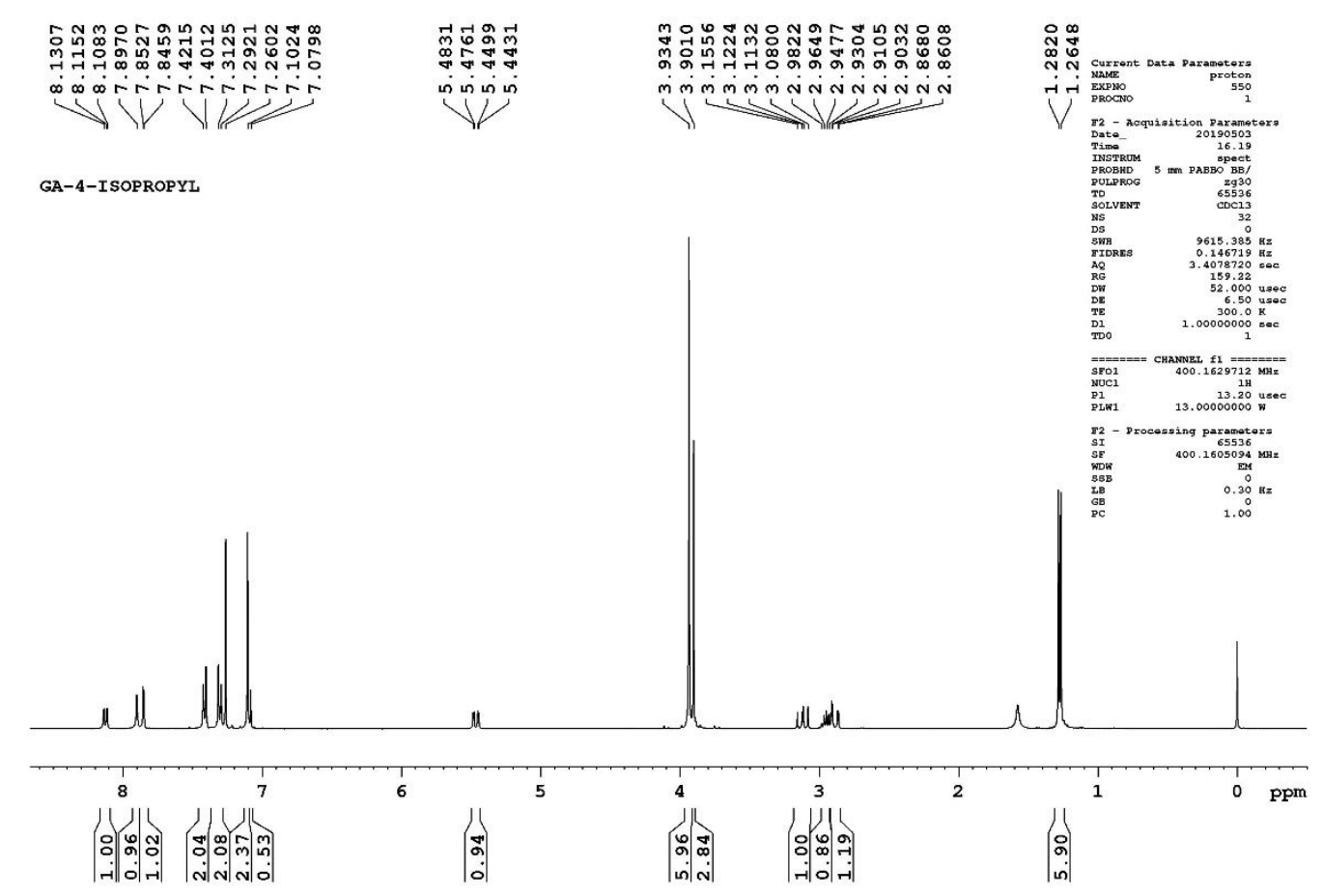

${ }^{1} \mathrm{H}$ Spectrum of Compound $5 \mathbf{j}$

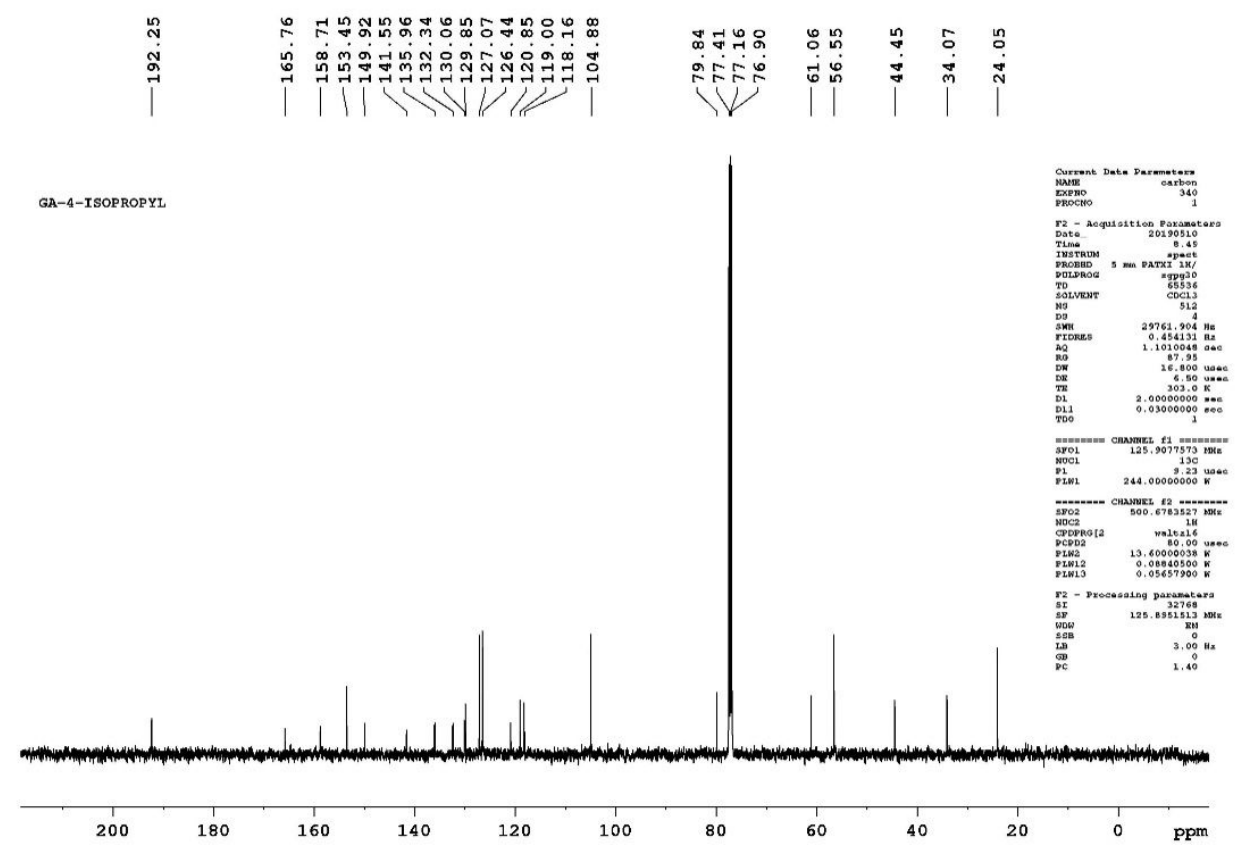

${ }^{13} \mathrm{C}$ Spectrum of Compound $5 \mathbf{j}$ 


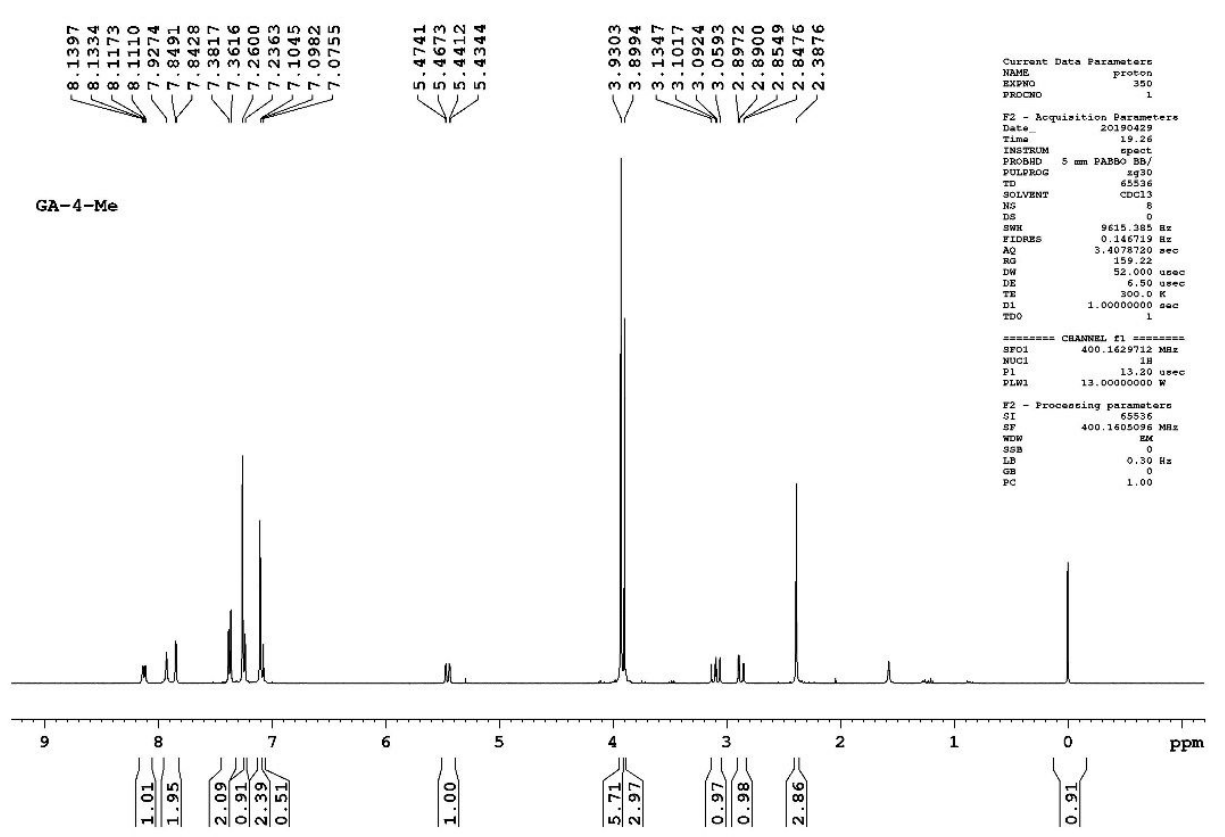

${ }^{1} \mathbf{H}$ Spectrum of Compound $\mathbf{5 k}$

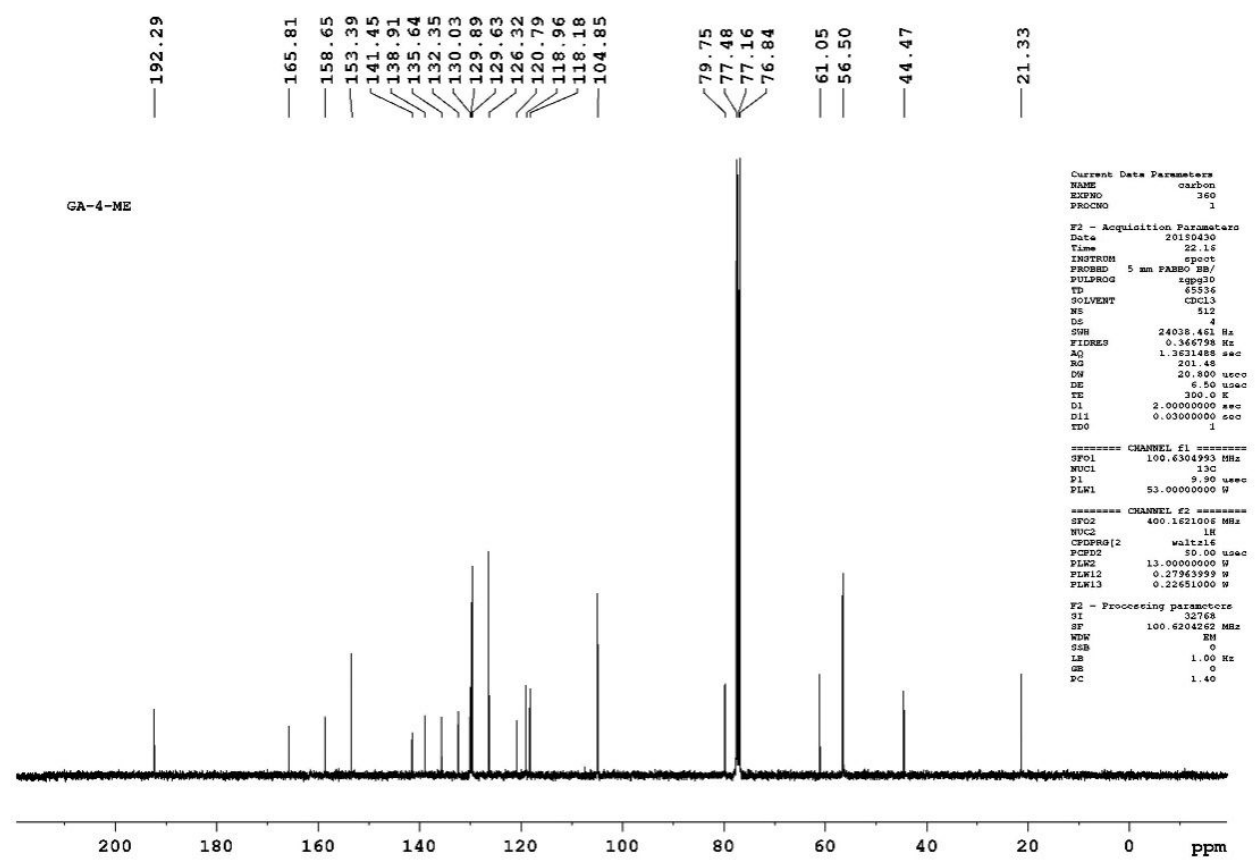

${ }^{13} \mathrm{C}$ Spectrum of Compound $5 \mathrm{k}$ 


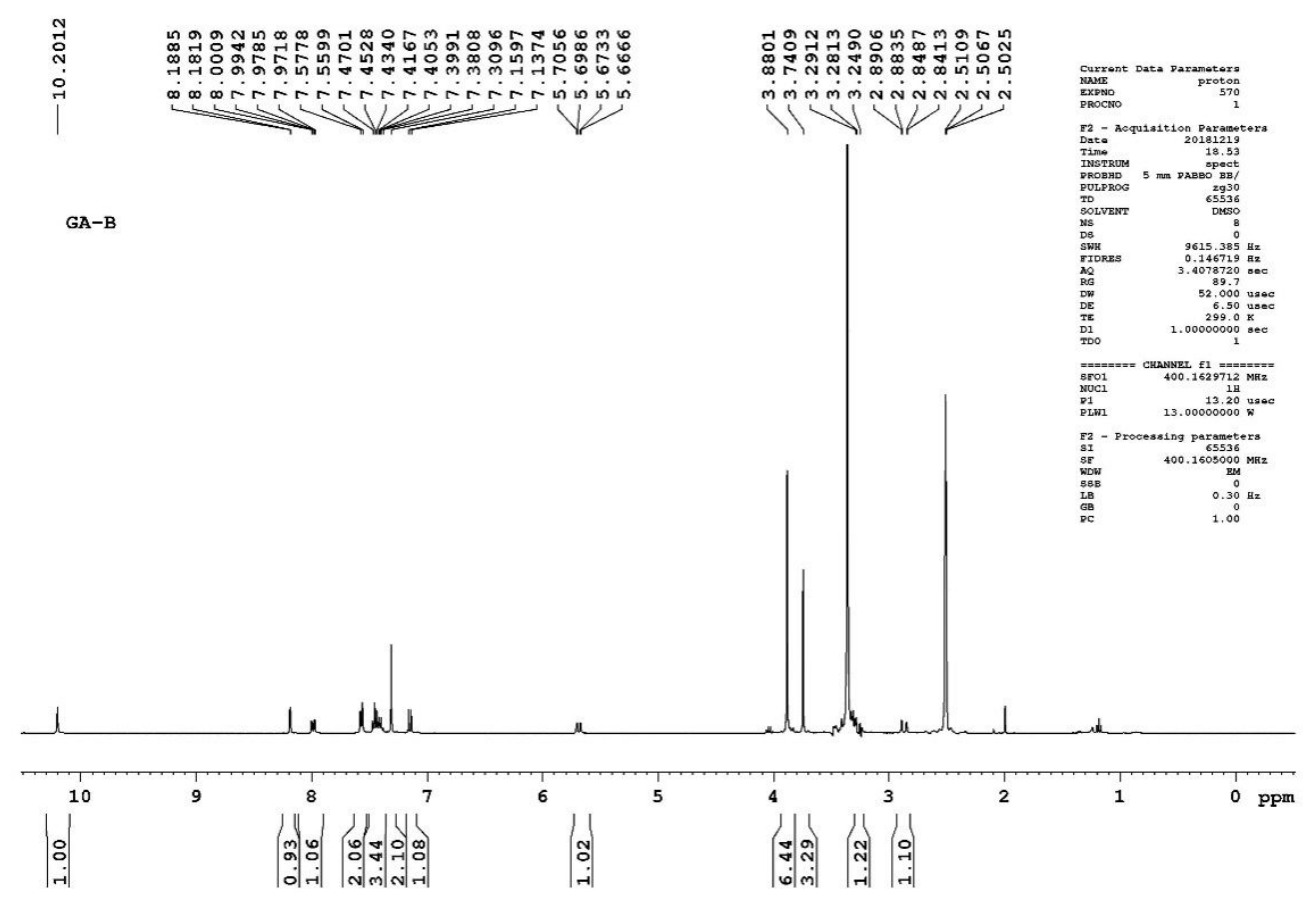

${ }^{1} \mathrm{H}$ Spectrum of Compound $5 \mathrm{I}$

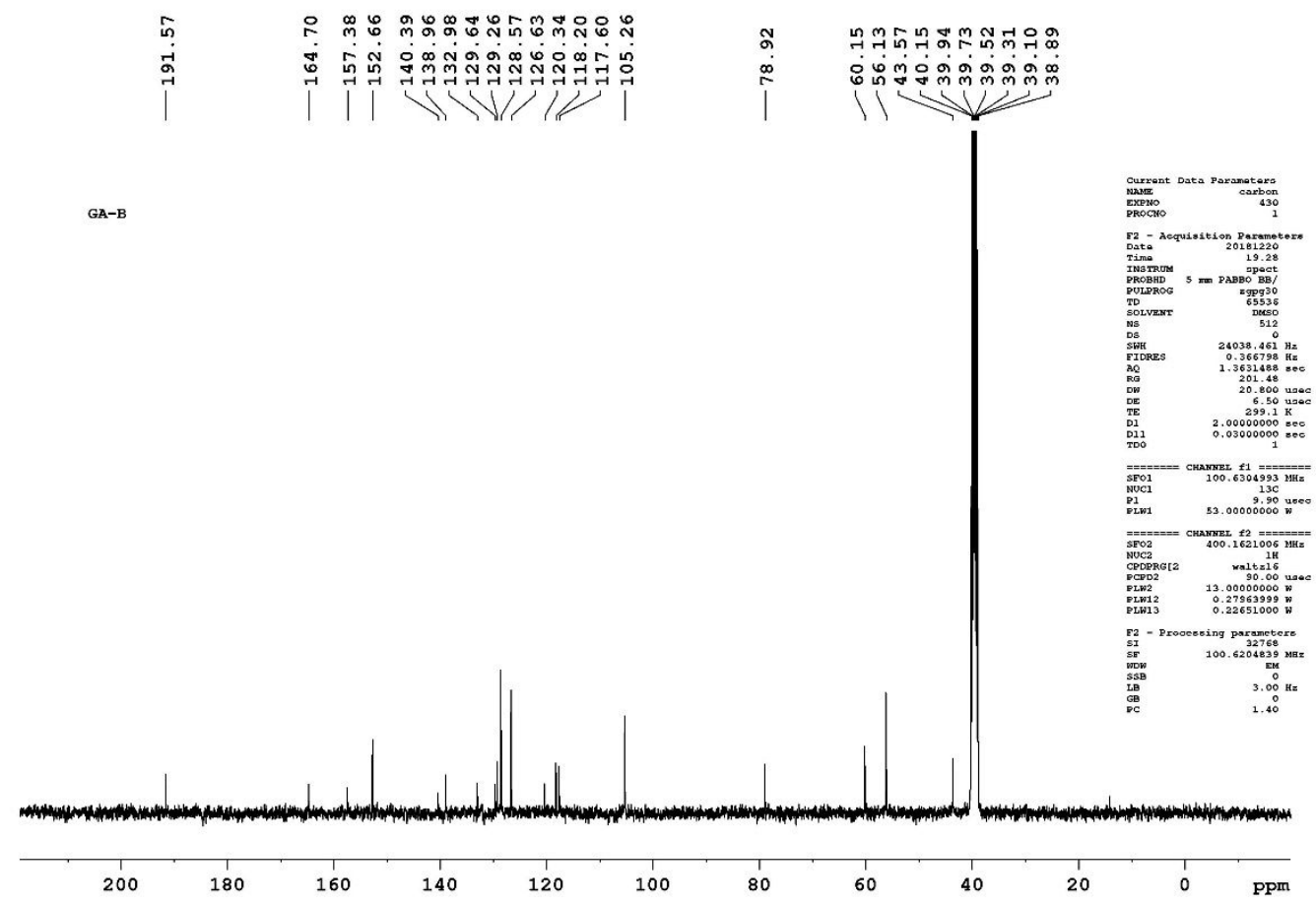

${ }^{13} \mathrm{C}$ Spectrum of Compound $5 \mathrm{I}$ 


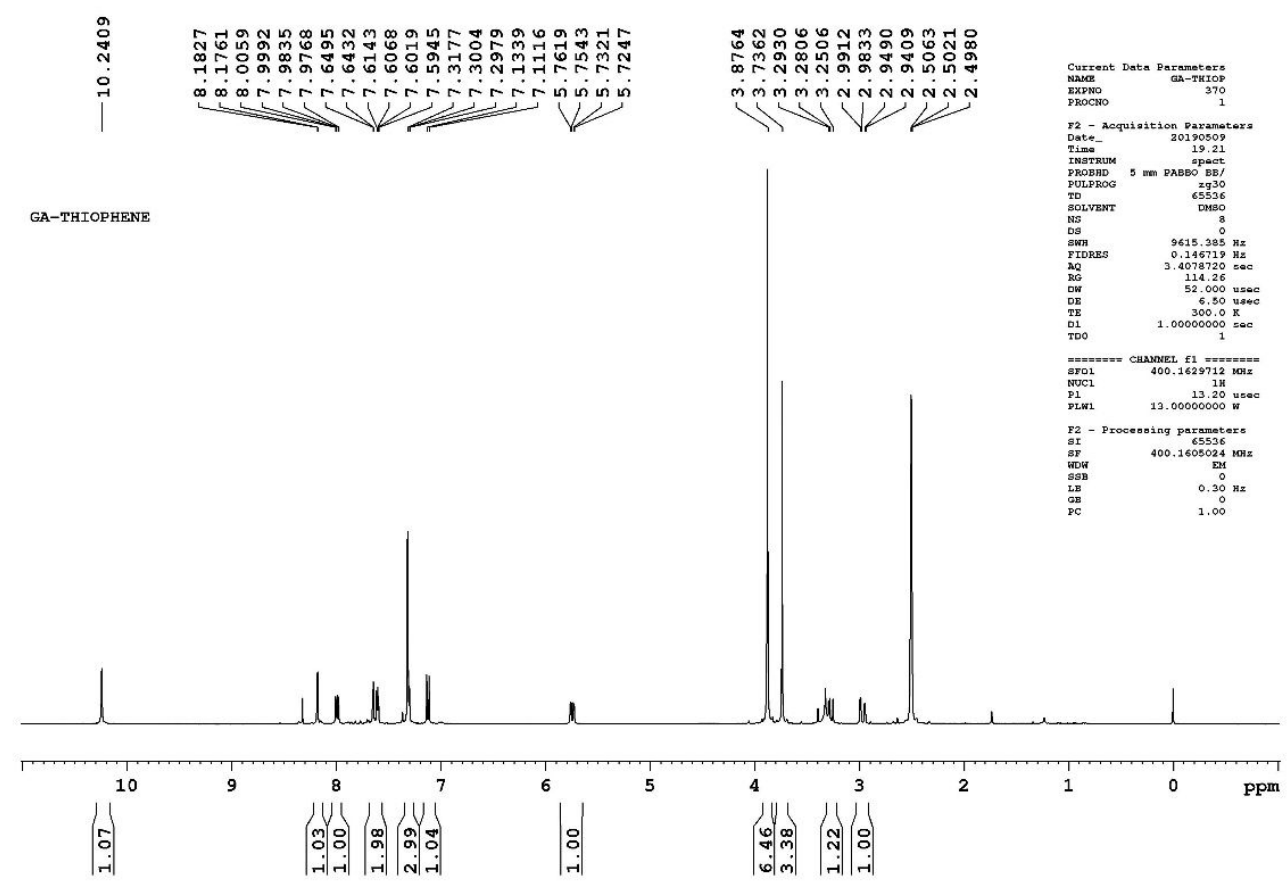

${ }^{1} \mathrm{H}$ Spectrum of Compound $5 \mathrm{~m}$

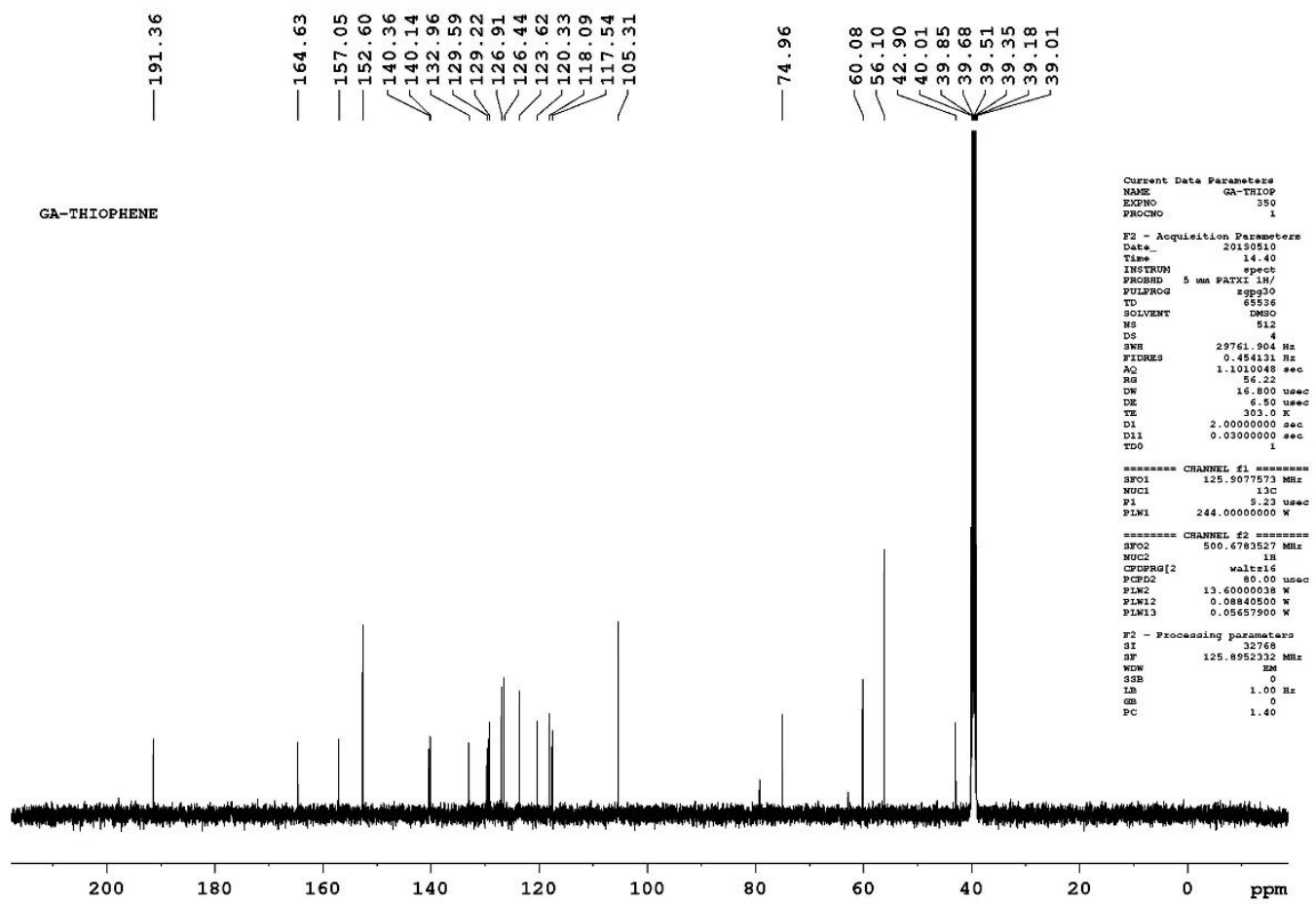

${ }^{13} \mathrm{C}$ Spectrum of Compound $5 \mathrm{~m}$ 


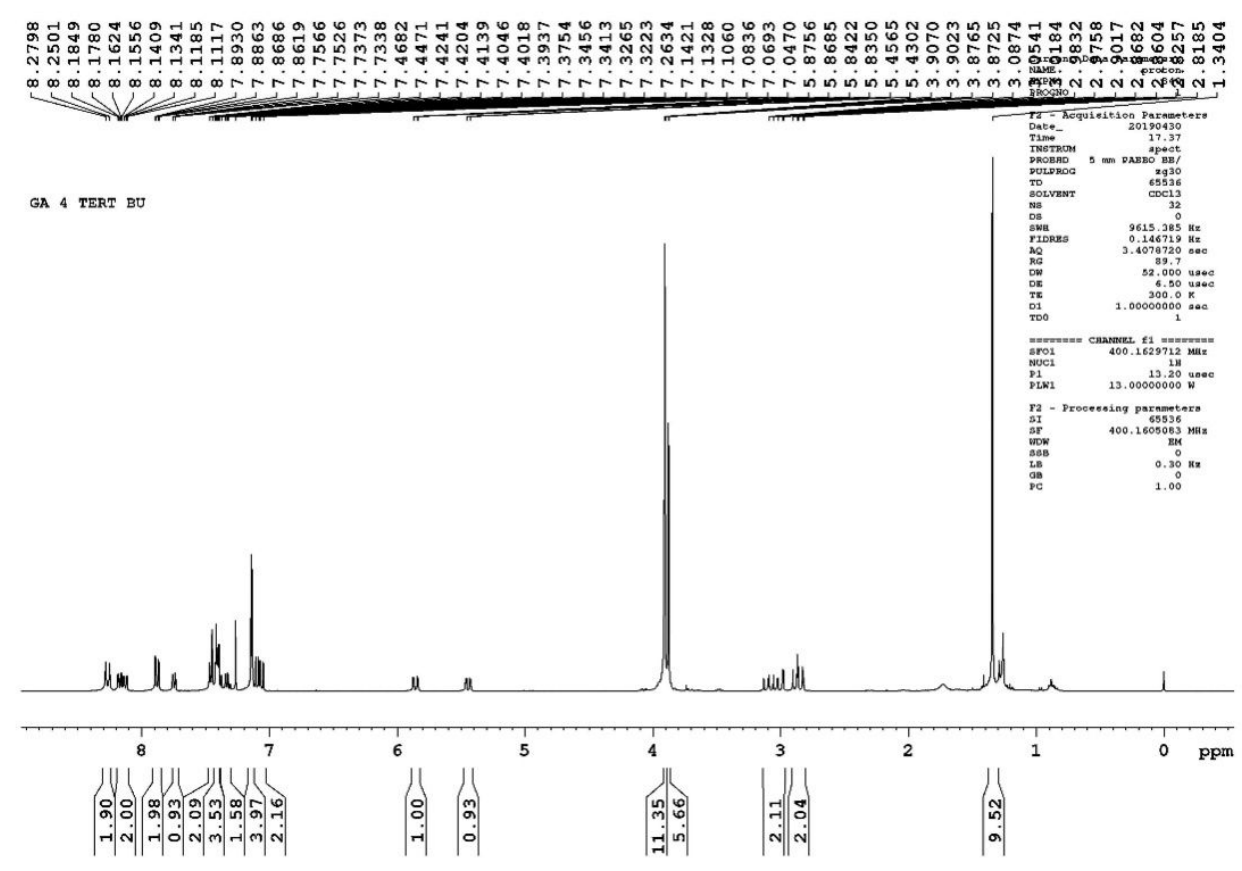

${ }^{1} \mathbf{H}$ Spectrum of Compound 5 n

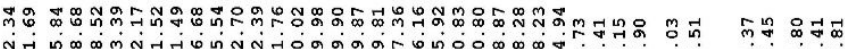

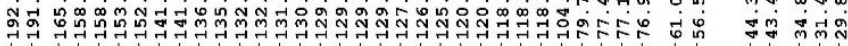

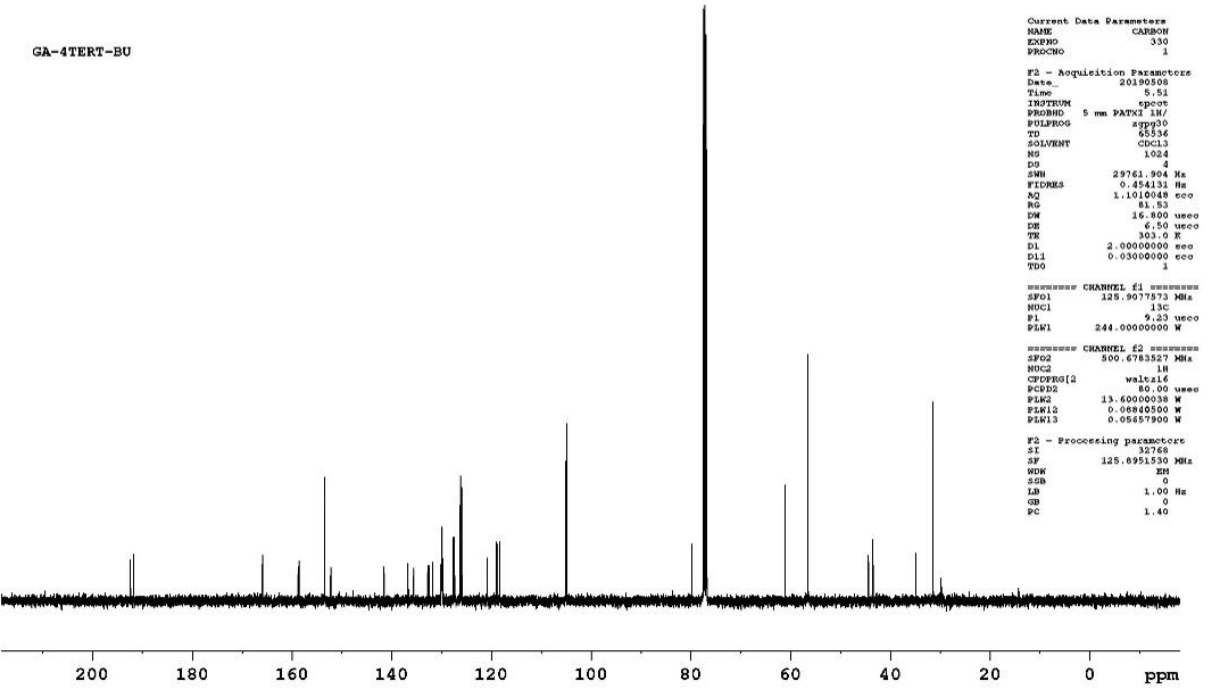

${ }^{13} \mathrm{C}$ Spectrum of Compound $5 n$ 


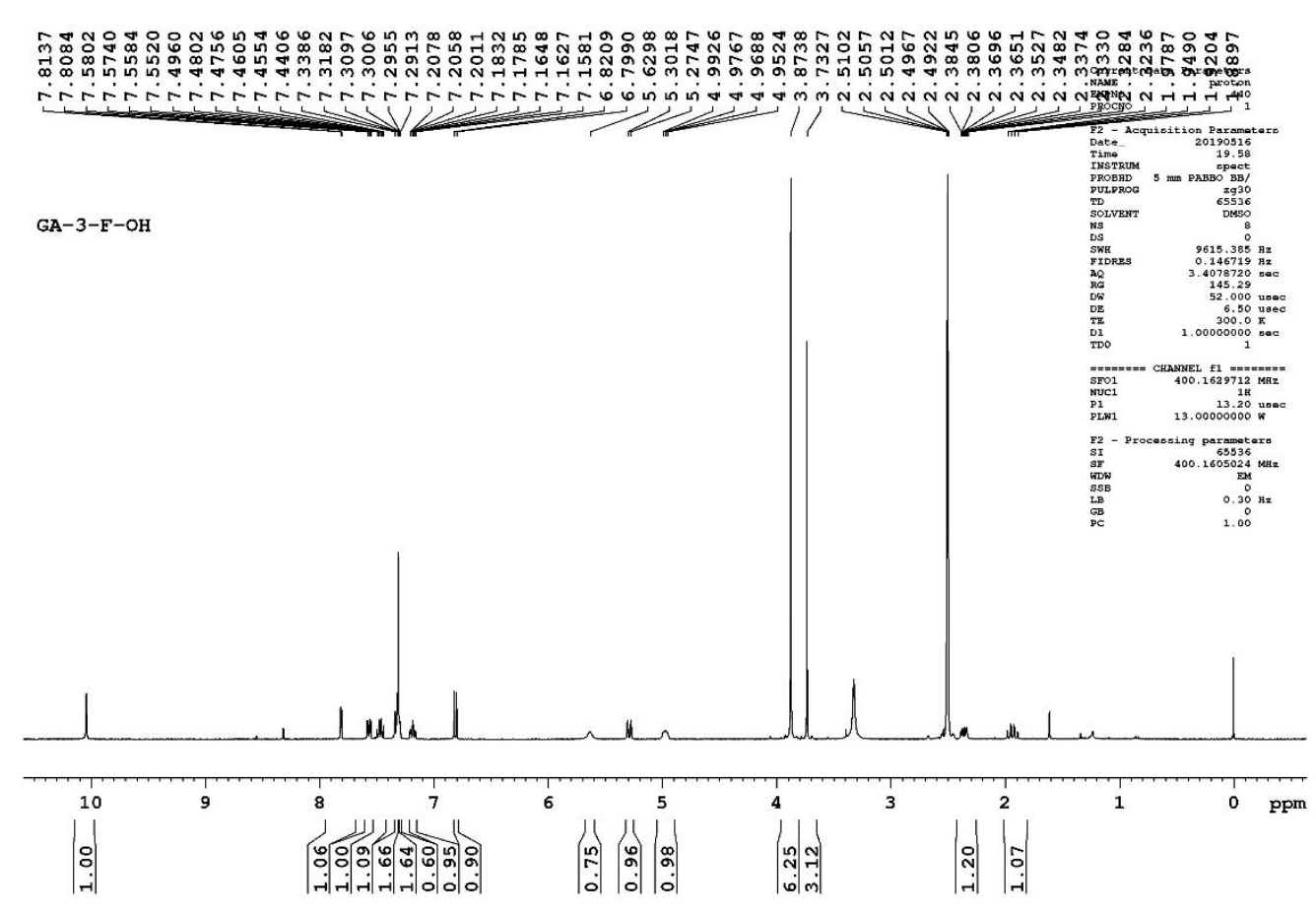

${ }^{1} \mathrm{H}$ Spectrum of Compound 60

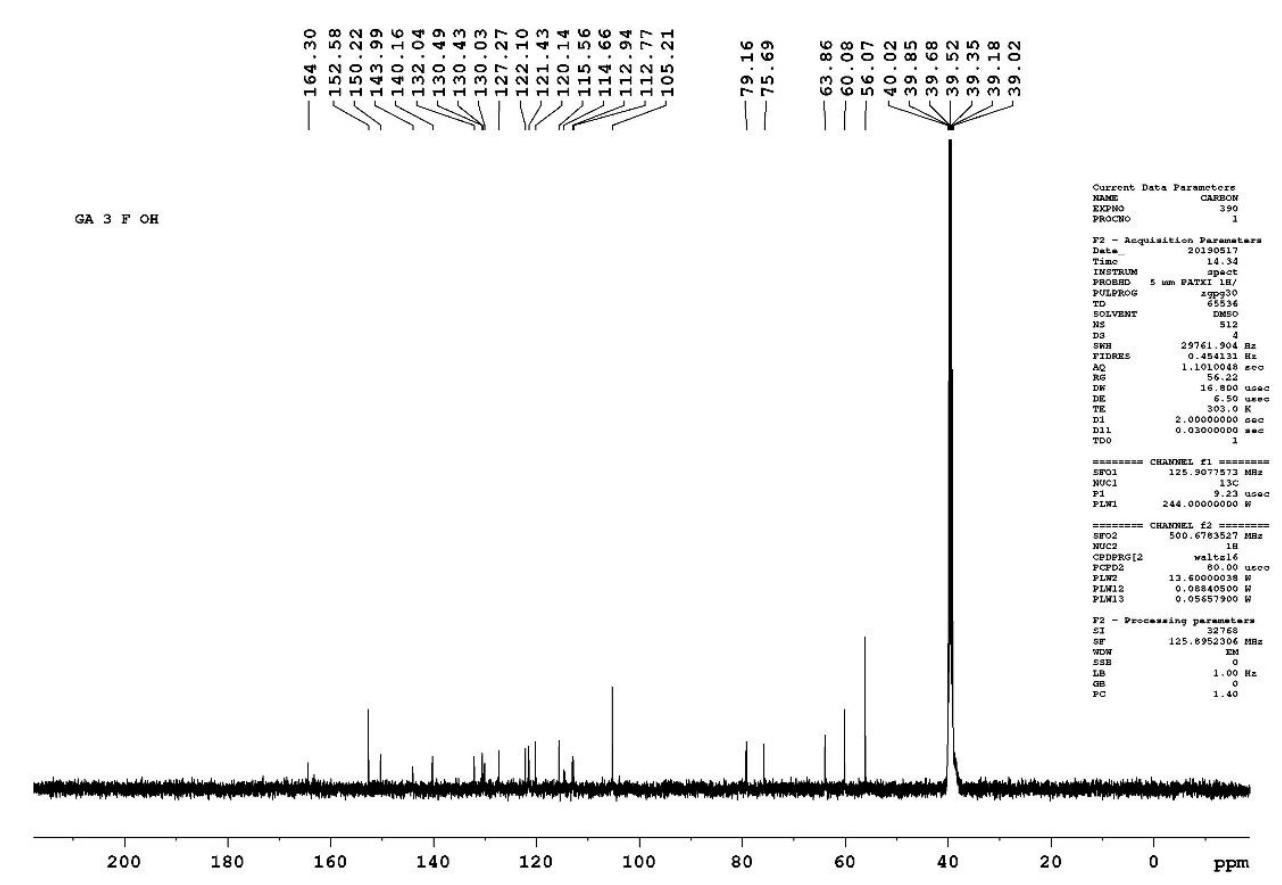

${ }^{13} \mathrm{C}$ Spectrum of Compound 60 


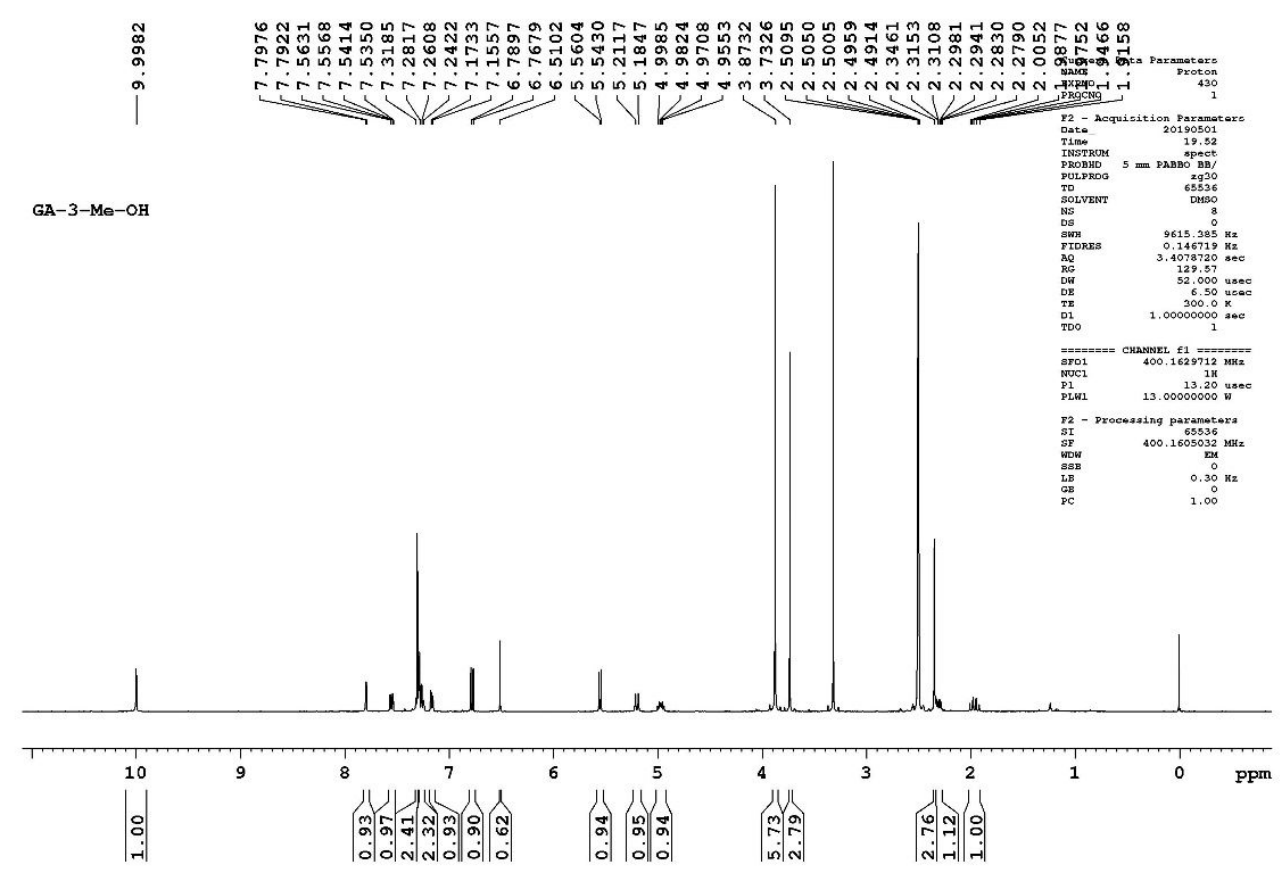

${ }^{1} \mathrm{H}$ Spectrum of Compound $6 \mathrm{p}$

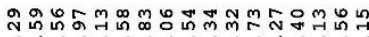

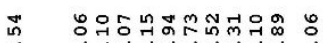

s.

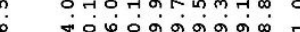

i

$\mathrm{GA}-3-\mathrm{Me}-\mathrm{OH}$

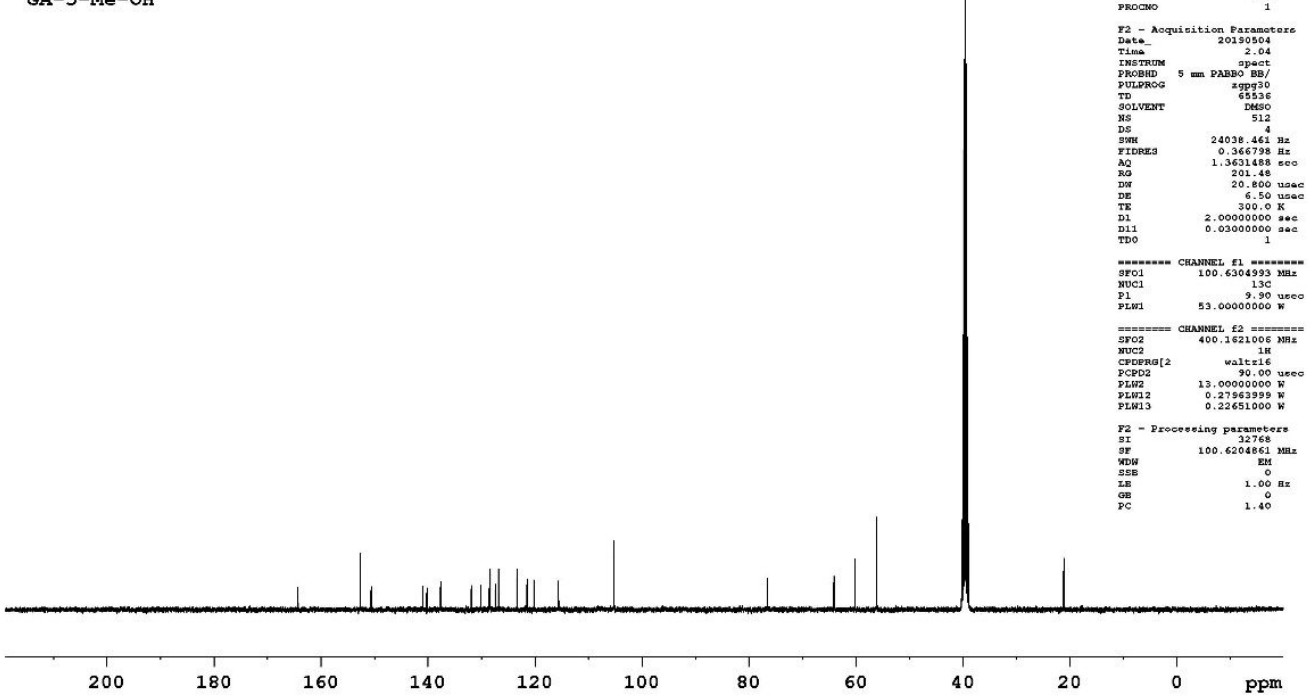

${ }^{13} \mathrm{C}$ Spectrum of Compound $6 \mathrm{p}$ 


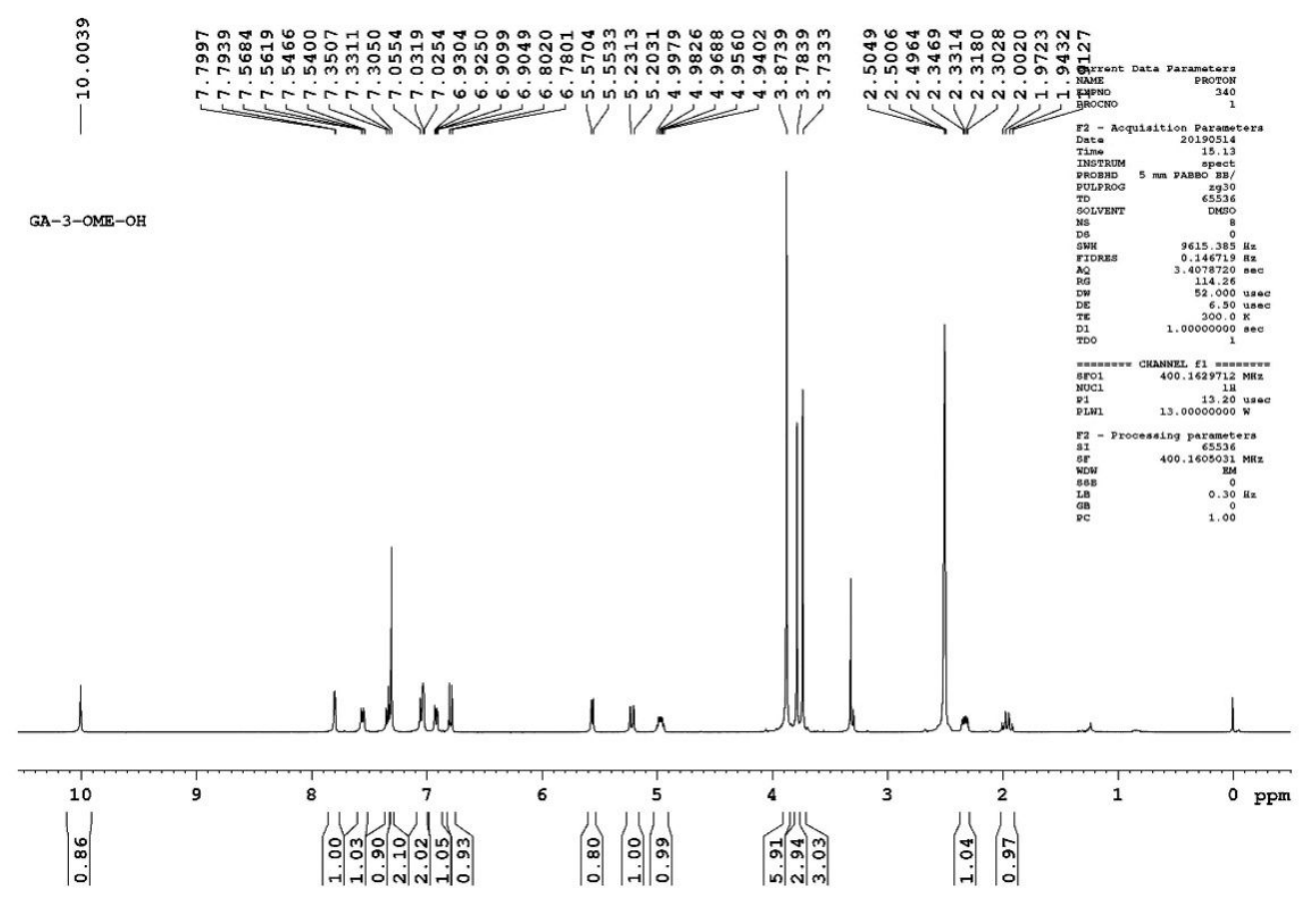

${ }^{1} \mathrm{H}$ Spectrum of Compound $6 \mathrm{q}$

GA 3 OME OH
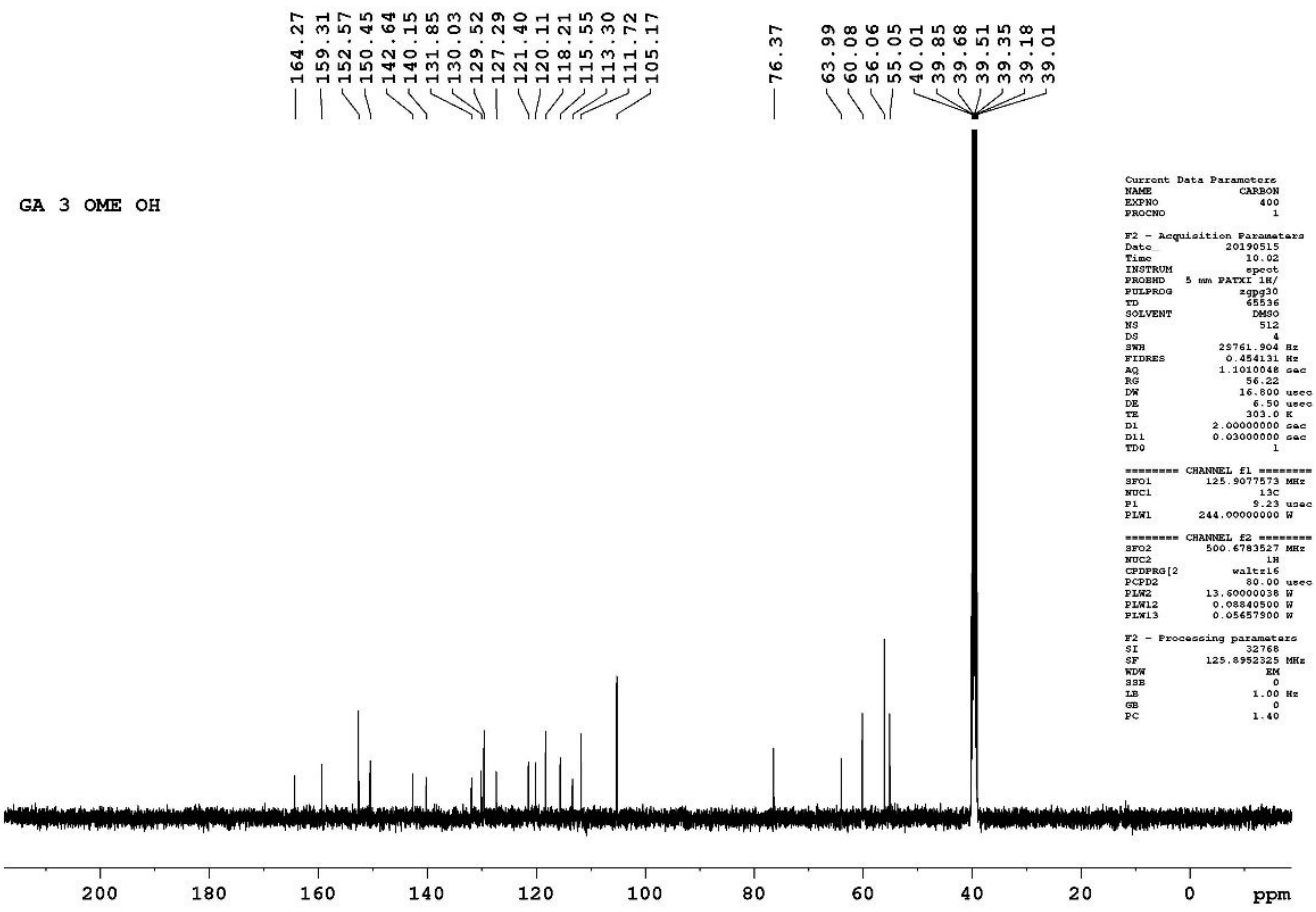

${ }^{13} \mathrm{C}$ Spectrum of Compound $6 \mathrm{q}$ 


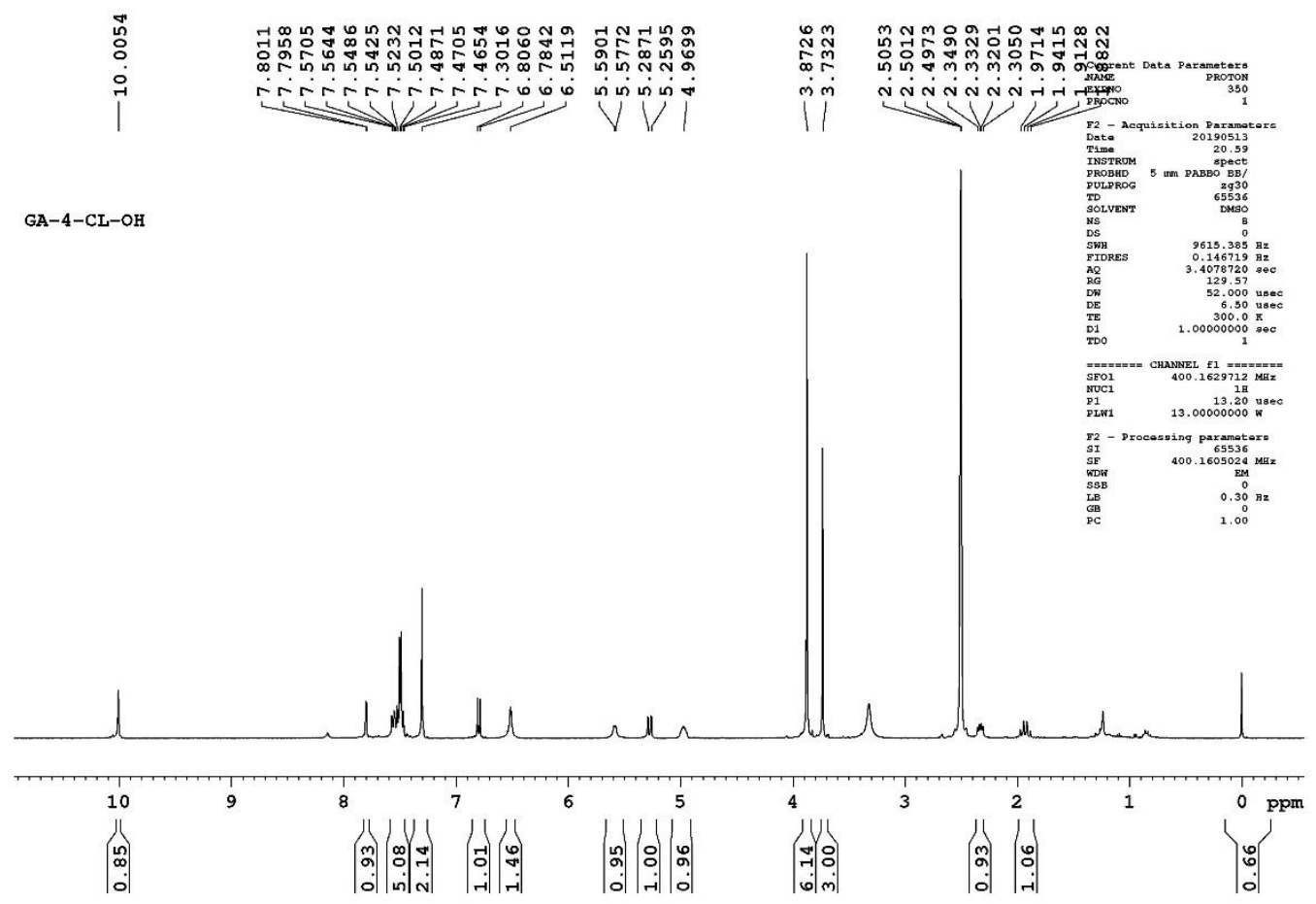

${ }^{1} \mathrm{H}$ Spectrum of Compound $6 \mathrm{r}$

กิ Фึํำ

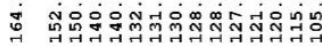

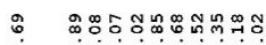

กิ ถ்ํำำ

GA-CL-OH
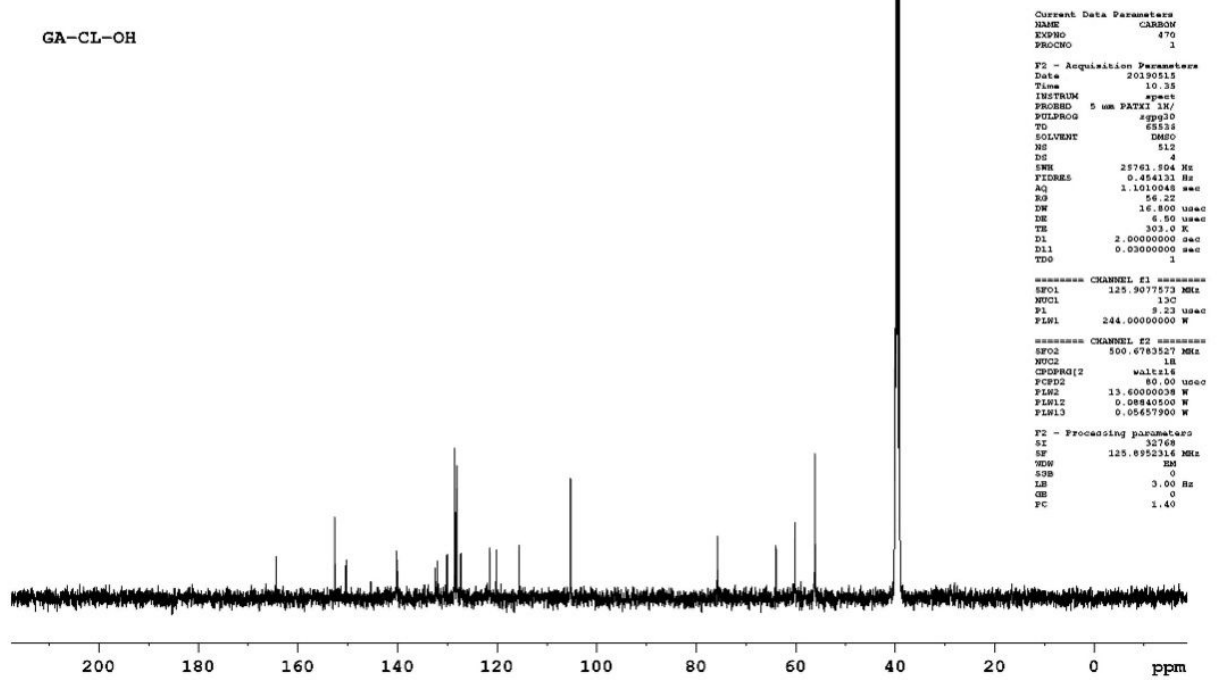

${ }^{13} \mathrm{C}$ Spectrum of Compound $6 \mathrm{r}$ 


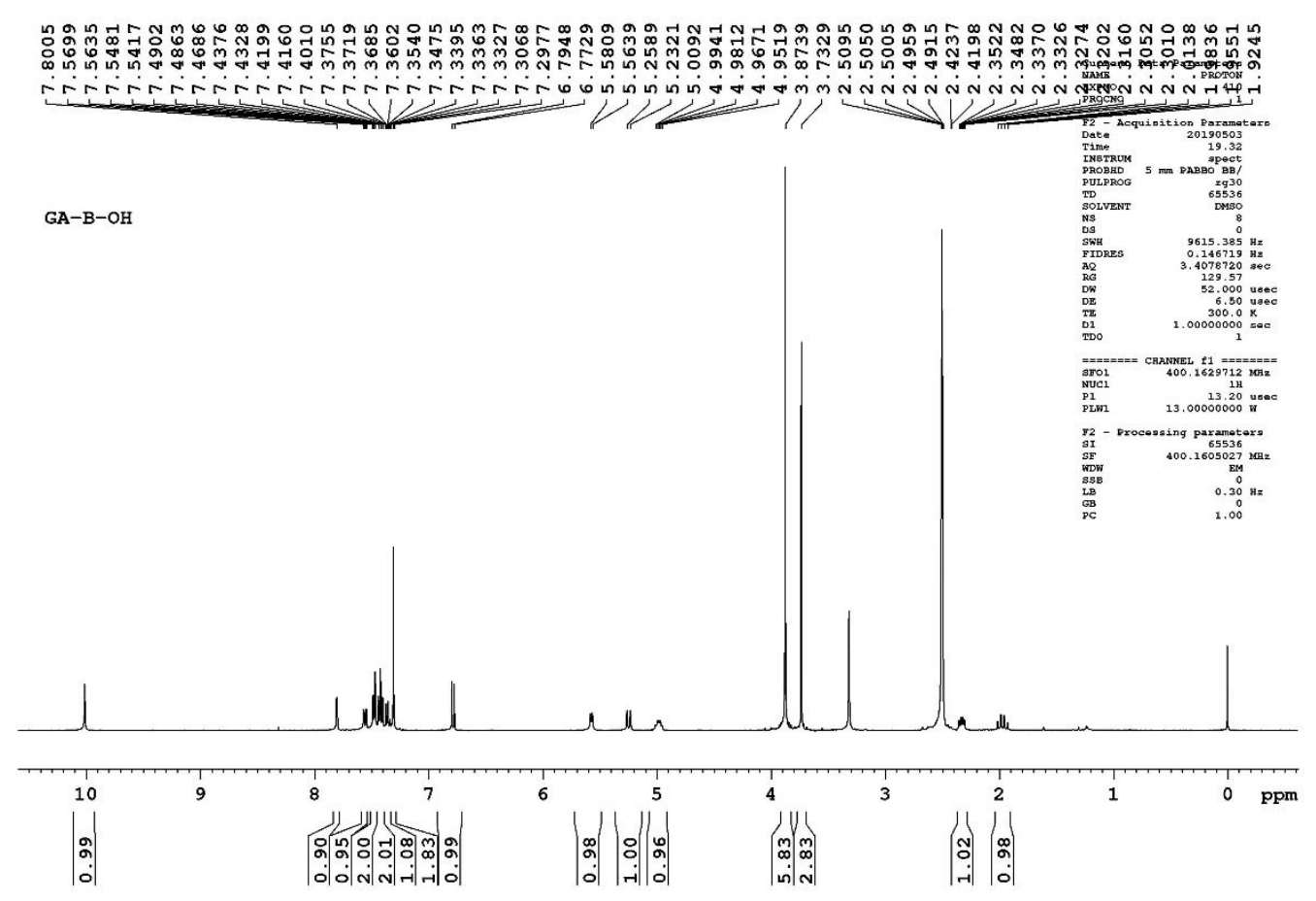

${ }^{1} \mathrm{H}$ Spectrum of Compound $6 \mathrm{~s}$

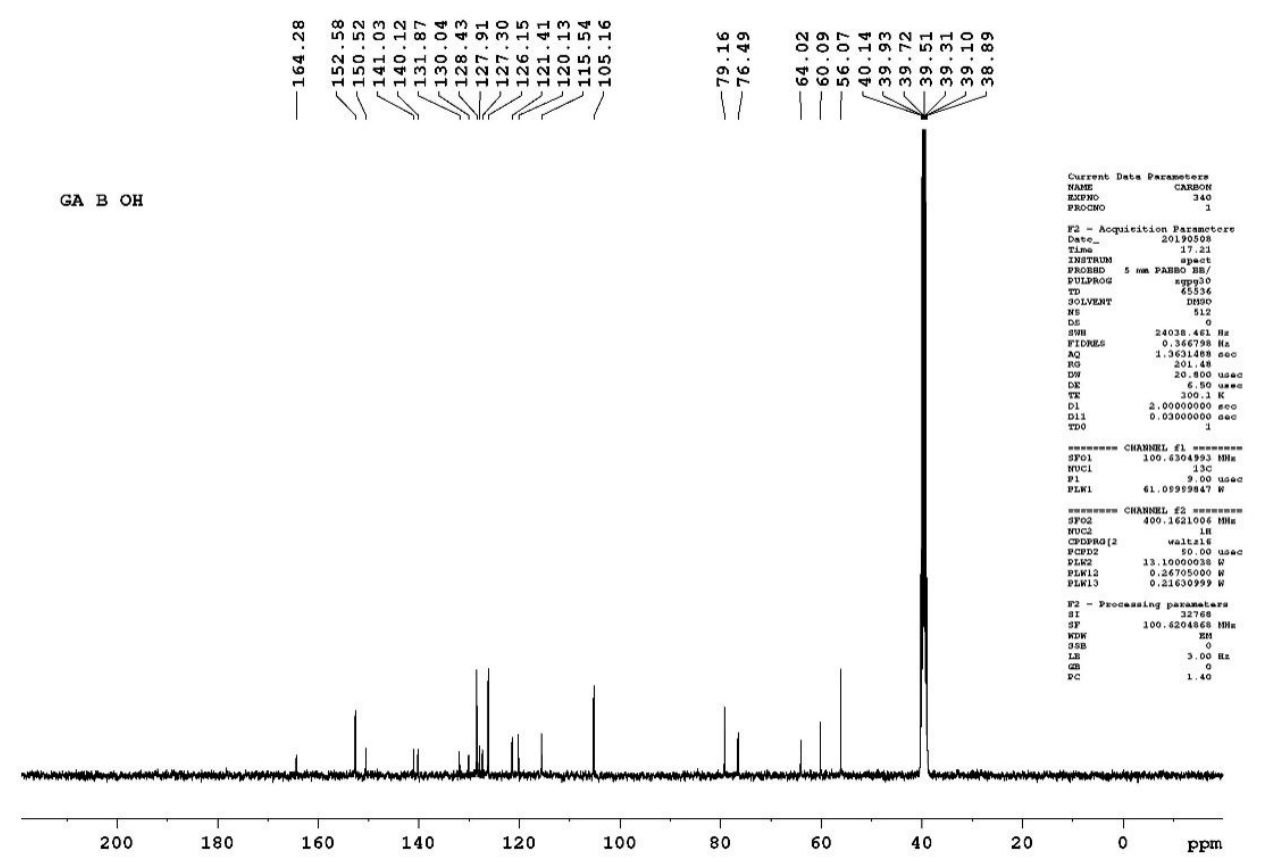

${ }^{13} \mathrm{C}$ Spectrum of Compound $6 \mathrm{~s}$ 


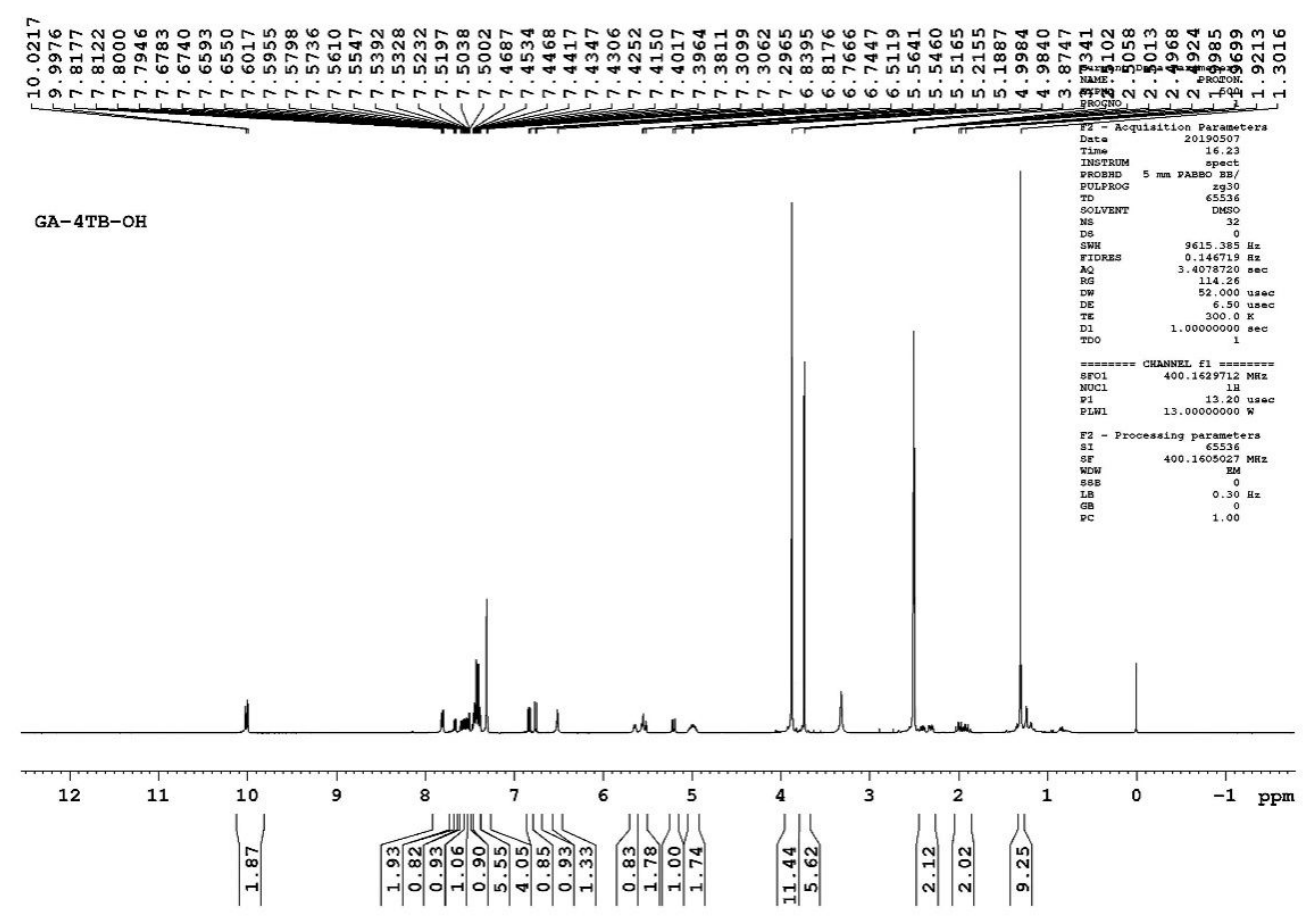

${ }^{1} \mathrm{H}$ Spectrum of Compound $6 \mathrm{t}$

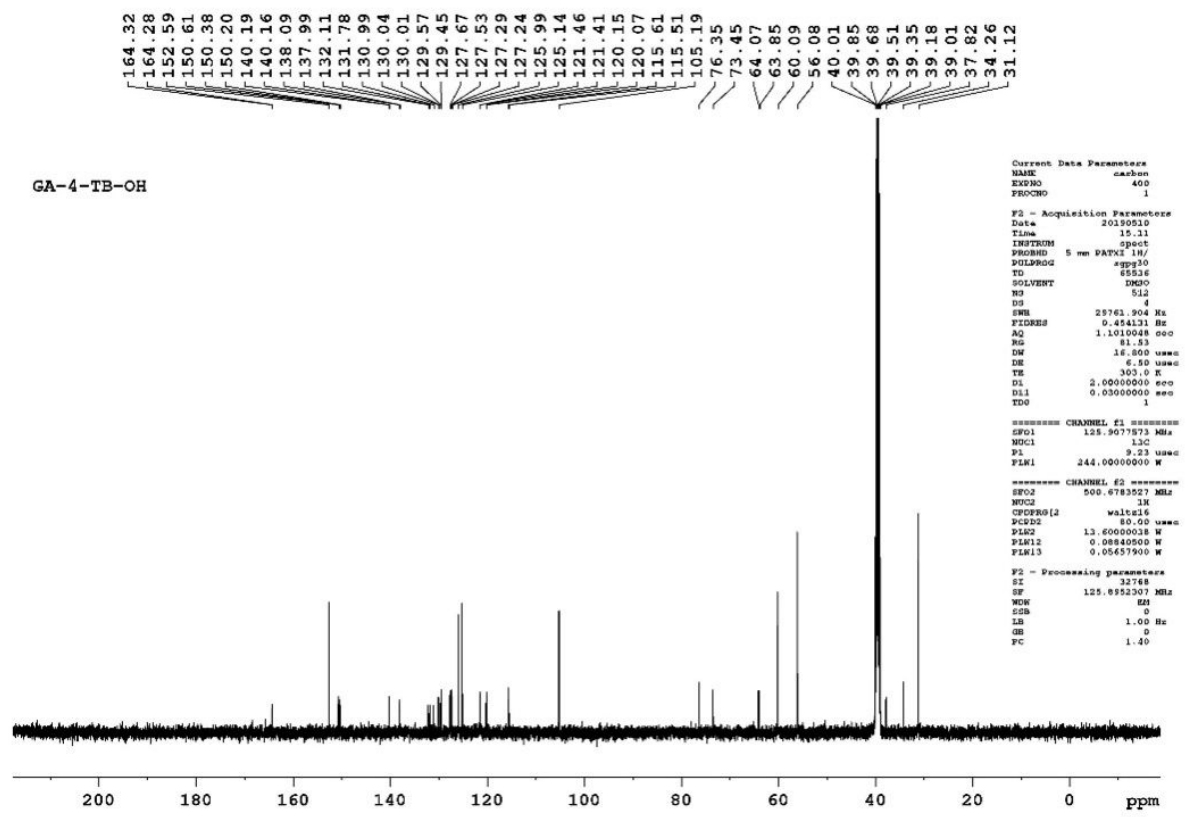

${ }^{13} \mathrm{C}$ Spectrum of Compound $6 \mathrm{t}$ 
HRMS spectrum of galloyl conjugates of flavanones (5a-5n and 6o-6t)

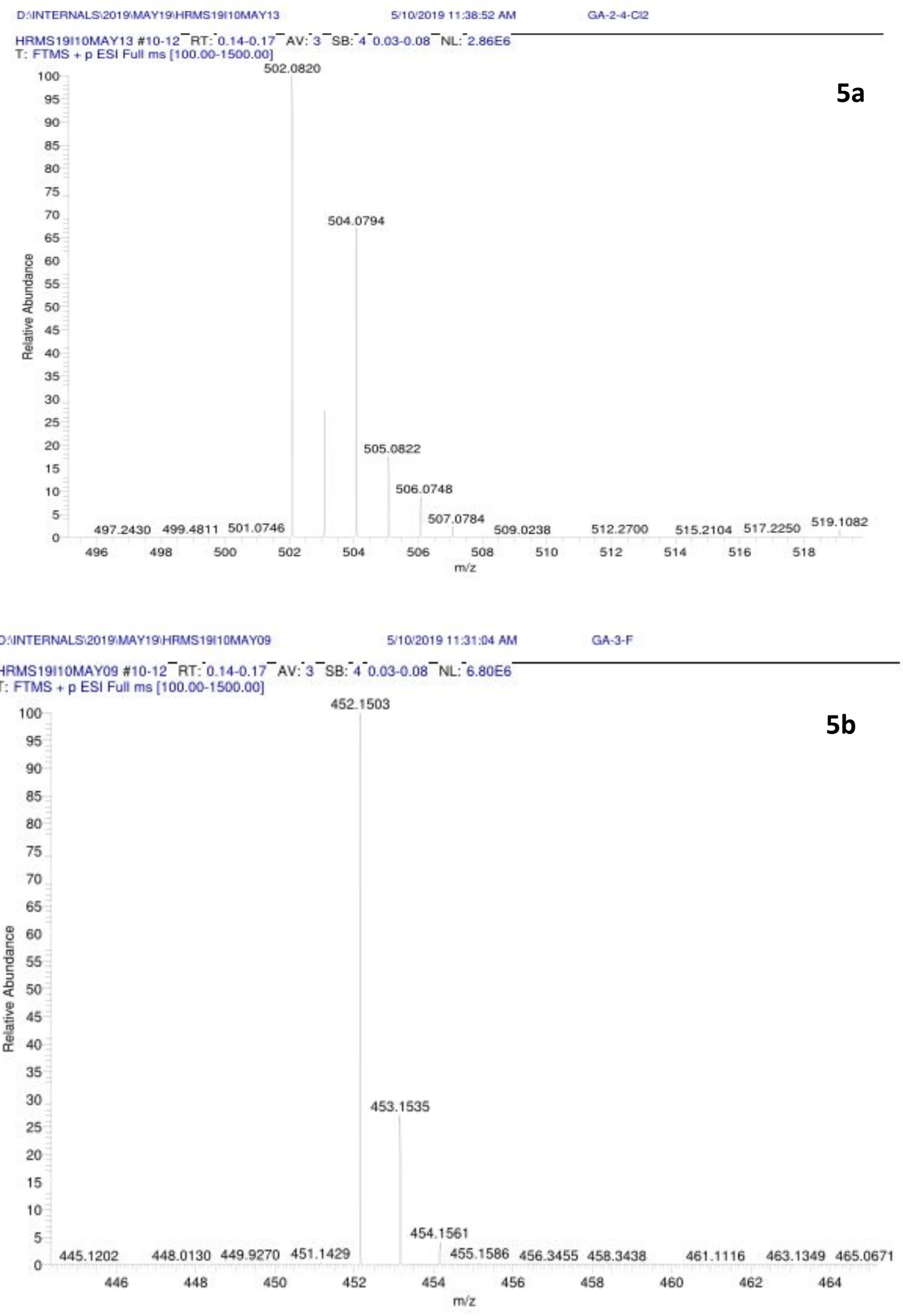


HRMS19110MAY12 \#8-13- ${ }^{-}:^{\circ} 0.11-0.18^{-}$AV: ${ }^{-}{ }^{-} \mathrm{SB}^{-} 4^{-} 0.03-0.08^{-} \mathrm{NL}:{ }^{-} 7.87 E 6$

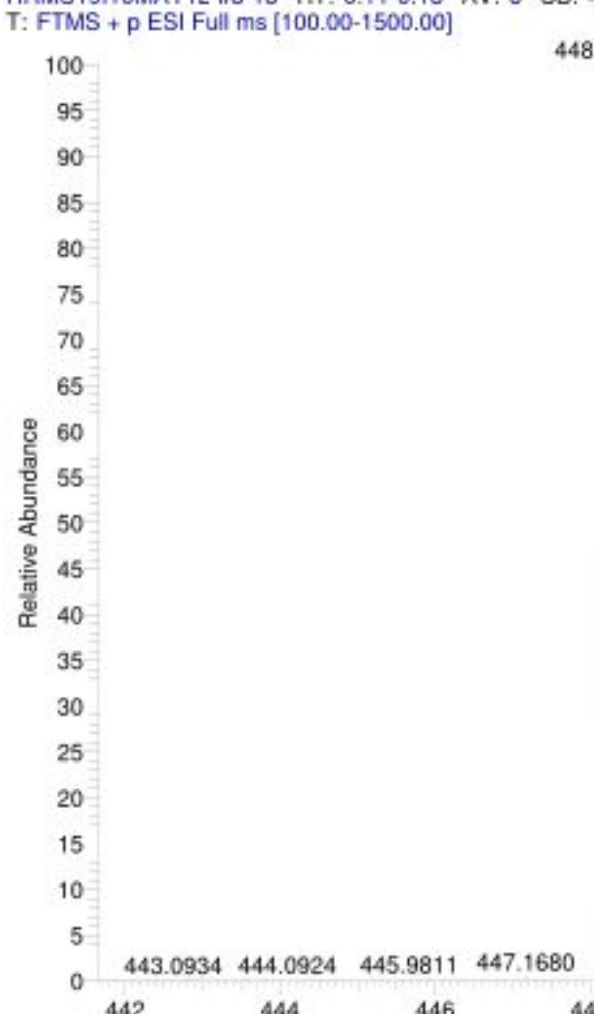

HRMS19110MAY14 \#15-21 ${ }^{-} \mathrm{RT}^{-} 0.21-0.30^{-} \mathrm{AV}^{-} 7^{-} \mathrm{SB}^{-} \mathbf{4}^{-} 0.03-0.08^{-} \mathrm{NL}:{ }^{-} 3.89 \mathrm{E} 6$ T: FTMS + p ESI Full ms [100.00-1500.00]

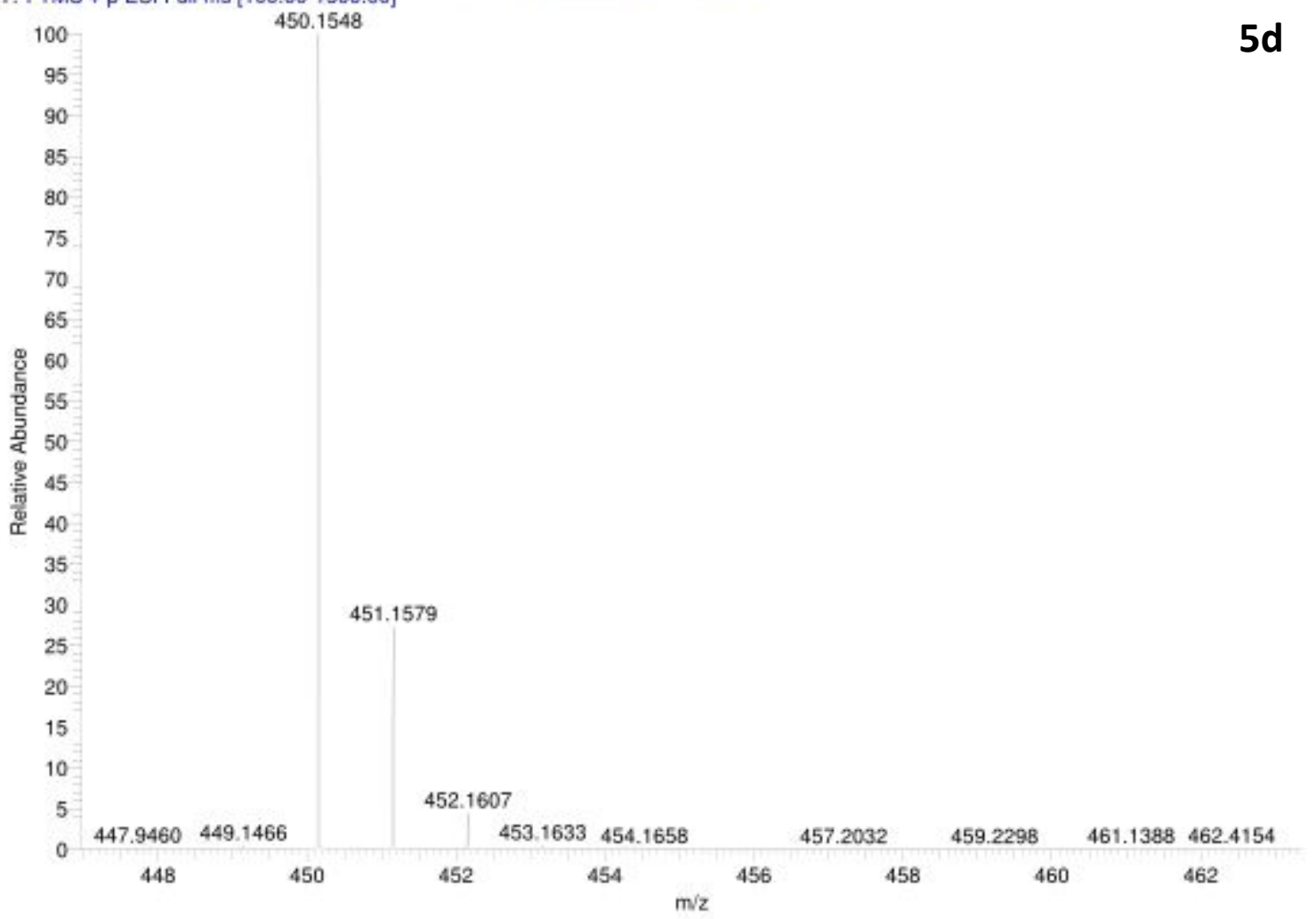


HRMS19110MAY11 \#8-10 ${ }^{-} \mathrm{RT}:{ }^{-0} 0.11-0.14^{-} \mathrm{AV}^{-}{ }^{-}{ }^{-} \mathrm{SB}:{ }^{-}{ }^{-} 0.03-0.08{ }^{-} \mathrm{NL}:{ }^{-} 5.41 \mathrm{E} 6$

T: FTMS + p ESI Full ms [100.00-1500.00]

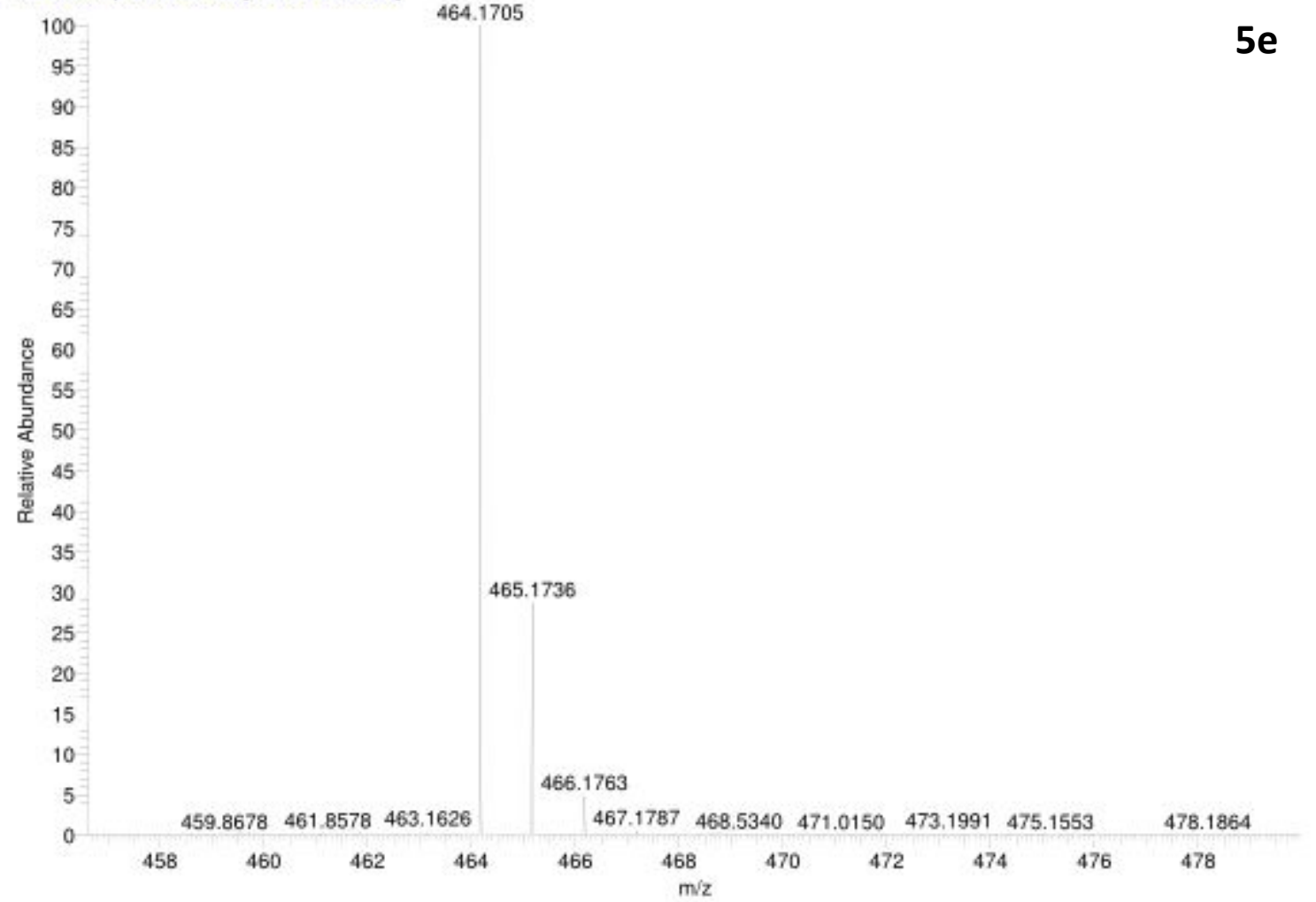

D.INTERNALSL2019MMAY19HRMS1910MAYO7

HRMS19110MAY07 \#9-15 ${ }^{-} \mathrm{RT}^{\circ}{ }^{\circ} 0.12-0.21^{-} \mathrm{AV}: 7^{-} \mathrm{SB}:{ }^{-}{ }^{-} 0.03-0.08{ }^{-} \mathrm{NL}:{ }^{-} 3.81 \mathrm{E} 6$

T: FTMS + p ESI Full ms [100.00-1500.00]

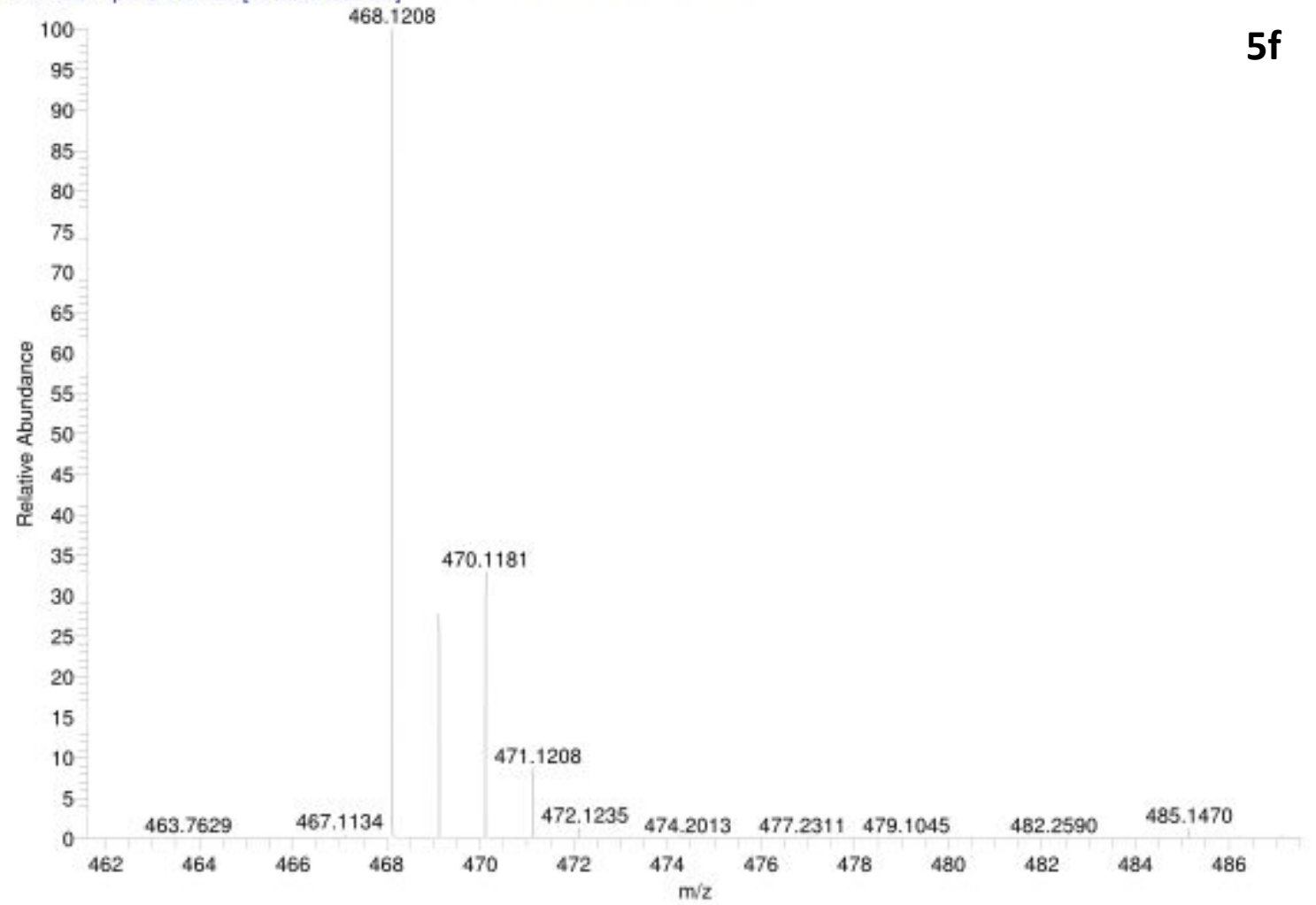




\section{SAIF [HRMS Report]}

\begin{tabular}{|c|c|c|c|}
\hline Data File: & HRMS20117DEC06 & Original Data Path: & $\begin{array}{l}\text { D:INTERNAL NEW } 2020 \text { DEC } \\
2020\end{array}$ \\
\hline Sample ID: & $\mathrm{GA}-4-\mathrm{CN}$ & Sample Name: & \\
\hline Acquisition Date: & 12/17/20 11:55:02 AM & Run Time(min): & 0.00 \\
\hline Vial: & CStk 1-01-6 & Injection Volume( $\mu)$ : & 100 \\
\hline
\end{tabular}

HRMS20I17DEC06 \#30-62 RT: 0.25-0.50 AV: 33 SB: 10.01 NL: 8.91E5

T: FTMS + c ESI Full ms [100.00-750.00]
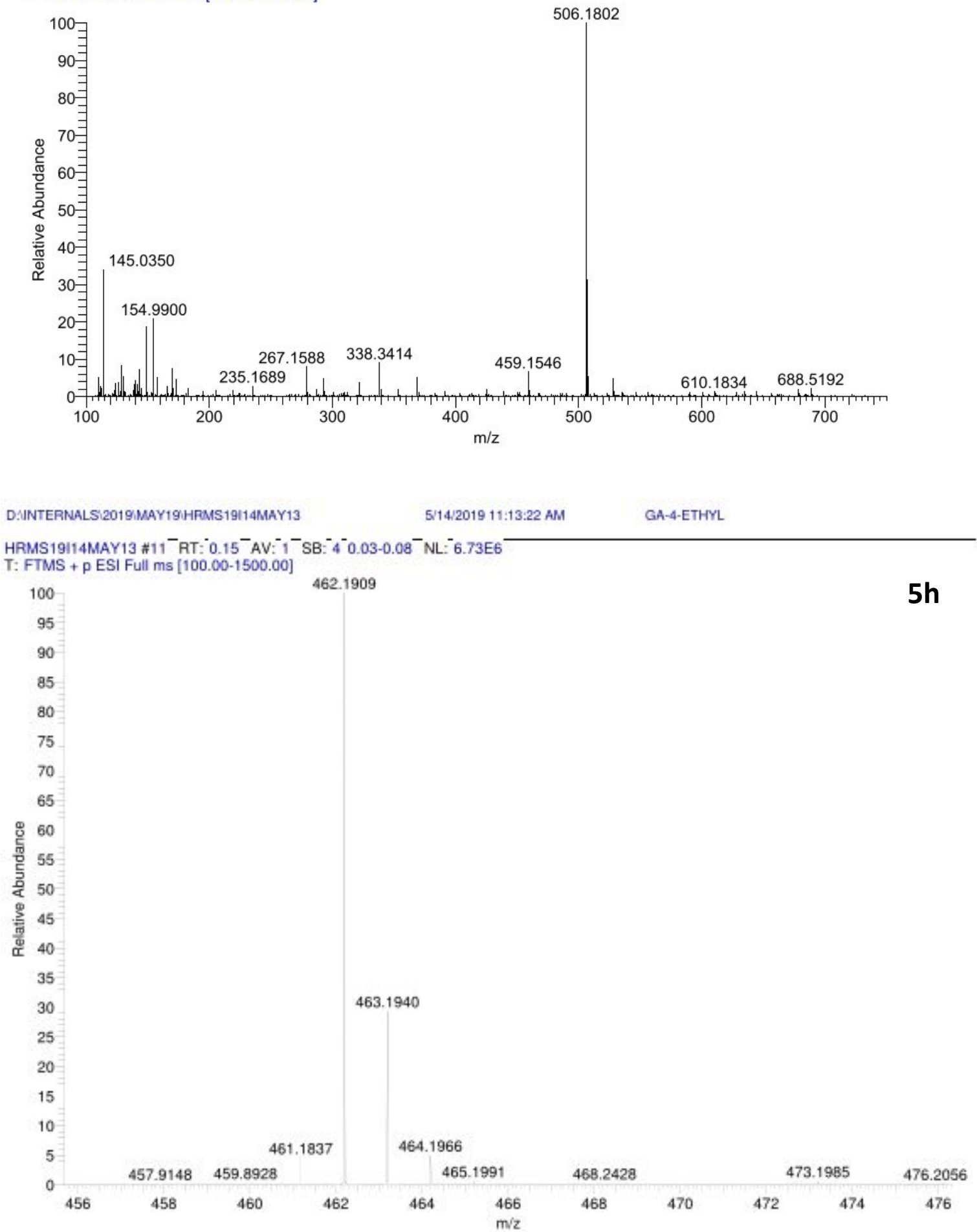


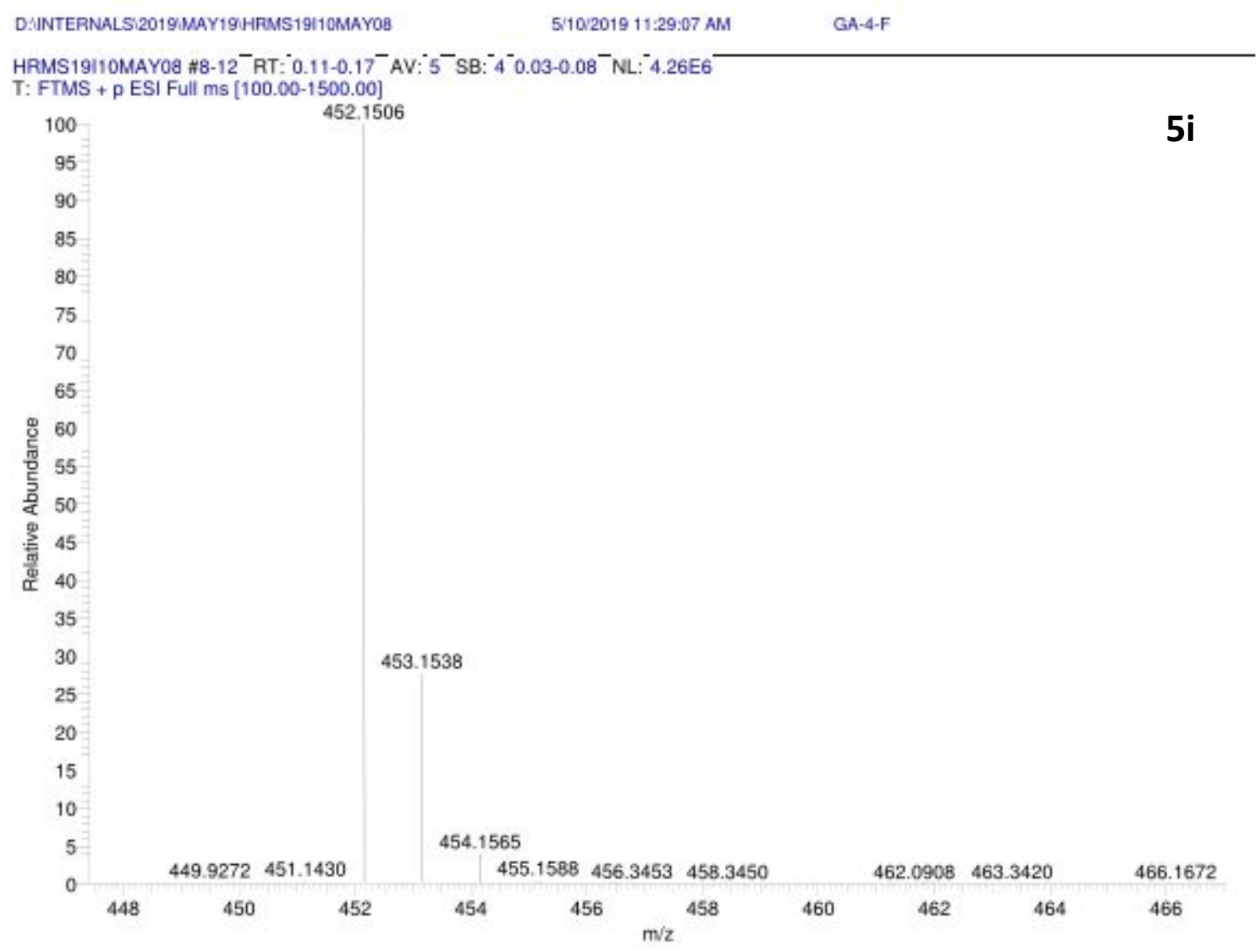

D:INTERNALSI2019MAY19HAMS1914MAY14

5/14/2019 11:15:21 AM

GA-4-ISOPROP

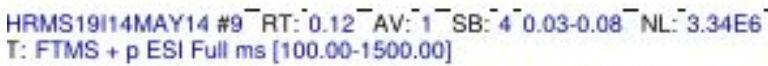

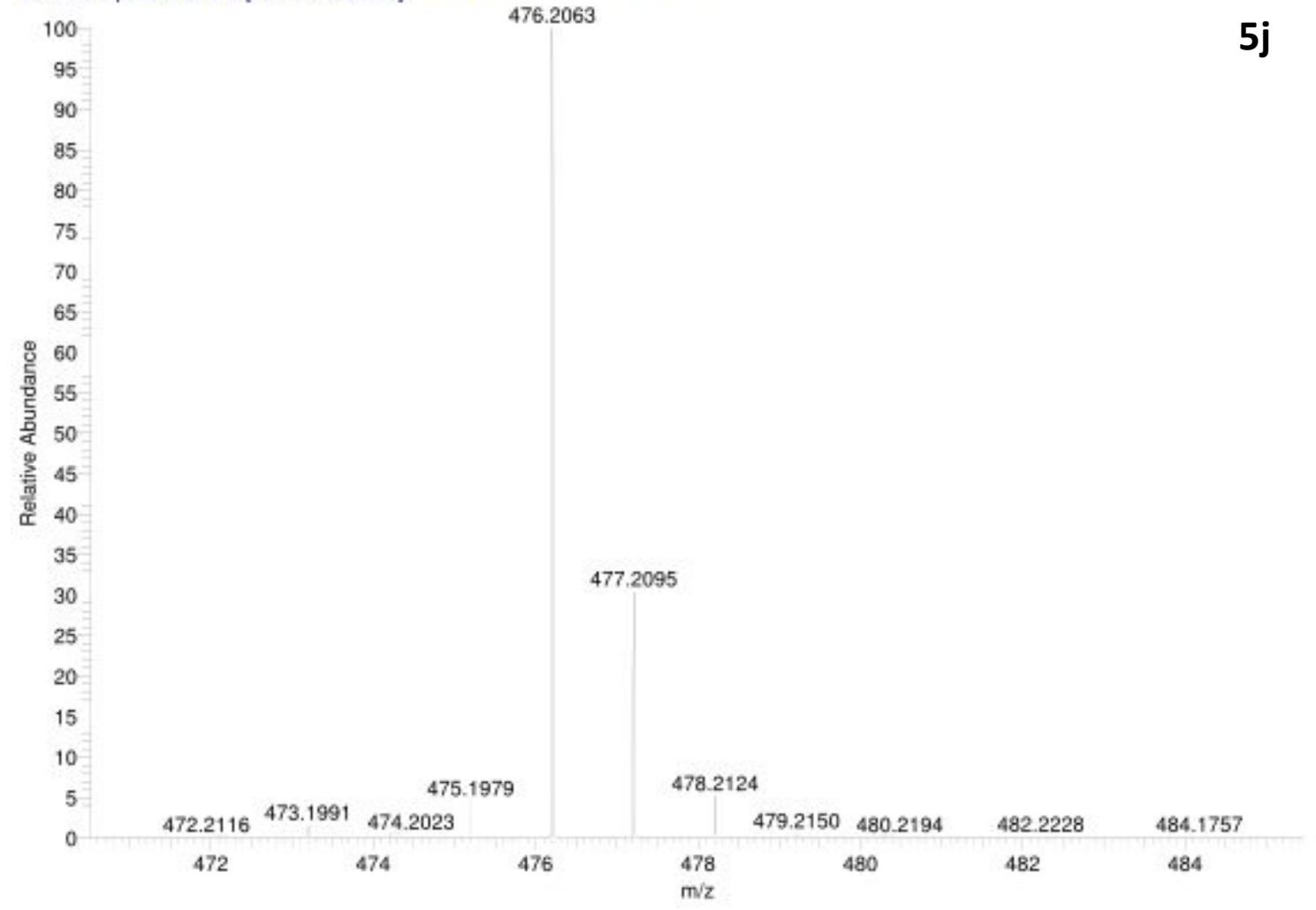




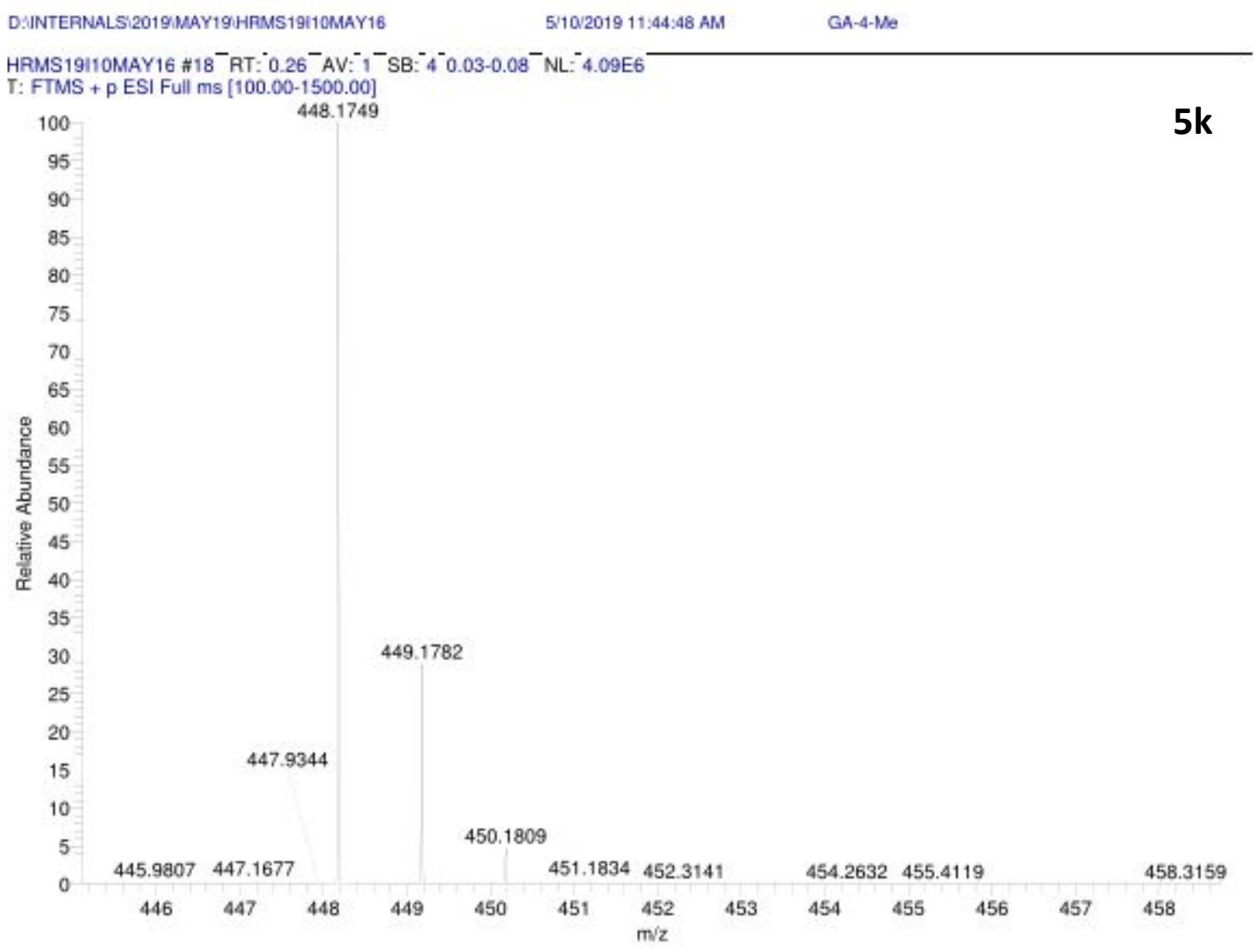

\section{SAIF [HRMS Report]}

\begin{tabular}{|c|c|c|c|}
\hline Data File: & HRMS20I30DEC 10 & Original Data Path: & $\begin{array}{l}\text { D:INTERNAL NEW } 2020 \backslash D E C \\
2020\end{array}$ \\
\hline Sample ID: & GA-B & Sample Name: & \\
\hline Acquisition Date: & $12 / 30 / 2011: 32: 18 \mathrm{AM}$ & Run Time(min): & 0.00 \\
\hline Vial: & CStk1-01:10 & Injection Volume $(\mu 1)$ : & 1.00 \\
\hline
\end{tabular}

HRMS20I30DEC10 \#30-62 RT: 0.25-0.50 AV: 33 SB: $10.01 \quad$ NL: 2.61E6

T: FTMS + c ESI Full ms [100.00-750.00]

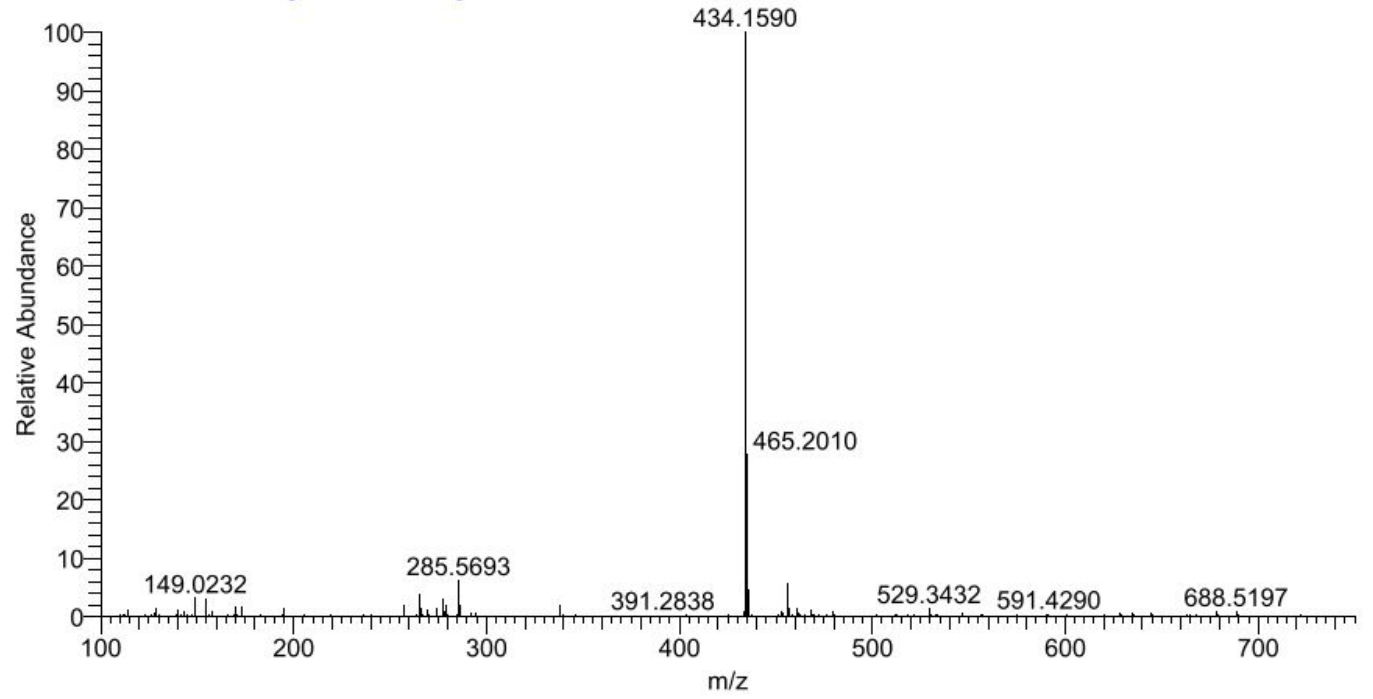


HRMS19110MAY15 \#7-10 ${ }^{-} \mathrm{RT}^{-0} 0.09-0.14^{-} \mathrm{AV}^{-} 4^{-} \mathrm{SB}^{-}{ }^{-}{ }^{-} 0.03-0.08^{-} \mathrm{NL}:{ }^{-} 4.86 E 6$

T: FTMS + p ESI Full ms [100.00-1500.00]

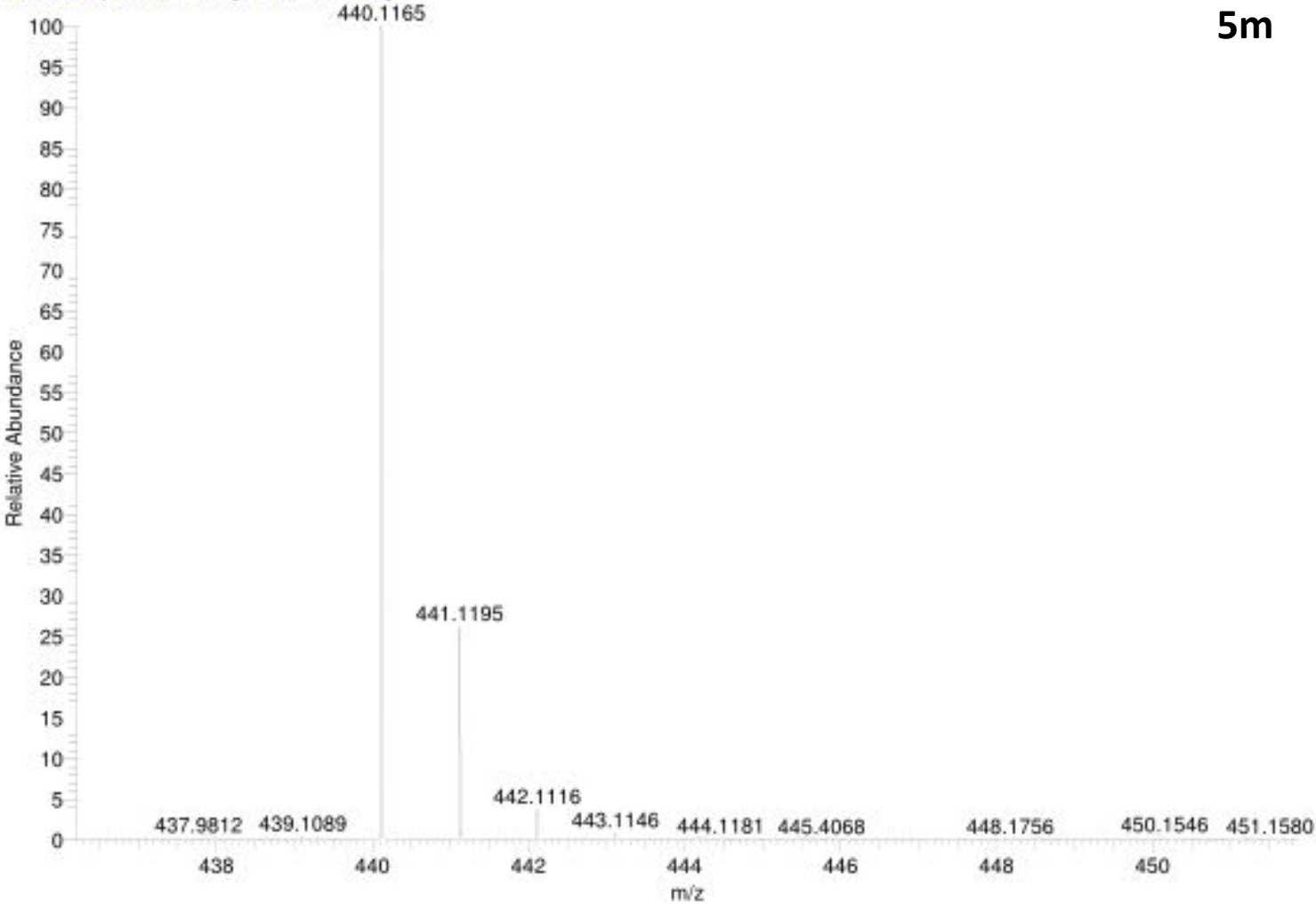

D.INTERNALS 2019MMAY19HAMS19I14MAY12

HRMS19/14MAY12 \#10-12 ${ }^{-}$RT: $0.14-0.17^{-} \mathrm{AV}^{-}{ }^{-}{ }^{-} \mathrm{SB}^{-} \mathbf{4}^{-} 0.03-0.08^{-} \mathrm{NL}:{ }^{-} 2.68 \mathrm{E} 6$

T: FTMS + p ESI Full ms [100.00-1500.00]

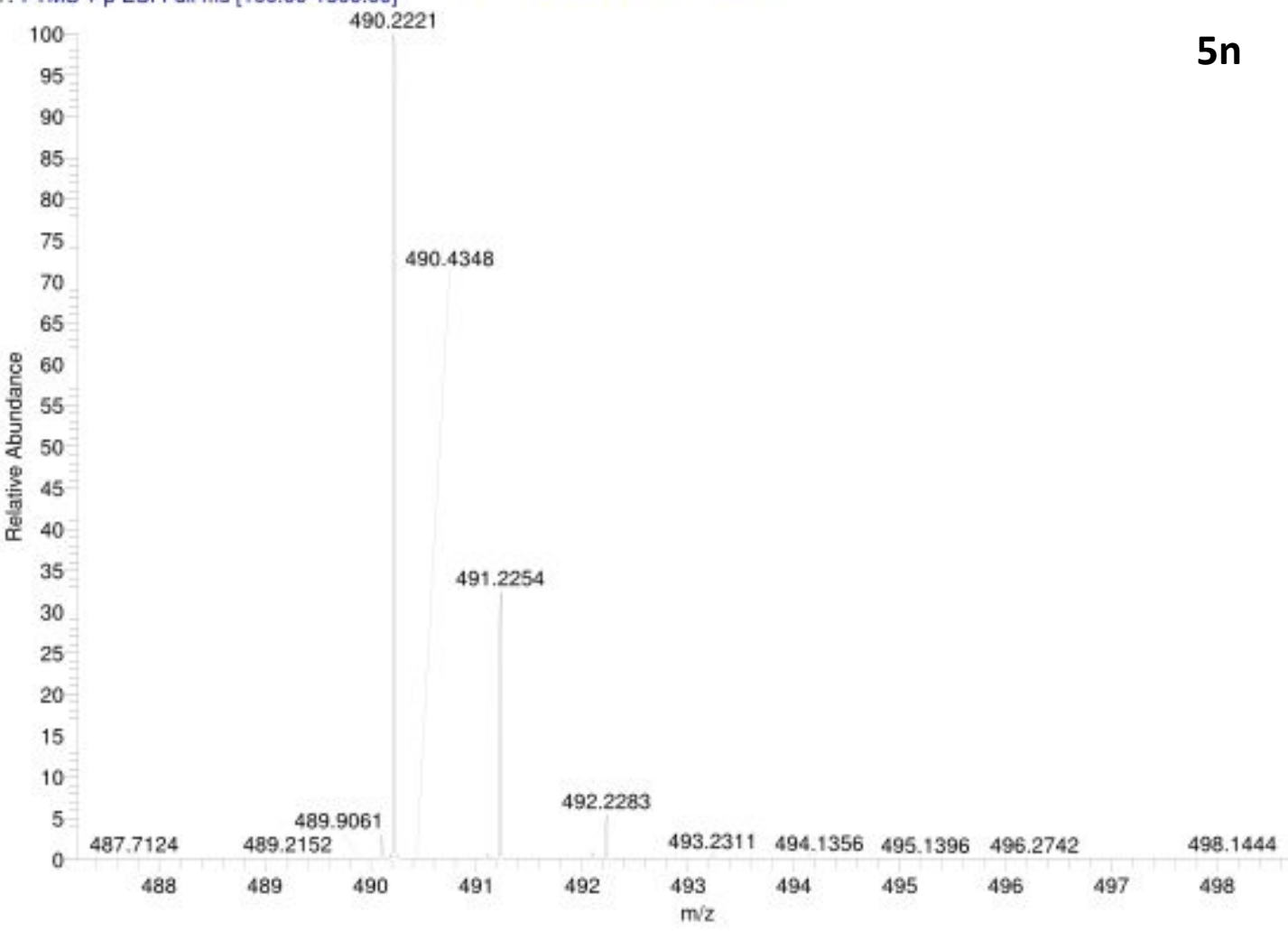


SAIF [HRMS Report]

\begin{tabular}{|c|c|c|c|}
\hline Data File: & HRMS20130DEC 11 & Original Data Path: & $\begin{array}{l}\text { D:INTERNAL NEW } 2020 \text { DEC } \\
2020\end{array}$ \\
\hline Sample ID: & GA-3-F-OH & Sample Name: & \\
\hline Acquisition Date: & 12/30/20 11:34:17 AM & Run Time(min): & 0.00 \\
\hline Vial: & CStk1-01:11 & Injection Volumes(ul): & 60 \\
\hline
\end{tabular}

HRMS20130DEC11 \#30-62 RT: 0.25-0.50 AV: 33 SB: 10.01 NL: 2.17E6

T: FTMS + c ESI Full ms [100.00-750.00]
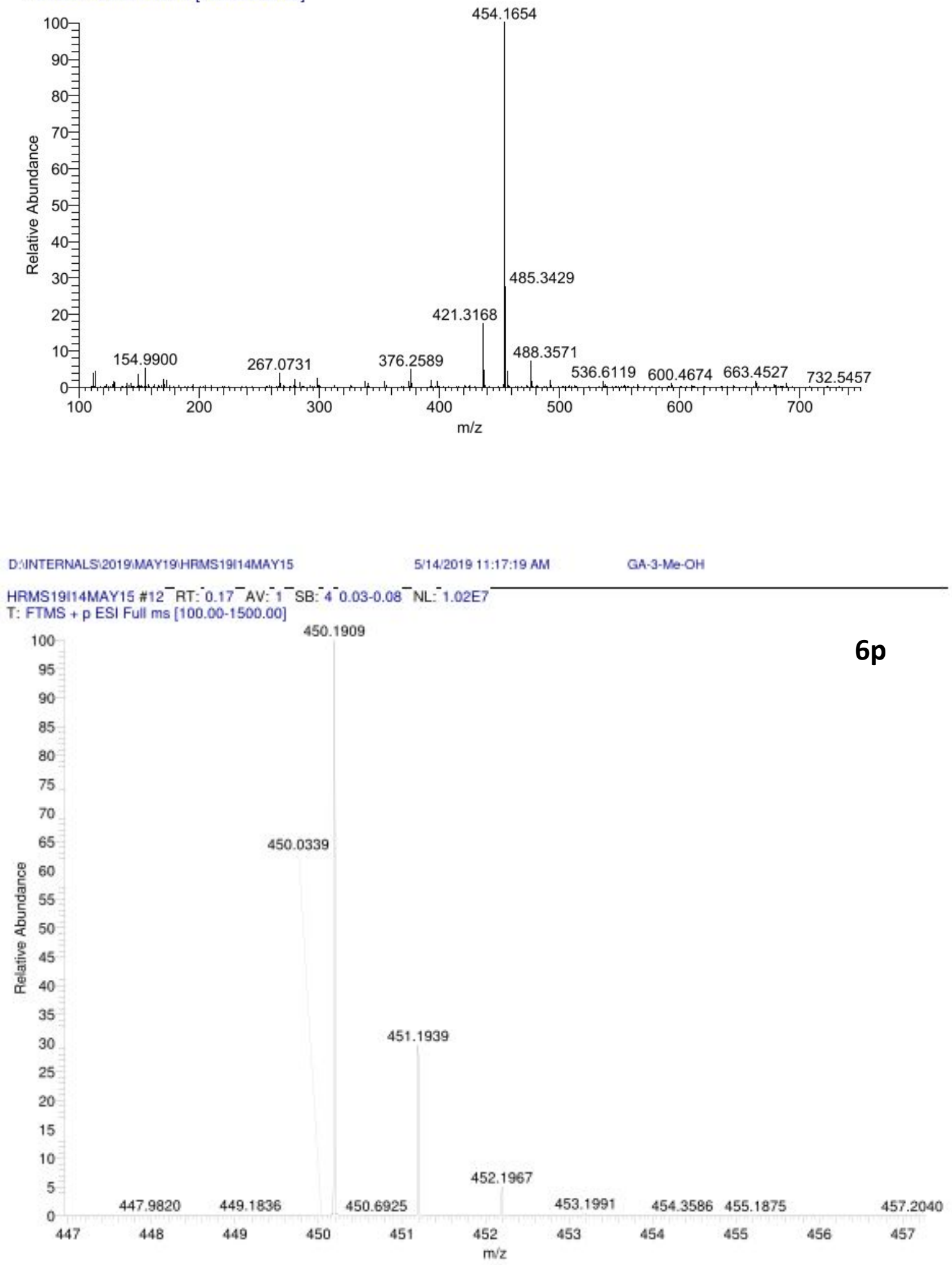


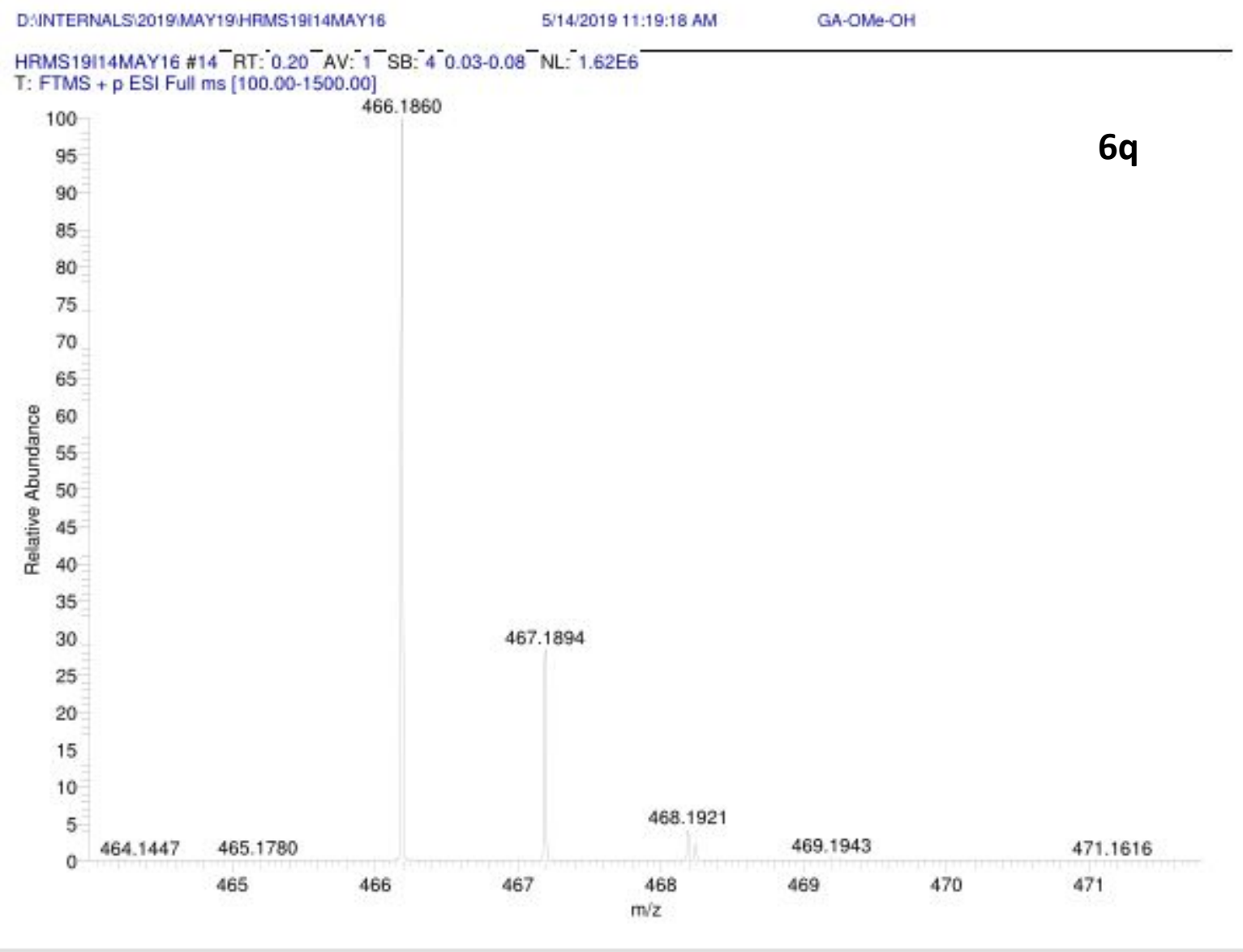

SAIF [HRMS Report]

\begin{tabular}{|c|c|c|c|}
\hline Data File: & HRMS20I1 IDEC11 & Original Data Path: & $\begin{array}{l}\text { D:INTERNAL NEW } 2020 \backslash \text { DEC } \\
2020\end{array}$ \\
\hline Sample ID: & $\mathrm{GA}-4 \mathrm{Cl}-\mathrm{OH}$ & Sample Name: & \\
\hline Acquisition Date: & 12/11/20 12:29:14 PM & Run Time(min): & 0.00 \\
\hline Vial: & CStk1-01:11 & Injection Volume( $(\mu)$ : & 1.00 \\
\hline
\end{tabular}

HRMS20I11DEC11 \#30-61 RT: 0.25-0.50 AV: 32 SB: 10.01 NL: $1.22 E 6$

T: FTMS + c ESI Full ms [100.00-750.00]

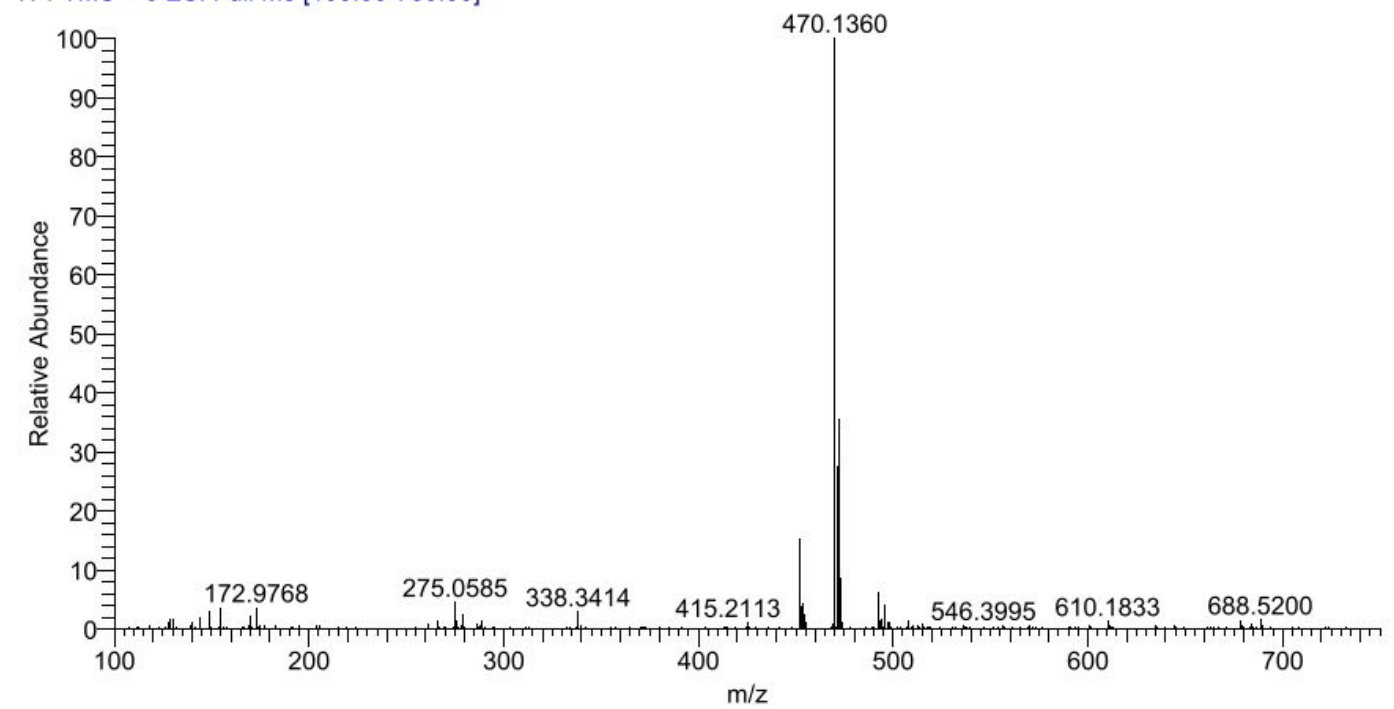




\section{SAIF [HRMS Report]}

\begin{tabular}{|c|c|c|c|}
\hline Data File: & HRMS20I30DEC 12 & Original Data Path: & $\begin{array}{l}\text { D:INTERNAL NEW } 2020 \backslash D E C \\
2020\end{array}$ \\
\hline Sample ID: & GA-B-OH & Sample Name: & \\
\hline Acquisition Date: & 12/30/20 11:36:16 AM & Run Time(min): & 0.00 \\
\hline Vial: & CStk1-01:12 & Injection Volume( $\mu 1)$ : & 1.00 \\
\hline
\end{tabular}

HRMS20I30DEC12 \#30-62 RT: 0.25-0.50 AV: 33 SB: 10.01 NL: $1.09 E 6$

T: FTMS + c ESI Full ms [100.00-750.00]

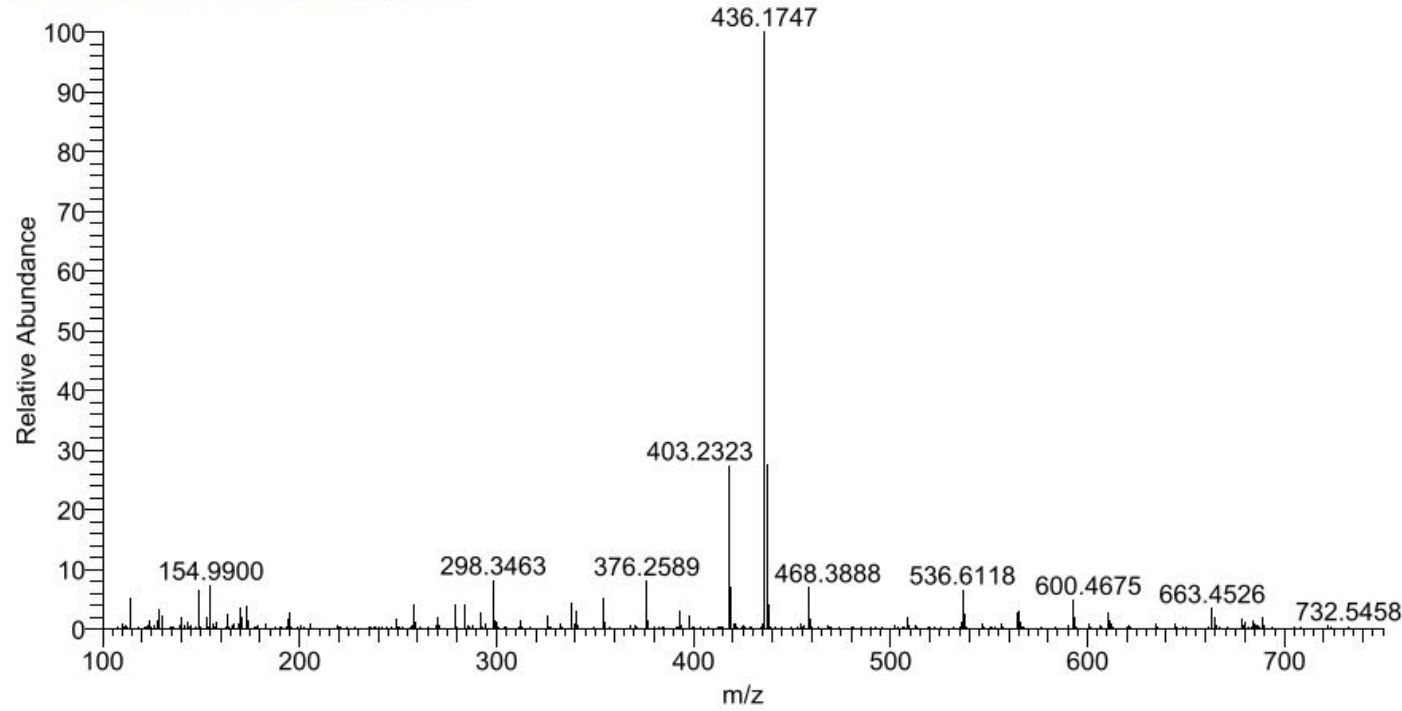

\section{SAIF [HRMS Report]}

\begin{tabular}{|c|c|c|c|}
\hline Data File: & HRMS20I17DEC07 & Original Data Path: & $\begin{array}{l}\text { D:UNTERNAL NEW } 2020 \backslash D E C \\
2020\end{array}$ \\
\hline Sample ID: & GA-4-TB-OH & Sample Name: & \\
\hline Acquisition Date: & 12/17/20 11:57:01 AM & Run Time(min): & 0.00 \\
\hline Vial: & CStk1-01:7 & Injection Volume(pl): & 1.00 \\
\hline
\end{tabular}

HRMS20I17DEC07 \#30-63 RT: 0.25-0.50 AV: 34 SB: 10.01 NL: $1.87 E 6$

T: FTMS + c ESI Full ms [100.00-750.00]

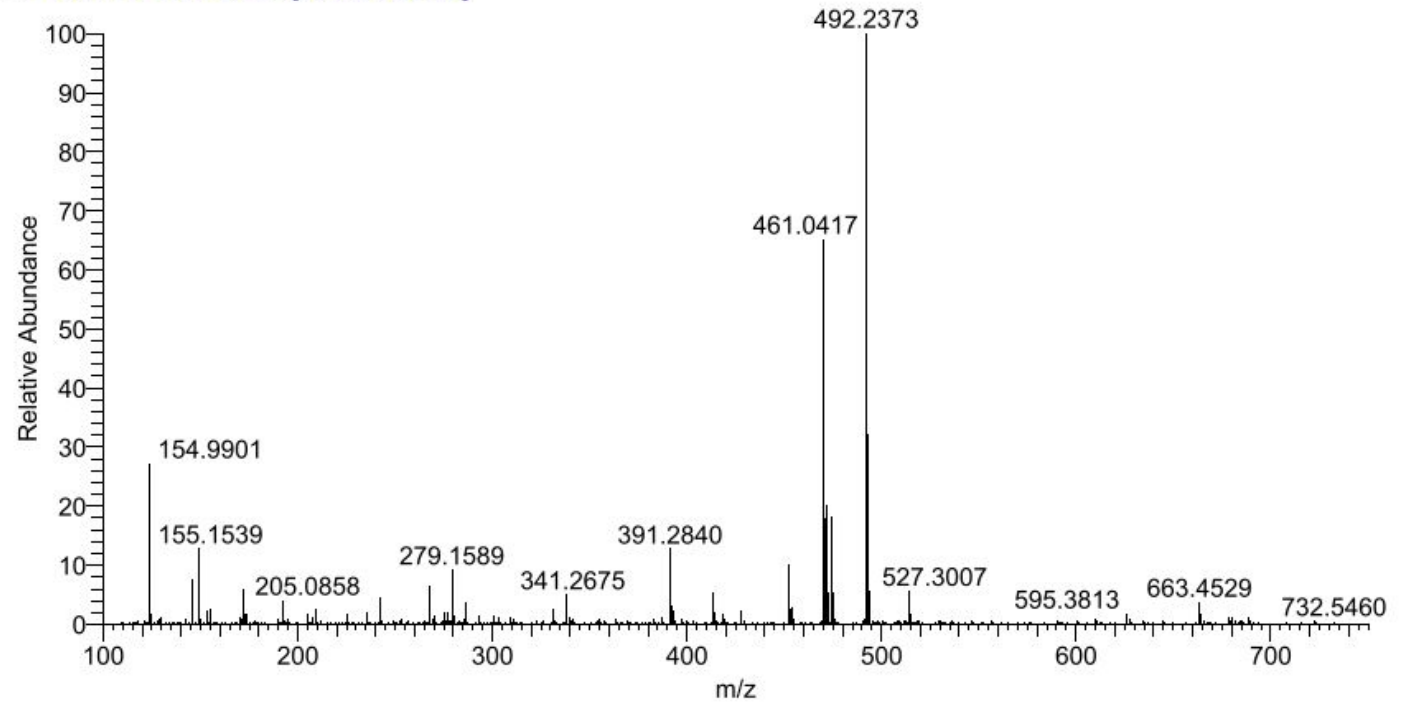


Table S1. Sequence of primers used

\begin{tabular}{|l|l|l|l|}
\hline GAPDH & $\begin{array}{l}\text { Glyceraldehyde } \\
\text { 3-phosphate } \\
\text { dehydrogenase }\end{array}$ & $\begin{array}{l}\text { F-CAGCAAGGATACTGAGAGCAAGAG } \\
\text { R-GGATGGAATTGTGAGGGAGATG }\end{array}$ & NM_017008.4 \\
\hline BMP-2 & $\begin{array}{l}\text { Bone } \\
\text { morphogenetic } \\
\text { protein2 }\end{array}$ & $\begin{array}{l}\text { F-CGGCTGCGGTCTCCTAA } \\
\text { R-GGGAAGCAGCAACACTAGA }\end{array}$ & NM_017178.1 \\
\hline RUNX-2 & $\begin{array}{l}\text { Runt-related } \\
\text { transcription }\end{array}$ & $\begin{array}{l}\text { F-CCACAGAGCTATTAAAGTGA } \\
\text { R-AACAAACTAGGTTTAGAGTCATCAAGC }\end{array}$ & NM_001278483.1 \\
\hline Col-1 & $\begin{array}{l}\text { Type 1 } \\
\text { Collagen }\end{array}$ & $\begin{array}{l}\text { F-CATGTTCAGCTTTGTGGACCT } \\
\text { R-GCAGCTGACTTCAGGGATGT }\end{array}$ & NM_053304.1 \\
\hline OCN & Osteocalcin & $\begin{array}{l}\text { F-ATAGACTCCGGCGCTACCTC } \\
\text { R-CCAGGGGATCTGGGTAGG }\end{array}$ & NM_013414.1 \\
\hline
\end{tabular}




\section{In vitro ALP data of all the compounds}

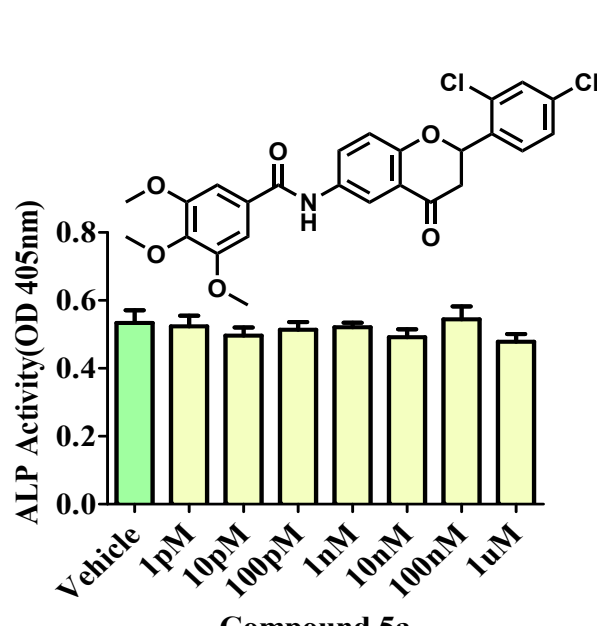

Compound 5a
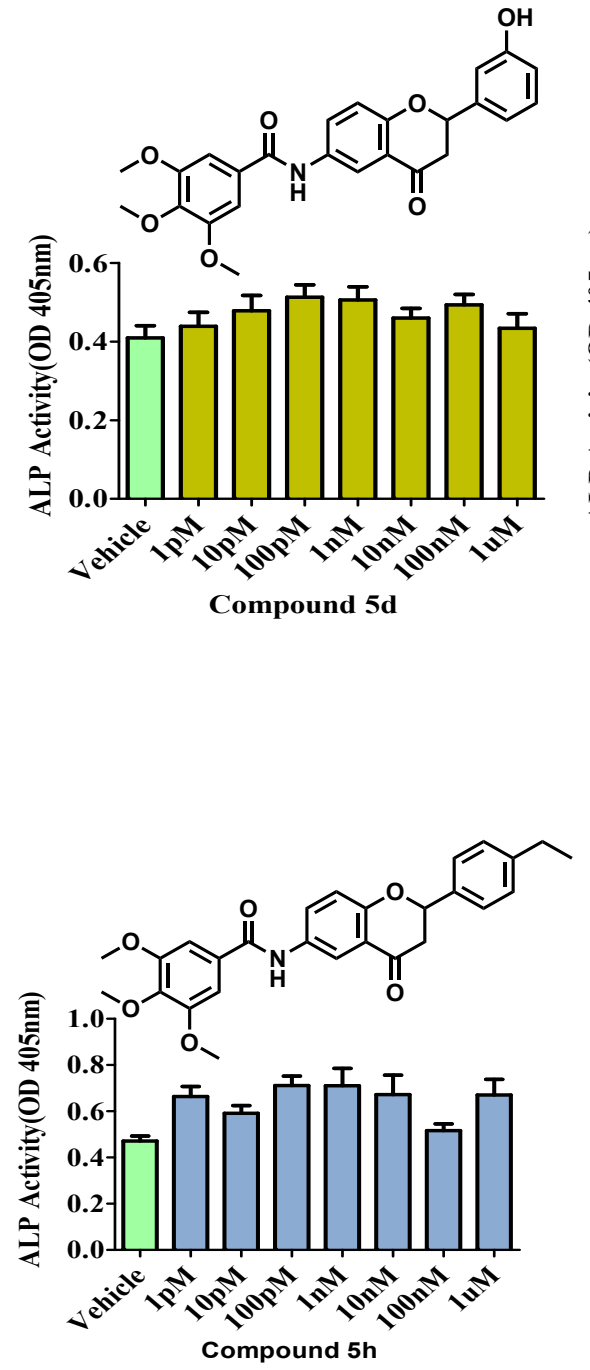
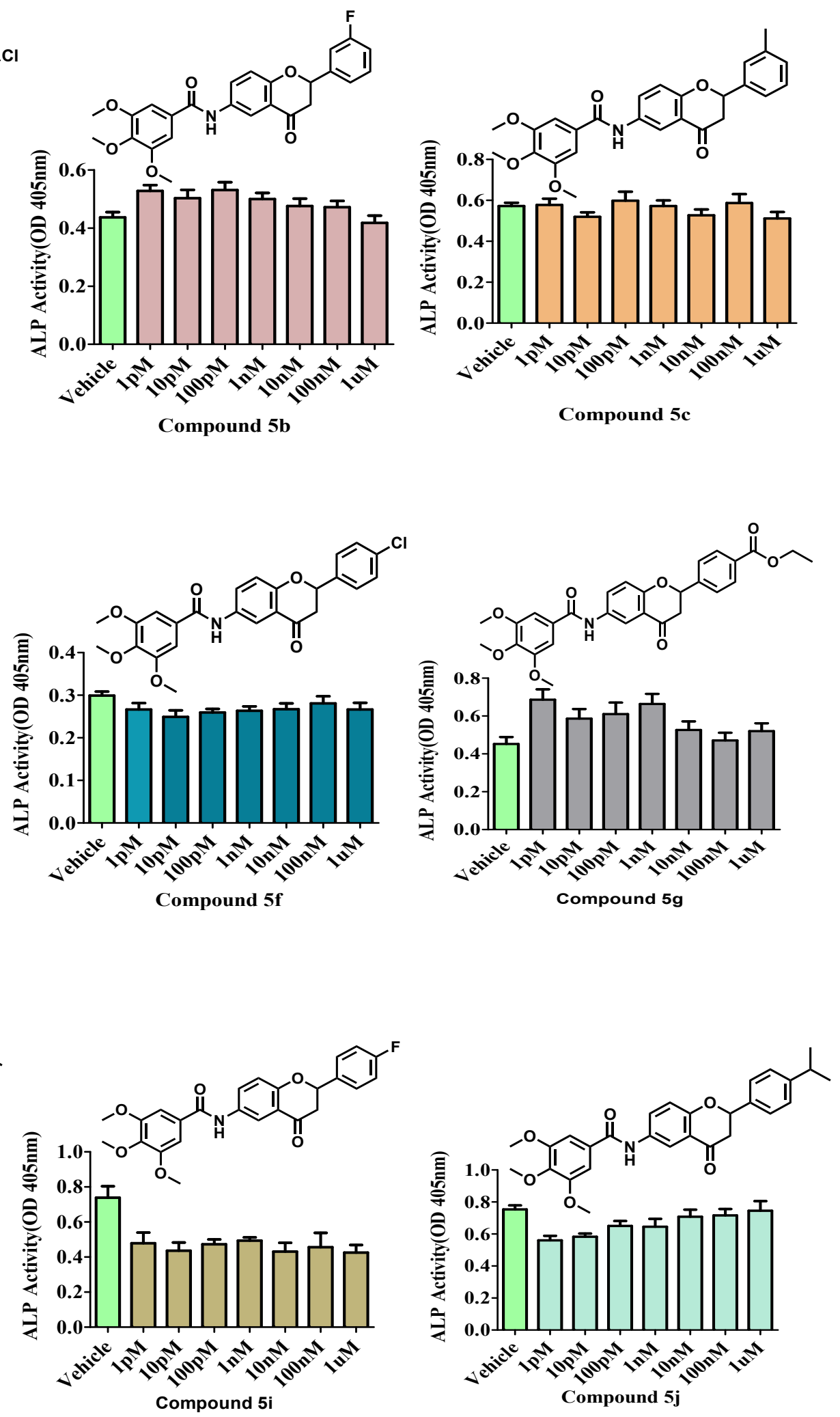

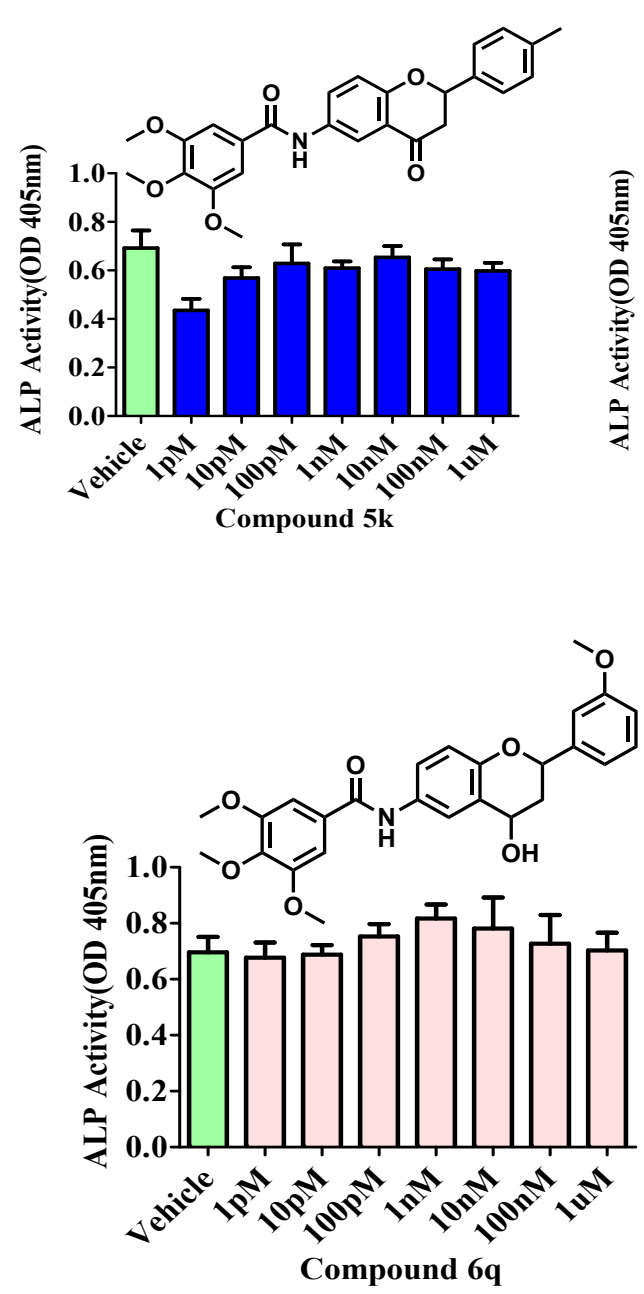
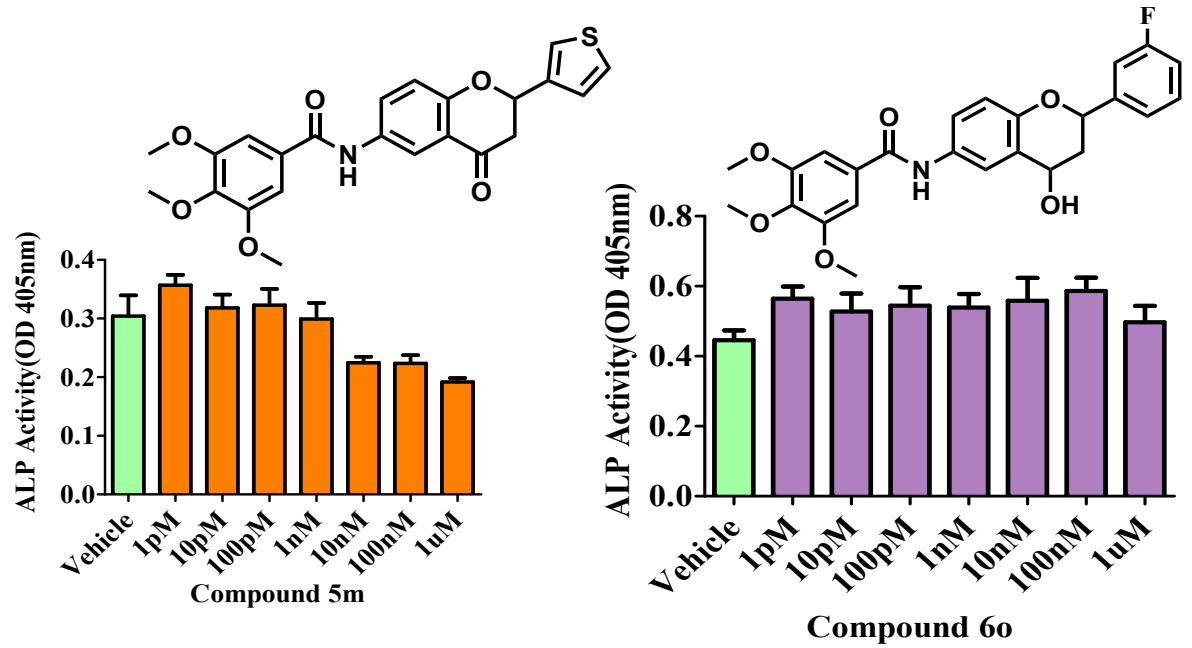

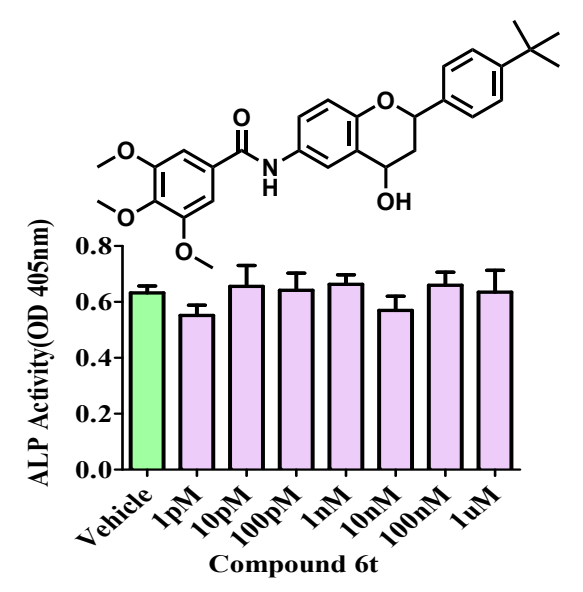

Figure S1. Screening of compounds on the basis of ALP activity. These compounds did not show elevated osteoblast differentiation. 


\section{Chiral separation of $5 \mathrm{e}$}

MPC Division C.D.R.I

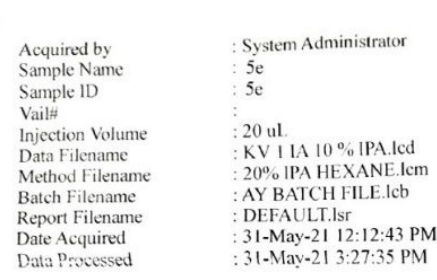

Data Processed : $\quad$ 31-Mav-21 3:27:35 PM

Chromatogram

KV I F:AYYHPLCKV I IA I0\% IPA.Icd

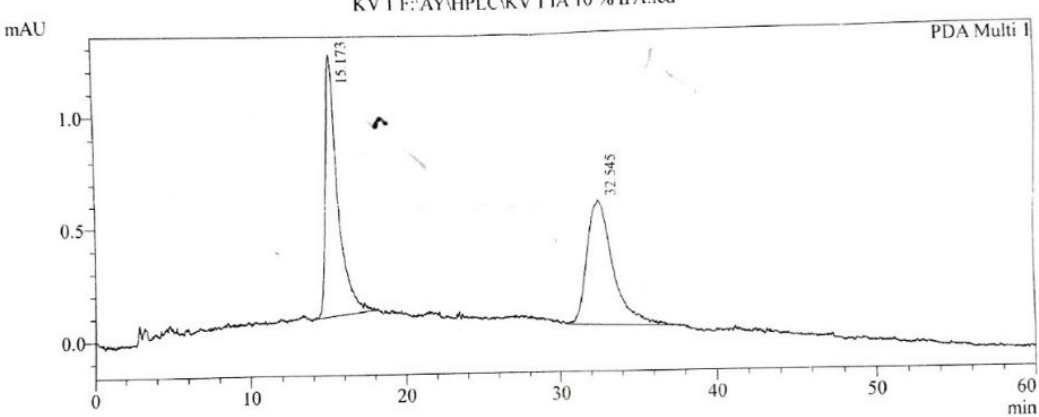

1 PDA Multi $1 / 387 \mathrm{~nm}, 4 \mathrm{~nm}$

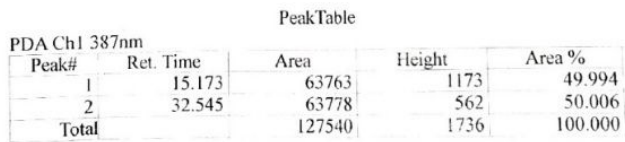

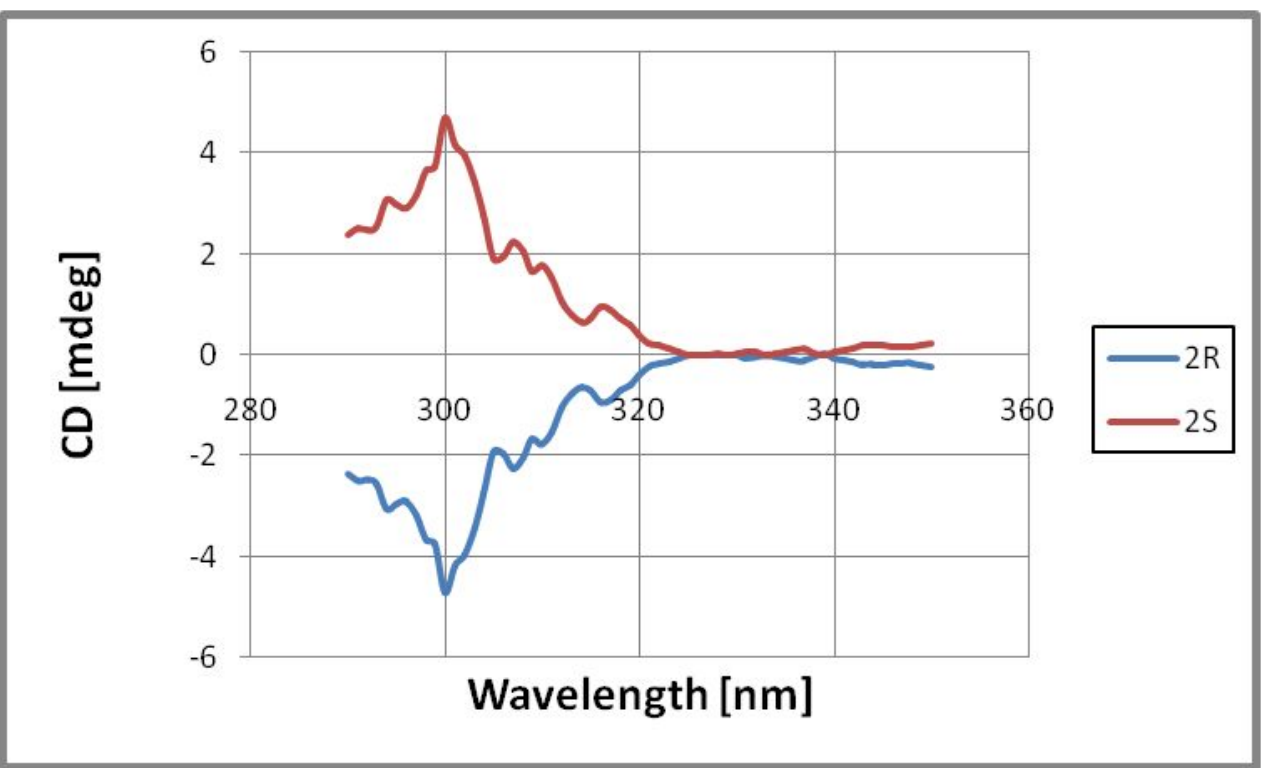

Figure S2. CD spectra of $R$ and $S$ isomers of compound 5e for $\mathrm{n} \rightarrow \pi^{*}$ transition 


\section{In silico studies of $5 \mathrm{e}$}

We next carried out docking study to assess whether or not the osteogenic compounds bind with BMP-2. Flavonoids are known for their protein binding and after absorption bind with albumin that impact their bio-distribution and active concentration in the blood. ${ }^{1}$ Besides, flavonoids modulate the function of specific proteins including bromodomain (epigenetic) proteins $^{2}$, SARS Cov2-S protein ${ }^{3,4}, \mathrm{Bcl}^{-\mathrm{B}^{5}}$, inositol phosphate kinase ${ }^{6}$, cyclooxygenase $\mathrm{II}^{7}$, RANKL and OPG. ${ }^{8}$ Modulation of protein function by flavanones depend on the number of H-bonds formed, their distances, stability and affinity, ability to fit to the active site, and hydrophobic and Van der Waals interactions. As 5e requires BMP-2 to exert its osteogenic effect, it was therefore considered important to test whether or not the compound affects the function of BMP-2. We first performed a docking study which revealed that osteogenic compound 5e, fit well into the binding pocket of BMP-2 and interacts through hydrogen bonds as well as hydrophobic interactions with the important amino acid residues (Figure S3 \& S4).
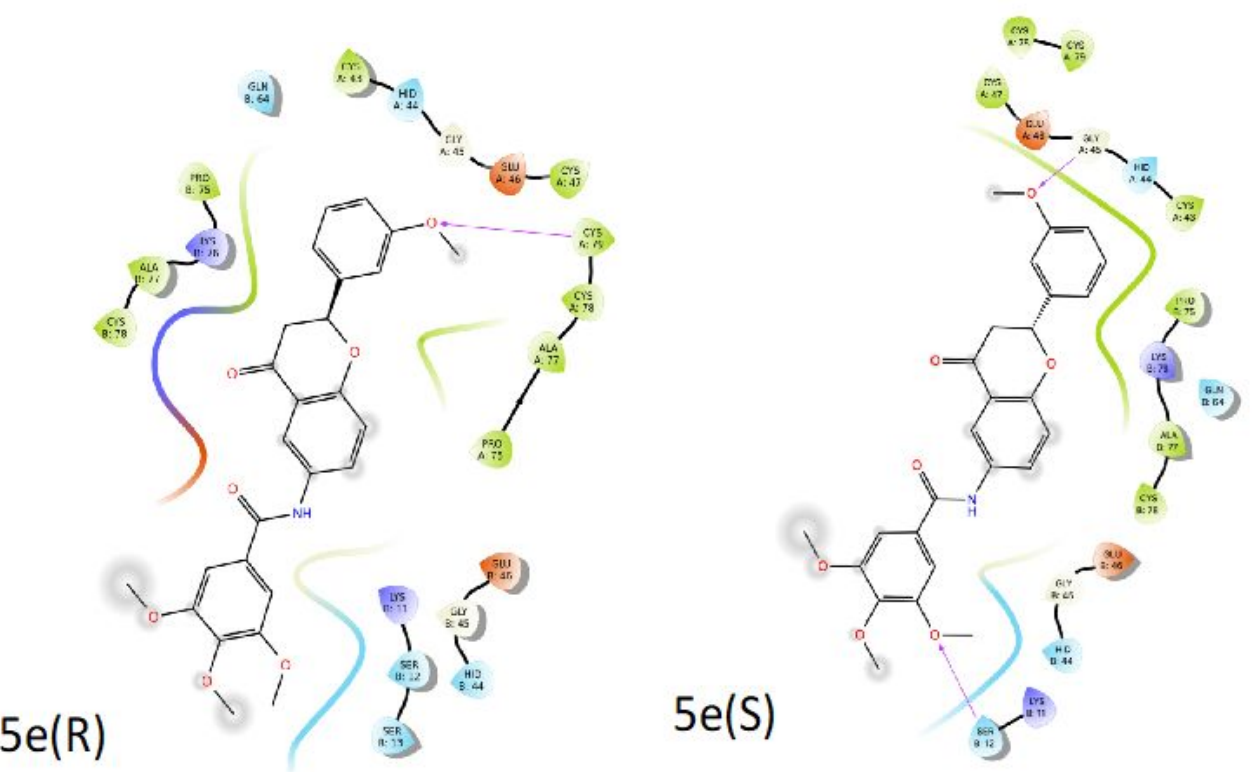

Figure S3. Molecular interactions between the compounds 5e and the active site residues of BMP-2 protein. The purple arrow represents the hydrogen bond interaction and the green surface line shows the hydrophobic interactions. 

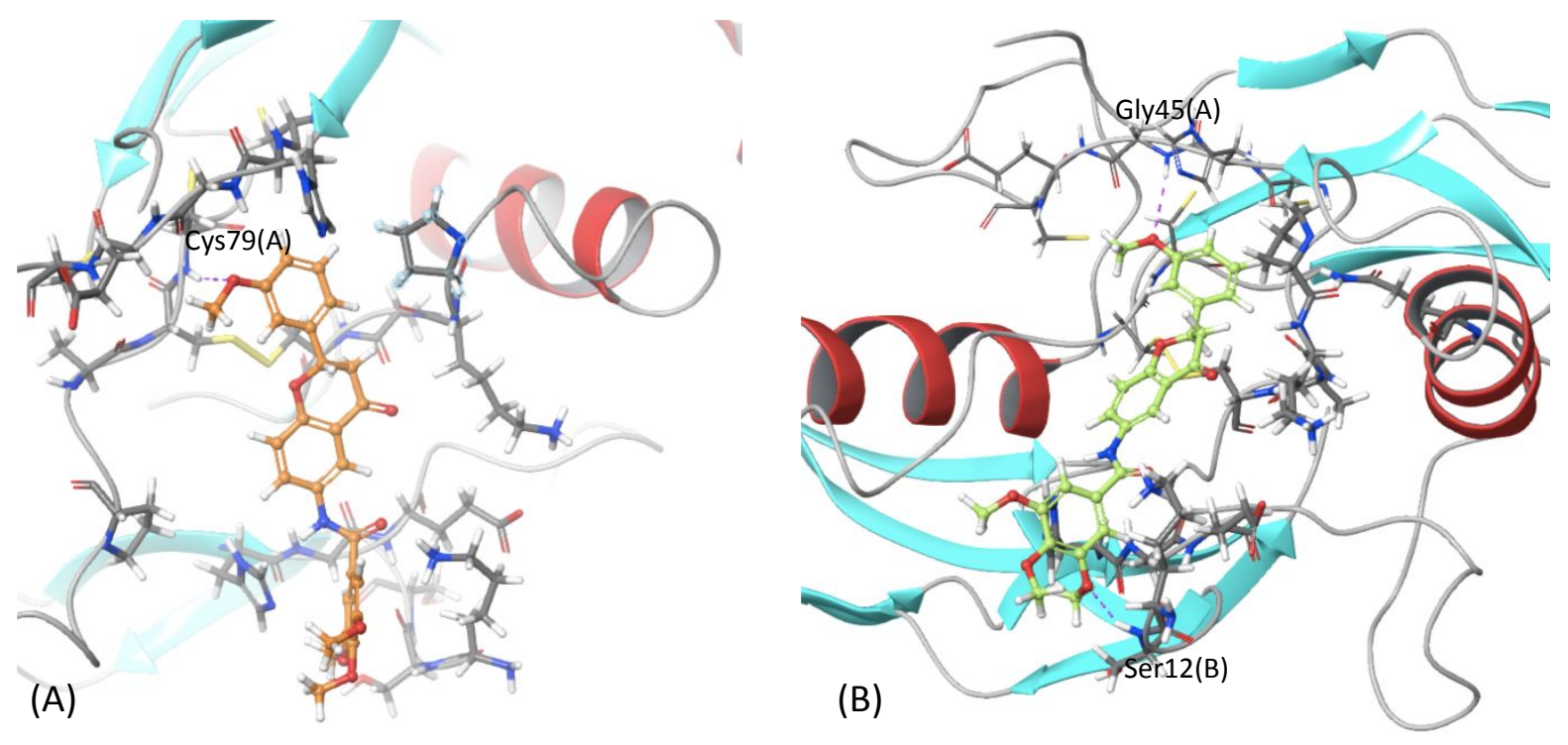

Figure S4. Molecular interactions between the racemic forms of 5e compound and the active site residues of BMP-2 protein (A) $\mathbf{5 e}(R)$ and (B) $\mathbf{5 e}(S)$. The purple dotted line represents the hydrogen bond interactions.

As the dimeric unit of BMP-2 protein plays a functional role, the dimeric structure of the protein (PDB ID-3BK3) was used for the interaction studies. From the previous literature, we found that residues Cys79, Cys78, and Cys47 of chain A and His44 of chain B play important roles in the binding of novel ligand molecules. ${ }^{9}$ The $\mathbf{5 e}$ compound is a racemic mixture of $\mathrm{R}$ and $\mathrm{S}$ forms. Docking studies provide the structural insights for both isomers. Compound $5 \mathrm{e}(\mathrm{S})$ at this pose shows one hydrogen bonds with amino group of Gly44 residue of chain A and another H-bond with amino group of Ser12 of chain B and Cys47, Cys47 of chain A and Pro75 and Ala77 of chain B were making hydrophobic interactions. On the other hand, 5e(R) shows one H-bond with Cys79 of chain A.Methoxy substituent at meta position of benzene ring stabilises the hydrogen bonding with Cys79.

As we can see in Figure S3 galloyl ring is involved in making H-bond as well as hydrophobic interactions with BMP-2 in compound 5e. Apart from galloyl ring flavanone moiety was found to be making strong hydrophobic interactions in the deep pocket at the junction of chain A and chain B.

The BMP-2 subunits are covalently linked by a single disulfide bond (Cys78 from both subunits) (1) which is retained after the binding of $\mathbf{5 e}$ compound and suggests that its binding does not affect BMP-2 protein dimer for which the functional evidence is shown through in vitro osteogenic assay. In that assay, presence of $\mathbf{5 e}$ does not alter the ALP activity of BMP-2 when compared with BMP-2 alone. 


\section{Supplementary References}

1. Bolli, A.; Marino, M.; Rimbach, G.; Fanali, G.; Fasano, M.; Ascenzi, P. Flavonoid binding to human serum albumin. Biochem. Biophys. Res. Commun. 2010, 398, 444-449.

2. Raj, U.; Kumar, H.; Varadwaj, P.K.Molecular docking and dynamics simulation study of flavonoids as BET bromodomain inhibitors. J. Biomol. Struct. Dyn. 2016,35, 23512362 .

3. Tutunchi, H.; Naeini, F.; Ostadrahimi, A.; Hosseinzadeh-Attar, M.J. Naringenin, a flavanone with antiviral and anti-inflammatory effects: A promising treatment strategy against COVID-19. Phytother. Res. 2020, 34, 3137-3147.

4. Russo, M.; Moccia, S.; Spagnuolo, C.; Tedesco, I.; Russo, G.L. Roles of flavonoids against coronavirus infection. Chem. Biol. Interact. 2020, 328, 109211.

5. Sachithanandam, V.; Parthiban, A.; Lalitha, P.; Muthukumaran, J.; Jain, M.; Elumalai, D.; Jayabal, K.; Sridhar, R.; Ramachandran, P.; Ramachandran, R. Biological evaluation of gallic acid and quercetin derived from Ceriops tagal: insights from extensive in vitro and in silico studies. J. Biomol. Struct. Dyn. 2020, 30, 1-13.

6. Gu, C.; Stashko, M.A.; Puhl-Rubio, A.C.; Chakraborty, M.; Chakraborty, A.; Frye, S.V.; Pearce, K.H.; Wang, X.; Shears, S.B.; Wang, H. Inhibition of Inositol Polyphosphate Kinases by Quercetin and Related Flavonoids: A Structure-Activity Analysis. J. Med. Chem. 2019, 62, 1443-1454.

7. Wang, P.; Bai, H.W.; Zhu, B.T. Structural basis for certain naturally occurring bioflavonoids to function as reducing co-substrates of cyclooxygenase I and II. PLoS One 2010, 5, e12316.

8. Akbar, I.Z.; Dewi, F.R.P.; Setiawan, B. In silico interaction of the active compounds of scurrula atropurpurea with the RANK/RANKL/OPG System in Diabetoporosis. Acta Inform. Med. 2019, 27, 8-11.

9. Modukuri, R. K.; Choudhary, D.; Gupta, S.; Rao, K. B.; Adhikary, S.; Sharma, T.; Siddiqi, M. I.; Trivedi, R.; Sashidhara, K. V. Benzofuran-dihydropyridine hybrids: A new class of potential bone anabolic agents. Bioorg. Med. Chem. 2017, 25, 6450-6466. 